\title{
Theoretical Model of Nurse Outcomes: Associations among Nurse Characteristics, Psychological Empowerment, Generation, Quality of Work life, and RN Job Satisfaction
}

Amy M. Sparks

West Virginia University

Follow this and additional works at: https://researchrepository.wvu.edu/etd

\section{Recommended Citation}

Sparks, Amy M., "Theoretical Model of Nurse Outcomes: Associations among Nurse Characteristics, Psychological Empowerment, Generation, Quality of Work life, and RN Job Satisfaction" (2011). Graduate Theses, Dissertations, and Problem Reports. 4795.

https://researchrepository.wvu.edu/etd/4795

This Dissertation is protected by copyright and/or related rights. It has been brought to you by the The Research Repository @ WVU with permission from the rights-holder(s). You are free to use this Dissertation in any way that is permitted by the copyright and related rights legislation that applies to your use. For other uses you must obtain permission from the rights-holder(s) directly, unless additional rights are indicated by a Creative Commons license in the record and/ or on the work itself. This Dissertation has been accepted for inclusion in WVU Graduate Theses, Dissertations, and Problem Reports collection by an authorized administrator of The Research Repository @ WVU.

For more information, please contact researchrepository@mail.wvu.edu. 
Theoretical Model of Nurse Outcomes: Associations among Nurse Characteristics, Psychological Empowerment, Generation, Quality of Work life, and RN Job Satisfaction

Amy M. Sparks RN, MSN, FNP-BC

\author{
Dissertation submitted to the School of Nursing \\ at West Virginia University \\ in partial fulfillment \\ of the requirements for the degree of
}

Doctor of Philosophy in Nursing

June Larrabee RN, Ph.D., Chair Stacey Culp Ph.D. Cynthia Persily RN, Ph.D. Kari Sandjecklin RN, Ed.D. Gretchen M. Spreitzer Ph.D.

Morgantown, West Virginia 


\begin{abstract}
Theoretical Model of Nurse Outcomes: Associations among Nurse Characteristics, Psychological Empowerment, Generation, Quality of Work life, and RN Job Satisfaction Amy M. Sparks
\end{abstract}

Background: Currently, nurse researchers have yet to clearly understand all of the factors related to registered nurse job satisfaction. Ruggiero (2005) posits that $62-67 \%$ of the variance in $\mathrm{RN}$ job satisfaction remains unexplained in nursing literature. Nurse characteristics, generation, psychological empowerment, and quality of work life have been found to impact RN job satisfaction. The literature lacks a comprehensive conceptual framework, which theoretically links each of these influential factors to $\mathrm{RN}$ job satisfaction.

Purpose: The purpose of this study was to investigate the relative influence of nurses' characteristics, psychological empowerment, generation, and quality of work life on RN job satisfaction. Another purpose of this study was to examine the relationships among the concepts in the Theoretical Model of Nurse Outcomes. The Theoretical Model of Nurse Outcomes was developed to guide this dissertation using the inductive and deductive theory synthesis process described by Walker and Avant (2005). The specific research questions were:

1) What relationships exist among the concepts of nurse characteristics, psychological empowerment, generation, quality of work life, and RN job satisfaction and 2) Are nurse characteristics, psychological empowerment, generation, and quality of work life predictors of RN job satisfaction?

Methods: This predictive, non-experimental study was conducted using anonymous web-based survey. The statistical package for Social Sciences (SPSS)/Predictive Analytics Software 
(PASW) Package 18 was used for the analysis in this study. Correlations, Chi-square test for independence, t-test, ANOVA, and General linear modeling (GLM) procedures were used in this study.

Findings: The sample included 223 RNs currently practicing in the United States. The average age of the nurses in this sample was 37 years and the average total years of experience as a $\mathrm{RN}$ was 9 years. The majority of the nurses in the sample were female (91\%), Caucasian (89.2\%), married (56\%), lived in the south (58\%), worked full time (56\%), and had a Bachelor of Science in Nursing (BSN) degree (51.1\%). Quality of work life and age were related to RN job satisfaction. Psychological empowerment, a predictor of $\mathrm{RN}$ job satisfaction, was related to nurses' age, experience, quality of work life, and RN job satisfaction. Quality of work life, psychological empowerment, years in current position, and generation were significant predictors of $\mathrm{RN}$ job satisfaction explaining $63.7 \%$ of the variance in $\mathrm{RN}$ job satisfaction.

Discussion: The findings of this study support the proposed relationships among the concepts in the Theoretical Model of Nurse Outcomes, offering a framework for future research including interventional studies about enhancing RN job satisfaction. In a profession in which nurses' job performance is directly influenced by their perceptions, understanding the factors that predict perceived job satisfaction is necessary to create environments that support nurses. 


\section{DEDICATION}

The author wishes to dedicate this dissertation to nurses. This work is in honor of the nurses that strive each day at the bedside to provide excellent care for their patients. 


\section{ACKNOWLEDGMENTS}

The author wishes to acknowledge Dr. June H. Larrabee for her superb guidance and mentorship over the last ten years. Her dedication and commitment to conducting and disseminating excellent nursing workforce related research has inspired me since I was an undergraduate student. It has been an honor that she has shared her gifts with me.

In addition, the author wishes to acknowledge my committee members, Dr. Cynthia Persily, Dr. Kari Sandjecklin, Dr. Gretchen Spreitzer, and Dr. Stacey Culp for their guidance in the development of this dissertation work. Their knowledge, skill, and dedication to research mentorship have been invaluable in not only developing this work, but gaining fundamental skills in conducting nursing research. 
Table of Contents

CHAPTER 1: STATEMENT OF THE PROBLEM ......................................................... 1

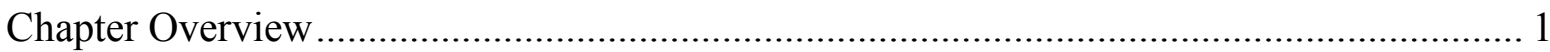

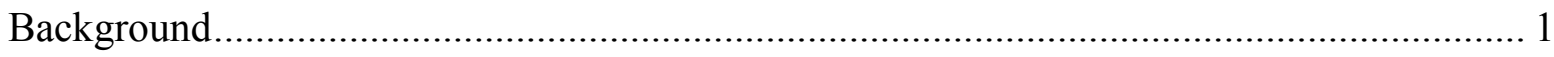

The Problem Statement ................................................................................................. 5

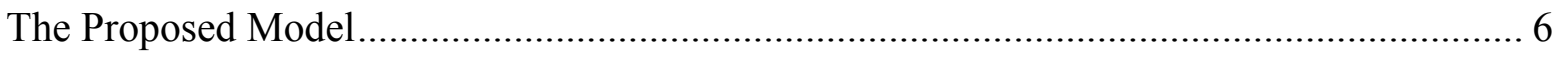

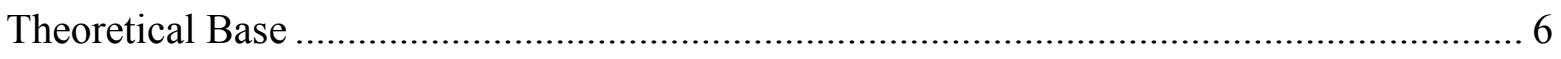

Theoretical Model of Nurse Outcomes .................................................................. 12

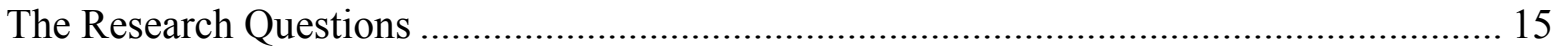

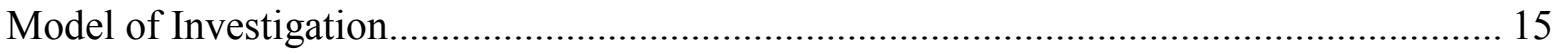

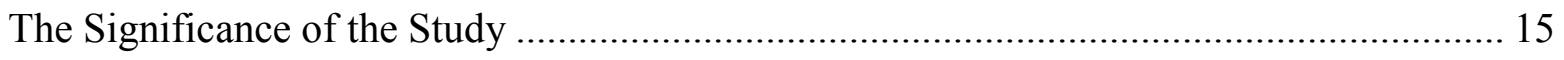

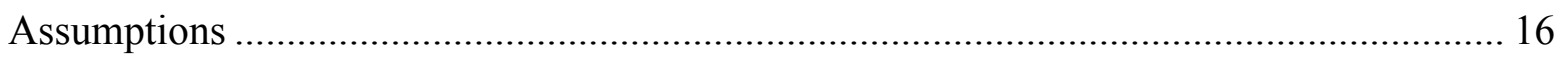

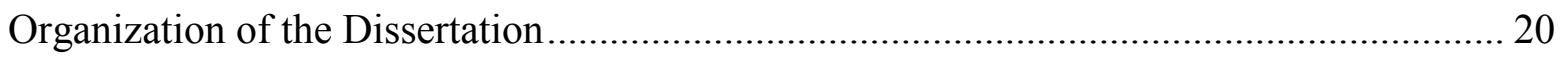

CHAPTER 2: REVIEW OF THE LITERATURE ....................................................... 21

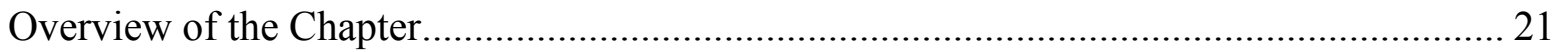

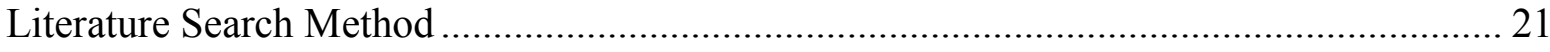

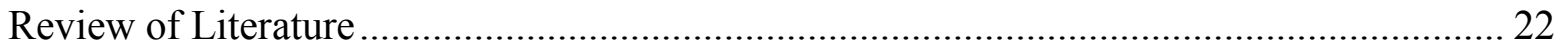

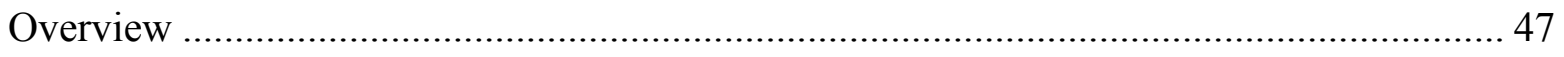

Review of Instruments .......................................................................................... 51

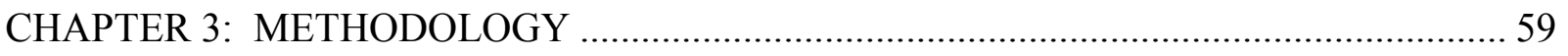

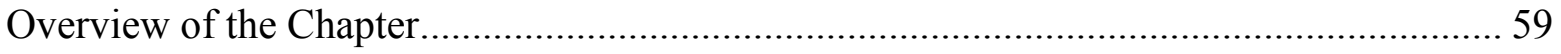

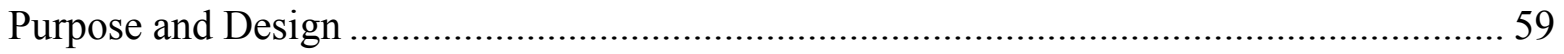

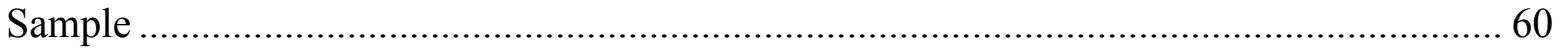

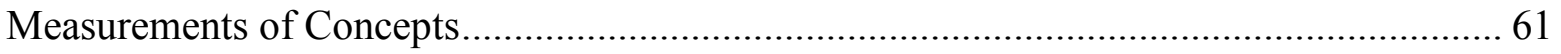




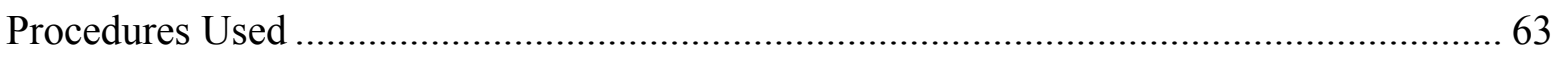

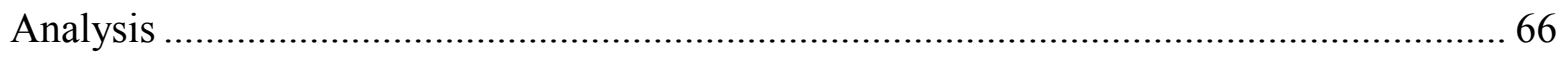

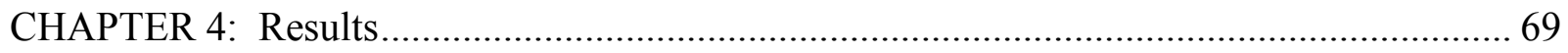

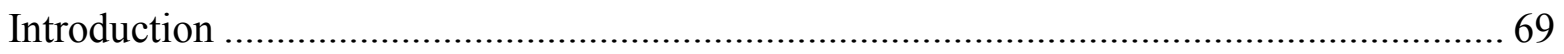

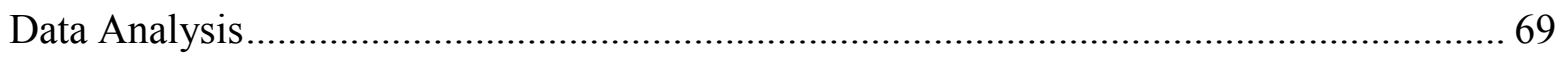

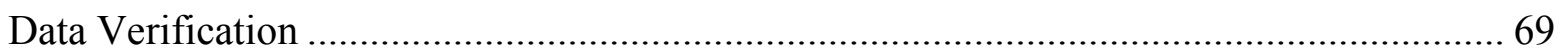

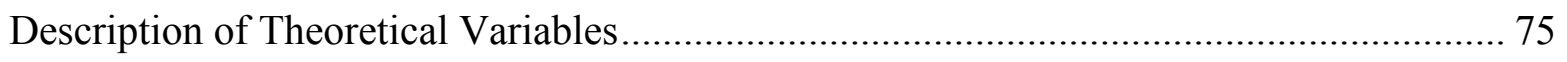

Summary

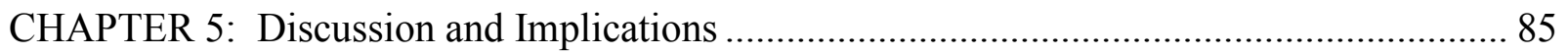

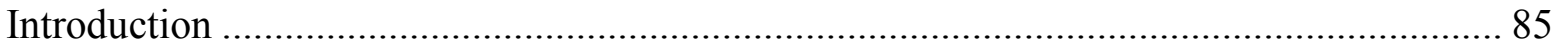

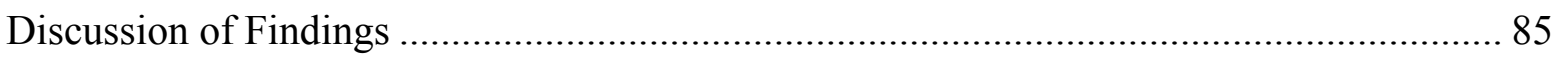

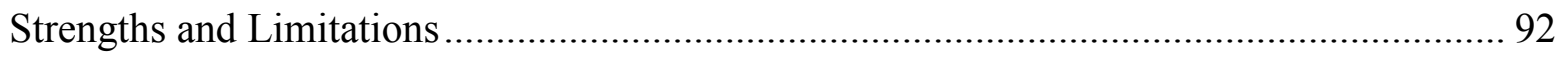

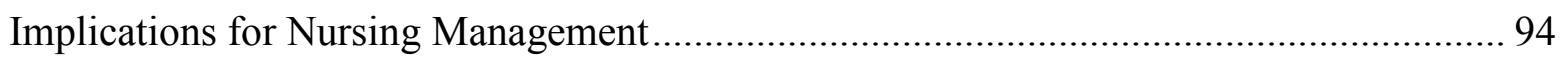

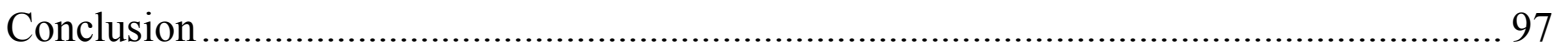

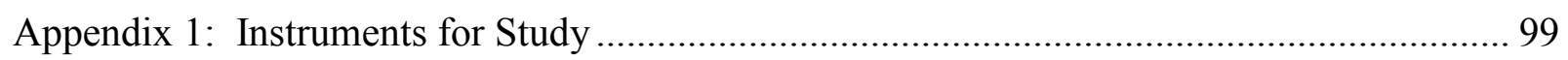

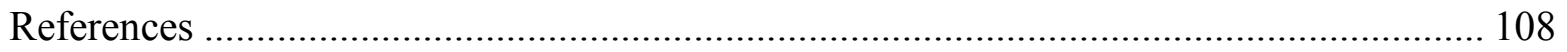




\section{CHAPTER 1: STATEMENT OF THE PROBLEM}

\section{Chapter Overview}

The purpose of chapter 1 is to present the case for the need to identify predictors of Registered Nurse (RN) job satisfaction. The background of $\mathrm{RN}$ job satisfaction literature is presented and focal concepts related to $\mathrm{RN}$ job satisfaction are identified. The purpose of the study, research questions, and significance of the study are discussed.

\section{Background}

The current nursing shortage has accentuated the need for $\mathrm{RN}$ retention strategies. The United States (U.S.) Department of Health and Human Services projects 1.2 million Registered nurse vacancies by the year 2014; 500,000 vacancies are due to anticipated retirements and the remaining 700,000 vacancies are related to increased demands placed on the health care system (Health Resources and Services Administration, 2008). There is additional concern that dissatisfied nurses will leave the profession, further aggravating the shortage. Job satisfaction is "the extent to which employees like their jobs" (Stamps, 1997). Because nurses' intent to leave their jobs has been linked to nurse job dissatisfaction (Boyle, Bott, Hansen, Woods, \& Taunton, 1999; Larrabee, et al., 2003; Sourdif, 2004), a priority focus for nurse retention strategists should be targeted at improving nurses' job satisfaction. Additionally, increasing RN job satisfaction has been found to be significantly correlated to decreased turnover rates (Cavanagh \& Coffin, 1992; Price \& Mueller, 1981). The loss of an experienced nurse is costly to the health care organization. Though difficult to precisely estimate the cost of replacing a nurse due to turnover, current estimates range from $\$ 21,000$ to $\$ 64,000$ per nurse (Minnesota Hospital Association, 
2005). Experienced and satisfied nurses not only decrease organizational costs, but also enhance the quality of patient care (Waldman, Kelly, Arora, \& Smith, 2004).

Currently, nurse researchers have yet to clearly understand all of the factors related to RN job satisfaction. Ruggiero (2005) posits that $62-67 \%$ of the variance in RN job satisfaction remains unexplained in nursing literature. Much of the RN job satisfaction research focuses on the influence of work environment factors and nurse characteristics on job satisfaction without a guiding theoretical framework. Researchers have demonstrated the influence of factors such as work environment (Adams \& Bond, 2000; Aiken, 2001; Best \& Thurston, 2006; Flanagan \& Flanagan, 2002; Hayhurst, Saylor, \& Stuenkel, 2005; Irvine \& Evans, 1995; Larrabee, et al., 2003; Lucas, Atwood, \& Hagaman, 1993; Shader, Broome, Broome, West, \& Nash, 2001; Ulrich, Buerhaus, Donelan, Norman, \& Dittus, 2005; Upenieks, 2002), nurse characteristics (Cimete, Gencalp, \& Keskin, 2003; Gifford, 2002; Kuokkanen, Leino-Kilpi, \& Katajisto, 2003; McNeese-Smith \& Van Servellen, 2000; Nogueras, 2006; Norman, et al., 2005; M. Price, 2002; Rambur, Palumbo, McIntosh, \& Mongeon, 2003; Shader, et al., 2001), psychological empowerment (Daiski, 2004; DeCicco, Laschinger, \& Kerr, 2006; Larrabee, et al., 2003; Morrison, Jones, \& Fuller, 1997; Siu, Laschinger, \& Vingilis, 2005), generation (McNeeseSmith \& Crook, 2003), and quality of life (Gifford, 2002) on RN job satisfaction.

\section{Work Environment}

Salary has been the most frequently reported work environment factor found to influence RN job satisfaction (Best \& Thurston, 2004, 2006; Chan \& Morrison, 2000; M. F. Chan, Luk, Leong, Yeung, \& Van, 2009; Cowin, 2002; Flanagan \& Flanagan, 2002; Gardulf, et al., 2005; Strachota, Normandin, O'Brien, Clary, \& Krukow, 2003; Tzeng, 2002; Wilson, Squires, Widger, Cranley, 
\& Tourangeau, 2008; Yin \& Yang, 2002). In addition to RN job satisfaction, salary has been found to be a significant predictor of nurses' intent to leave a job (Tzeng, 2002) and the top reason for potential turnover (Yin \& Yang, 2002). However, Fang (2001) found that salary had no significant influence on nurses' turnover intention. Despite the abundance of literature investigating the association of the work characteristic salary to RN perceptions of their work environment, the findings have been inconsistent. In addition to work environment, nurse researchers have investigated nurse characteristics that potentially influence $\mathrm{RN}$ job satisfaction.

\section{Nurse Characteristics}

Nurse characteristics such as age (Cimete, et al., 2003; Curtis, 2008; Ea, Griffin, L'Eplattenier, \& Fitzpatrick, 2008; McNeese-Smith \& Van Servellen, 2000; Price, 2002), experience (Cimete, et al., 2003; Ea, et al., 2008), education (Curtis, 2008), gender (Penz, Stewart, D'Arcy, \& Morgan, 2008), and geographic region (Ma, Samuels, \& Alexander, 2003) have been found to impact RN job satisfaction. As with work environment, there are contradictory findings regarding the association of nurse characteristics on $\mathrm{RN}$ job satisfaction. Age has been identified as a predictor of $\mathrm{RN}$ job satisfaction in some studies (Ea, et al., 2008; McNeese-Smith \& Van Servellen, 2000) whereas other researchers reported no relationship between age and RN job satisfaction (Adams \& Bond, 2000; Ma, et al., 2003; Penz, et al., 2008). In addition, the education level of the nurse appears to have some influence on nurses' perception of their jobs (Nogueras, 2006; Suzuki, et al., 2006); yet, this too was inconclusive as previous studies reported no relationship (Adams \& Bond, 2000; Cimete, et al., 2003). Inconsistent findings in the literature have encouraged researchers to explore potential mediating factors between work environment and nurse characteristics and RN job satisfaction. Among these potential mediating factors are generation and psychological empowerment. 
Generation

There are currently four generations of nurses in the work force: Veterans (born between 1925-1945), Baby Boomers (born between 1946-1964), Generation X (born between 19631980), and Millennials (born between 1981-2000) (Sherman, 2006). Generational differences in overall job satisfaction have been found; Baby Boomer nurses have reported higher overall job satisfaction and significantly less burnout than Generation X nurses (Widger, et al., 2007; Wilson, et al., 2008). Recent research has demonstrated that Generation X nurses experience a significant incongruence between their values and work environments, leading to burnout and intent to leave (Leiter, Jackson, \& Shaughnessy, 2009). This suggests that generation could be a mediating factor between nurses' environments and their perceptions of their environments.

\section{Psychological Empowerment}

Psychological empowerment, as defined by Spreitzer (1995), is a motivational construct manifested in four cognitions: meaning, competence, impact, and self-determination. This construct is described as an active process in which an individual "feel(s) able to shape his or her work role and context" (Spreitzer, 1995, p. 1444). Psychological empowerment has been identified as a primary predictor of job satisfaction and intent to leave a job (Larrabee, et al., 2003). However, there has been minimal investigation of psychological empowerment in RN job satisfaction literature. Nurses reported that a self-perceived consequence to psychological empowerment is an increased ability to change their environments (Daiski, 2004). This supports that psychological empowerment may be a mediating influence between a nurses' environment and RN job satisfaction. 
Quality of Work Life

Quality of work life is the value assigned to one's work context. Quality of nursing work life, in part, has been defined as an ability to satisfy personal needs through work experiences (Brooks, 2001), which indicates that quality of work life directly influences RN job satisfaction. $\mathrm{RN}$ job satisfaction is an outcome of nurses' perceived quality of work life (Gifford, 2002). Quality of work life is one of the most inconsistently defined concepts in RN job satisfaction literature. Frequently, quality of work life is not clearly delineated from the concept of job satisfaction. There have been many instruments and combination of instruments used to capture nurses' perceptions of their work environments. The most frequently reported factors related to nurses' perceptions of their quality of work life are autonomy (Aiken, Clarke, \& Sloane, 2002; Blegan, 1993; Bratt, Broome, Kelber, \& Lostocco, 2000; Upenieks, 2002; Wells, Roberts, \& Medlin, 2002), managers' leadership styles (Jones, Stasiowski, Simons, Boyd, \& Lucas, 1993; Kuokkanen, et al., 2003; Larrabee, et al., 2003; Moore, 2001; Moss \& Rowles, 1997; Yeatts \& Seward, 2000; Yin \& Yang, 2002) and physician collaboration (M. F. Chan, et al., 2009). Autonomy, as a component of quality of work life, has been identified as an important predictor of job satisfaction (Dwyer, Schwartz, \& Fox, 1992; McCloskey, 1990). Increased levels of autonomy have been found to be associated with increased job satisfaction (Aiken, et al., 2002; Blegan, 1993; Bratt, et al., 2000; Upenieks, 2002; Wells, et al., 2002).

\section{The Problem Statement}

There is limited evidence concerning the relative influence of nurse characteristics, psychological empowerment, generation, and quality of work life on RN job satisfaction. The literature lacks a comprehensive conceptual framework, which theoretically links each of these 
influential factors to $\mathrm{RN}$ job satisfaction. The purpose of this study was to investigate the relative influence of nurses' characteristics, psychological empowerment, generation, and quality of work life on RN job satisfaction. Another purpose of this study was to examine the relationships among the concepts in the Theoretical Model of Nurse Outcomes.

\section{The Proposed Model}

The Theoretical Model of Nurse Outcomes (Figure 1) was developed to guide this dissertation using the inductive and deductive theory synthesis process described by Walker and Avant (2005). Theoretical and empirical evidence found in the nursing literature was synthesized to identify the conceptual links among the model concepts: work environment, nurse characteristics, generation, psychological empowerment, quality of work life, and job satisfaction. Specifically, a review of literature was conducted for each concept based on the concept's relative influence on $\mathrm{RN}$ job satisfaction. A review of theories pertinent to the model concepts identified theoretical support for proposed relationships of the focal concepts. As described in the process of theory synthesis (Walker \& Avant, 2005), higher order concepts were developed for each of the model concepts. The following section reviews the theoretical underpinnings of the Model of Nurse Outcomes.

\section{Theoretical Base}

The theories of self-transcendence and basic human values were used to support the model concepts and the conceptual propositions in this theory. The conceptual dimensions of psychological empowerment were used to further strengthen the propositions of the theoretical model. 


\section{Theory of Self-Transcendence}

The theory of self-transcendence supports the primary assumption that job satisfaction is a result of a mediated process influenced by nurses' interpretations of reality. Reed (2003) defined self-transcendence as the ability to "expand self-boundaries intrapersonally, interpersonally, temporally, and transpersonally" (p.147). The theory of self-transcendence is consistent with the perspective that human beings are constantly developing within the context of their environment. The theory evolved from initial research that indicated that depressed elders had lower levels of self-transcendence (measured with the Self-Transcendence Scale). The theory has since been applied to study a variety of clinical issues such as end of life, bereavement, dementia, sobriety, cancer, and depression. Positive relationships were identified between vulnerability and self-transcendence, and between self-transcendence and well being (Reed, 2003).

Reed (2003) developed three concepts which logically describe the role of vulnerability, or "awareness of personal mortality" (p.148). Vulnerability could potentially trigger selftranscendence, influencing a person's sense of well being or "sense of feeling whole and health" (Reed, 2003, p.148). Reed (2003) theorized that a human's vulnerability could trigger selftranscendence, influencing their well-being. When feeling vulnerable, persons may struggle to find meaning or gratefulness in their situation. However, if persons can transform stressful or vulnerable situations, through self-transcendence, into a process of healing, then well-being may be enhanced. Job stress could be viewed as a threat to nurses' well being and perceptions of job satisfaction. 
Within the context of Reed's (2003) theory, the innate ability to transcend a situation and find meaning in difficult work environments is a developmental process leading to the potential for interventions aimed at improving nurse self-transcendence (inner human potential). The idea of self-transcendence as an innate ability of humans to improve their awareness of the environment and expand their perspective is philosophically supported by Newman's (1991) unitary-transformative paradigm. From the unitary-transformative perspective, phenomena are identified through patterns and interaction with the larger whole in which, "thoughts, values, feelings, choices, and purpose" are considered influential in the interpretation of reality (Newman, 1991, p. 300). Thus, considering how nurses perceive actual work environments and examining those psychological thoughts, feelings, and values impacting their perceptions would be important for future job satisfaction research.

\section{The Theory of Basic Human Values}

Value systems are essential to human development and influence persons' perceptions, choices, and behaviors (Rokeach, 1973, 1979). The basis of the theory of basic human values was established by the early works of Rokeach $(1973,1979)$ who noted that values are intrinsic within persons as well as shared at the societal level. Values are prioritized by persons and serve as the guiding framework for conflict resolution within their lives.

Values are developed during the formative years (Rokeach, 1973) and, thus, are shared by generational cohorts (Inglehart, 1990; Lyons, 2005; Mannheim, 1993; Schonpflug, 2001; Whitbeck \& Gecas, 1988). A generation is a cohort of persons who are broadly socialized together. Generational cohorts are born and raised within the same societal, political, and historical context, shaping a shared belief system based on a similar world view (Hu, Herrick, C., 
\& Hodgin, K. , 2004; Kupperschmidt, 2000; Mannheim, 1993). Because members of a generational cohort experience similar societal influences during the formative years and those societal influences are considered unstable and changing over time, generations have been noted to differ in their values (Lyons, 2005). A secondary analysis (Lyons, 2005) on data from 979 Canadian knowledge workers identified that Generation X and Baby Boomer nurses differed significantly in their values. Specifically, achievement, hedonism, and stimulation were valued more by Generation X than Baby Boomers; whereas, security, benevolence, universalism, conformity, and tradition were more valued by Baby Boomers. Thus, basic human values theory provides a basis for understanding how socialization impacts generations of persons' value systems.

\section{Conceptual Dimensions of Psychological Empowerment}

Psychological empowerment served as a primary anchoring concept for this theoretical model. An anchoring concept, as described by Walker and Avant (2005), is the primary concept identified to theoretically link model concepts. Conceptual analysis of psychological empowerment provided the rationale for proposing psychological empowerment as a mediating factor between work environment/nurse characteristics and quality of work life/RN job satisfaction. Psychological empowerment has been viewed from the synergistic paradigm, in which persons are viewed as interrelated with intrinsic and extrinsic connections. The sharing and collaboration through those connections strengthen involved persons, thus promoting empowerment (Katz, 1984). Much of the nursing literature regarding psychological empowerment references the early conceptual work of Conger and Kanungo (1988). In this work, empowerment is viewed from the perspective of the motivational process theory, in which empowerment is linked to expectancy and self-efficacy theories. According to the expectancy theory, persons' motivations will increase depending on the outcome of a given task in light of 
their expectations. Persons gain a sense of mastery and strengthened self-efficacy if they are empowered, regardless of a favorable expected outcome. Empowerment can be an intrinsic process or it can be externally enhanced by a leader's recognition of one's performance (Conger \& Kanungo, 1988).

Thomas and Velthouse (1990) developed a cognitive model of empowerment from a multifaceted intrinsic task motivation theory which "involves those generic conditions by an individual, pertaining directly to the task, that produce motivation and satisfaction" (p. 668). From this perspective, empowerment is viewed as a process of task assessment influenced by persons' interpretation of their environments. Although the conceptual development of psychological empowerment is based on psycho-social theories, the theories are harmonious with nursing's paradigmatic unitary-transformative perspective (Reed, 2003) in that both assume that nurses have the ability to change their perceptions despite environmental conditions.

As an intrinsic process, psychological empowerment is difficult to define. Most generally, it is delineated by the manifestations that an empowered person demonstrates. Spreitzer (1995) offered a definition based on Thomas \& Velthouse's (1990) work, in which psychological empowerment is "a motivational construct manifested in four cognitions: meaning, competence, self-determination, and impact” (p. 1443). Empowered nurses demonstrated the following qualities: moral principles, personal integrity, expertise, futureorientedness, and sociability (Kuokkanen \& Leino-Kilpi, 2000). Based on the literature (Kuokkanen \& Leino-Kilpi, 2000; Kuokkanen, et al., 2003; Spreitzer, 1995; Thomas \& Velthouse, 1990), psychological empowerment is defined as a motivational process in which inherent characteristics, as well as environment factors, influence persons' abilities to discover the meaning, enhanced competence, and self-determination necessary to impact their 
environments. The four primary defining attributes developed by Spreitzer (1995) are amenable to change and development throughout the person's lifespan.

Meaning is the value a person assigns to his or her work with consideration to the person's beliefs, values, and behaviors (Spreitzer, 1995). Competence, or self-efficacy, is the person's assessment of his or her abilities to perform work activities with proficiency (Spreitzer, 1995). Self-determination is a person's perception of choice in initiating behaviors and making decisions in the work place (Spreitzer, 1995). Self-determination has also been described as the person's sense of freedom to make choices and accept responsibility for decisions (Fulton, 1997; Rodwell, 1996). Impact is the person's perceived ability to influence the work environment (Spreitzer, 1995).

The consequences or outcomes related to psychological empowerment are described in the literature as positive behavioral effects leading to enhanced work performance. Kanter (1977) noted that the outcomes of psychological empowerment are work effectiveness, achievement and successes, respect and cooperation, and patient satisfaction. Conger \& Kanungo (1988) proposed that high psychological empowerment results in the initiation and persistence of behavior to accomplish task objectives. The outcomes of increased psychological empowerment are increased effectiveness and innovative behavior (Spreitzer, 1995). Nurses have reported that an additional outcome of empowerment is an increased ability to change their environments (Daiski, 2004). Psychological empowerment can theoretically be viewed as a part of a greater internalization process impacting perceptions. 
Theoretical Model of Nurse Outcomes

\section{Model Concepts}

Work environment. The concept of work environment is nested within a higher order concept of work context. Work environment is defined as the setting and atmosphere in which the nurse works. Work context broadly encompasses all factors associated with the nurses' place of work that are vulnerable to interpretation by the nurse. Work environment is posited to be a factor within the nurses' work context that influences RN job satisfaction. The nurses' work environment factors in this theoretical model would include factors such as salary (Best \& Thurston, 2006; M. F. Chan, et al., 2009; Gardulf, et al., 2005; Wilson, et al., 2008), job position (Chen-Chung, Samuels, \& Alexander, 2003; Curtis, 2008; Manojlovich, 2005; McGillis Hall, Doran, \& Pink, 2008), manager's leadership style (Kuokkanen, et al., 2003; Larrabee, et al., 2003), self-scheduling (Hung, 2002; Wilson, et al., 2008; Yin \& Yang, 2002), length of shift (Aiken, et al., 2002; Flanagan \& Flanagan, 2002; Strachota, et al., 2003), and hours worked per week (McGillis Hall, et al., 2008; Sarmiento, Laschinger, \& Iwasiw, 2004; Sourdif, 2004).

Nurse characteristics. The concept of nurse characteristics is nested within the higher order concept of individual context. Individual context broadly encompass all factors uniquely identifiable to the nurse and is vulnerable to interpretation by the nurse. Nurse characteristics are defined as the nurse's physical and demographic attributes. Within the context of this theory, personality traits are purposefully not included in this conceptual definition. The nurse characteristics included in this framework are the nurse's age, gender, education, and experience (Adams \& Bond, 2000; Nogueras, 2006; Norman, et al., 2005). 
Psychological Empowerment. The concept of psychological empowerment is nested within the higher order concept of internalization. Internalization is the integrative process of assigning meaning to external conditions based on one's value and belief systems. Internalization is influenced by a person's values and belief systems and is a proposed mediating factor between the nurse's work context and his/her perceived work environment. A component of internalization is psychological empowerment. Persons' abilities to discover the meaning, enhanced competence, and self-determination necessary to impact their environments is influenced by their work environments and personal characteristics. Within the context of this model, it is theorized that work factors and personal characteristics do not necessarily enhance or improve one's psychological empowerment. Rather, the ability to be empowered is intrinsically motivated, and with optimal psychological empowerment, persons could find meaning and satisfaction despite their difficult environments. This ability is, however, theorized to be either enhanced or attenuated by how nurses' actual work environments resonates with their value systems.

Generation. The concept of generation is nested within the high order concept of socialization. Socialization is the reflective process of analysis and the assimilation of societal value and belief systems into one's identity. Based on the basic human values theory, values influence how persons interpret and assign meaning to their external environments. Generation is a cohort sharing birth years and significant life events (Kupperschmidt, 2000). Because of diverse socialization, generational cohorts have been noted to differ in their values. Generation, based on generational cohorts' similar socialization during their value system development, is proposed to mediate the influence of work environment/nurse characteristics and perceived quality of work/RN job satisfaction. 
Quality of Work Life. Quality of work life is nested within the higher order concept of perceived work environment. Perceived work environment broadly encompasses those concepts that reflect how the nurse interprets their work and individual contexts. Quality of work life is the value assigned to one's work and individual contexts and is mediated by the nurses' psychological empowerment and generational socialization.

\section{Model Propositions}

Table 1 describes the concepts, theoretical definitions, operational definitions, and indicators for investigating associations among nurse characteristics, generation, psychological empowerment, quality of work life, and RN job satisfaction.

1. Relationships exist among the concepts of work environment, nurse characteristics, internalization (psychological empowerment), socialization (generation), quality of work life, and RN job satisfaction.

2. Internalization (psychological empowerment) and Socialization (generation) mediate the concepts in the nurses' work context and perceived work environment.

3. Internalization (psychological empowerment) predicts quality of work life and job satisfaction.

4. Nurse characteristics, generation, psychological empowerment, and quality of work life are predictors of $\mathrm{RN}$ job satisfaction. 


\section{The Research Questions}

The primary aim of this study is to do initial testing of the Theoretical Model of Nurse Outcomes by investigating the relative influence of nurse characteristics, generation, psychological empowerment, and quality of work life on RN job satisfaction. To effectively measure the nurses' work environment as defined in this theoretical model, the researcher would need to measure these factors without potential bias from the nurses' perceptions. Work environment factors were not included in this study due to a lack of resources to properly measure these factors. The specific research questions were:

1. What relationships exist among the concepts of nurse characteristics, psychological empowerment, generation, quality of work life, and RN job satisfaction?

2. Are nurse characteristics, psychological empowerment, generation, and quality of work life predictors of $\mathrm{RN}$ job satisfaction?

\section{Model of Investigation}

Figure 2 illustrates the model of investigation based on the Theoretical Model of Nurse Outcomes.

\section{The Significance of the Study}

$\mathrm{RN}$ job satisfaction is an outcome of a complex multi-conceptual process. Many descriptive studies have been conducted to identify the predictors of RN job satisfaction: however, the research findings have been inconsistent and no one study was found that investigated the relative influence of nurse characteristics, psychological empowerment, generation, and quality of work life on $\mathrm{RN}$ job satisfaction. The proposed theoretical model, the 
Theoretical Model of Nurse Outcomes, offers a framework for research that includes focal concepts currently found in nursing literature. Testing of this theoretical model may shed insight into the inconsistent findings about predictors of $\mathrm{RN}$ job satisfaction. Understanding the relationships of factors that influence $\mathrm{RN}$ job satisfaction is a necessary preliminary step to develop effective nurse retention strategies. The current nursing shortage has emphasized the need for strategies aimed at retaining nurses. With staffing burdens projected to worsen over the next ten years within a stressed health care system, hospital administrators and health care policy advocates will be encouraged to explore re-investing the current health care system. It is imperative that nurse researchers provide evidence to support health care system reforms while considering nurses' needs.

\section{Assumptions}

The Theoretical Model of Nurse Outcomes is based on a primary assumption that individuals' perceptions of their environments are influenced by the individuals' internalization process. In addition, individuals' socialization influences the internalization process. This process in which individuals perceive their environments is a dynamic process amenable to change. Additional assumptions of the study include that the sample represents the population, the instruments are valid and measure the constructs, and the respondents will answer the survey truthfully. 
Table 1- Study concepts, theoretical definitions, operational definitions, and indicators

\begin{tabular}{|c|c|c|c|}
\hline Concept & Theoretical Definition & Operational Definition & Indicator \\
\hline $\begin{array}{l}\text { Nurse } \\
\text { Characteristics }\end{array}$ & $\begin{array}{l}\text { The nurse's physical and } \\
\text { demographic attributes. }\end{array}$ & $\begin{array}{l}\text { Nurse Demographic } \\
\text { Survey }\end{array}$ & $\begin{array}{l}\text { Responses to } \\
\text { survey questions }\end{array}$ \\
\hline $\begin{array}{l}\text { Psychological } \\
\text { Empowerment }\end{array}$ & $\begin{array}{l}\text { a motivational process in } \\
\text { which inherent } \\
\text { characteristics, as well as } \\
\text { environment factors, } \\
\text { influence persons' abilities to } \\
\text { discover the meaning, } \\
\text { enhanced competence, and } \\
\text { self-determination necessary } \\
\text { to impact their environments }\end{array}$ & $\begin{array}{l}\text { Psychological } \\
\text { Empowerment Instrument } \\
\text { (Spreitzer, 1995) }\end{array}$ & $\begin{array}{l}\text { Psychological } \\
\text { empowerment } \\
\text { score }\end{array}$ \\
\hline Generation & $\begin{array}{l}\text { a cohort sharing birth years } \\
\text { and significant life events }\end{array}$ & $\begin{array}{l}\text { Veterans (born between } \\
\text { 1925-1945), Baby } \\
\text { Boomers (born between } \\
\text { 1946-1964), Generation X } \\
\text { (born between 1963-1980), } \\
\text { and Millennials (born } \\
\text { between 1981-2000). }\end{array}$ & Birth year \\
\hline $\begin{array}{l}\text { Quality of } \\
\text { Work Life }\end{array}$ & $\begin{array}{l}\text { The value assigned to one's } \\
\text { work and individual } \\
\text { contexts. }\end{array}$ & $\begin{array}{l}\text { The Revised Nursing } \\
\text { Working Index (NWI-R) }\end{array}$ & NWI-R score \\
\hline $\begin{array}{l}\text { Job } \\
\text { Satisfaction }\end{array}$ & $\begin{array}{l}\text { The extent to which } \\
\text { employees like their jobs. }\end{array}$ & $\begin{array}{l}\text { The Global Job } \\
\text { Satisfaction Questionnaire }\end{array}$ & $\begin{array}{l}\text { Global Job } \\
\text { Satisfaction } \\
\text { score }\end{array}$ \\
\hline
\end{tabular}


Figure 1. The Theoretical Model of Nurse Outcomes

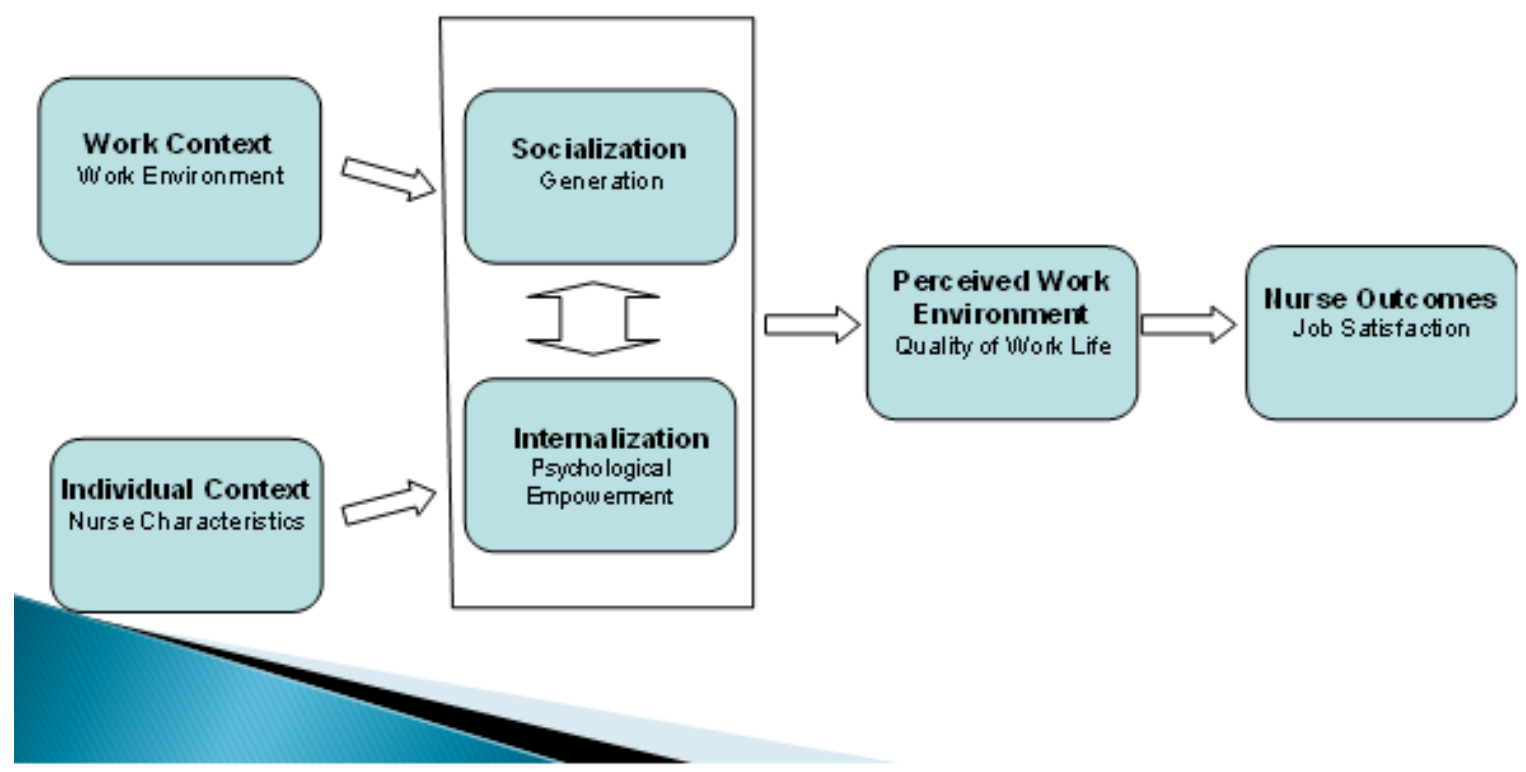


Figure 2: Model of Investigation

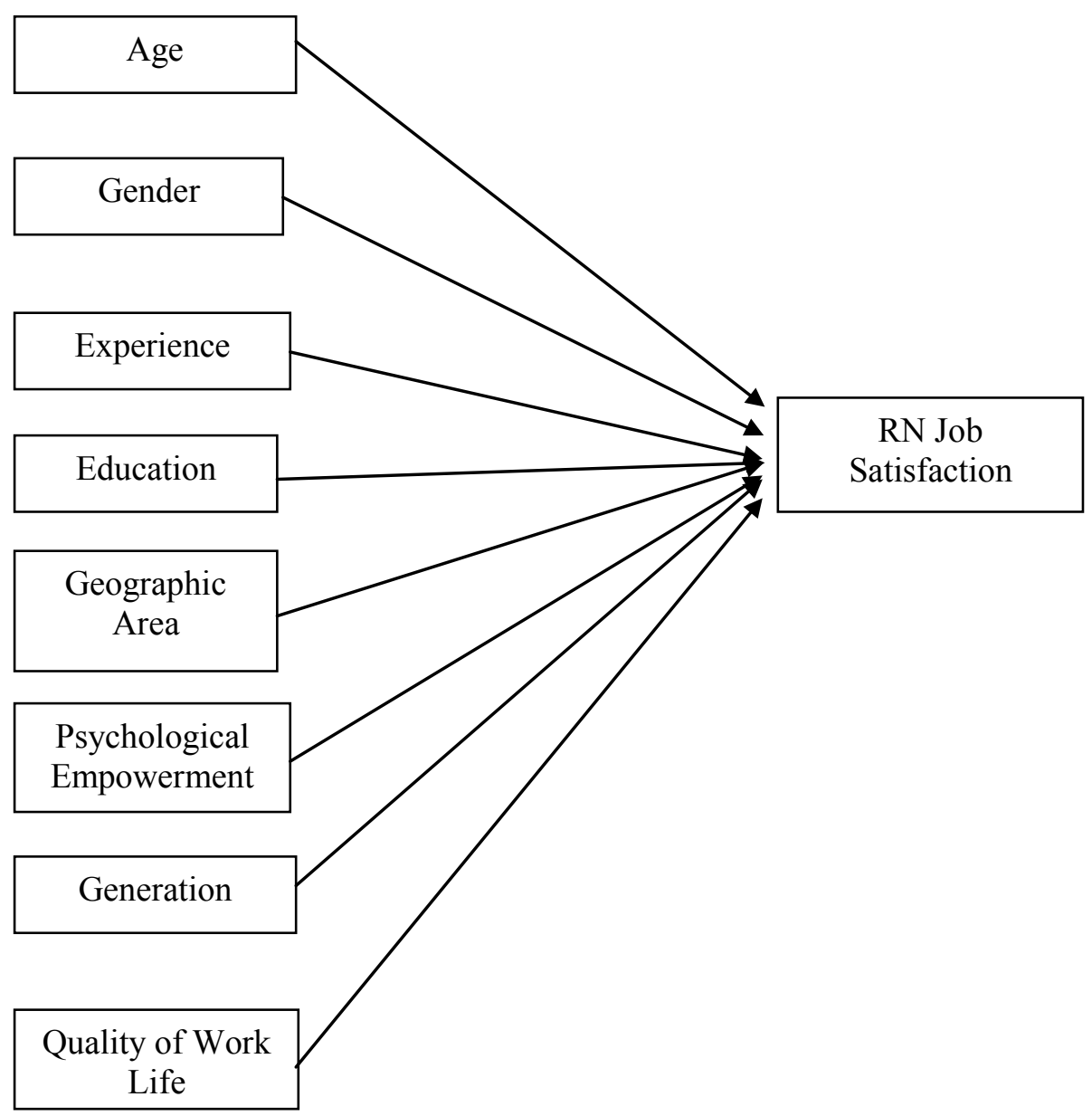




\section{Organization of the Dissertation}

Chapter 2 provides the review of literature supporting the development of the theoretical model and proposed study concepts. A critical review and appraisal of the literature related to the study concepts and instruments used to measure the concepts are presented. Finally a synthesis of the literature is discussed.

Chapter 3 presents the methodology and procedures used to conduct the study. The research method and measurement of concepts are provided. A description of the sample is discussed. The statistical procedures used to analyze the data collected in the study are described.

Chapter 4 presents the findings of the study. Descriptive statistics describing the sample are presented. The statistical analyze results for each research question is presented.

Chapter 5 presents a discussion of the findings related to each research question and hypothesis. The findings of this study are compared to previously reported findings. The theoretical model is evaluated in light of the findings of this study. The strengths and limitations of the study are reported. Additionally, the implications of the study findings for practice and research are discussed. 


\title{
CHAPTER 2: REVIEW OF THE LITERATURE
}

\author{
Overview of the Chapter
}

The purpose of this literature review is to present the empirical evidence to support the Theoretical Model of Nurse Outcomes. First, the review of literature related to each of the model concepts (nurse characteristics, psychological empowerment, generation, quality of work life, and job satisfaction) are discussed. Second, the propositional statements and links between the concepts are discussed based on the critical analysis of the literature. Third, the gaps in the literature are discussed. Fourth, a review of the instruments used to measure each of the concepts in the Theoretical Model of Nurse Outcomes is presented. Finally, a rationale of the instruments used to measure each of the concepts is provided.

\section{Literature Search Method}

The purpose of the literature search and review was to retrieve current research articles that relate to examining the influence of nurses' characteristics, psychological empowerment, and generation on perceived quality of life and/or nurse job satisfaction. A systematic search was conducted within the following databases: CINAHL (1975-2010), PubMed (1975-2010), Psych INFO (1975-2010), and all full text databases available at West Virginia University. Over three thousand hits were provided with keywords such as 'nurse satisfaction' and 'job satisfaction.' Additional key words, such as 'job tension,' 'intent to leave,' 'job stress,' 'burnout,' 'nurse characteristics,' ‘age,' 'experience,' ‘education,' 'retention', 'turnover,' 'staff morale,' 'role expectations,' 'psychological empowerment,' 'quality of work life,' 'generational differences,' and 'generation' were combined with nurse and job satisfaction. The inclusion criteria were that the articles were written in English, the sample was comprised, at least in part, of registered 
nurses (RNs), the articles were primary research studies, contained a pertinent literature review or critical appraisal of measurement instruments, and the primary focus of the study was nurse job satisfaction. Each article was then reviewed for relevance to the concepts presented in the theoretical framework. The strength and limitations of the evidence was reviewed by the process outlined by the U.S. Preventive Services Task Force (USPSTF) (Harris, et al., 2001).

\section{Review of Literature}

The literature review is organized by the following concepts: Nurse Characteristics, Psychological Empowerment, Generation, and Quality of Work Life. The research studies pertinent to each concept were reviewed because of their relevance to nurse job satisfaction; therefore, the concept of job satisfaction does not have a separate review of literature.

\section{Relationship of Nurse Characteristics and Registered Nurse (RN) Job Satisfaction}

Nurse characteristics have been associated with RN job satisfaction (Adams \& Bond, 2000; Cimete, et al., 2003; Curtis, 2008; Ea, et al., 2008; Ma, et al., 2003; McNeese-Smith \& Van Servellen, 2000; Penz, et al., 2008; M. Price, 2002). Within the context of the Theoretical Model of Nurse Outcomes, nurse characteristics are defined as the nurse's physical and demographic attributes. Over 130 nurse job satisfaction research studies examined nurse characteristics. Because nurse characteristics are often gathered in demographic questionnaires, the volume of studies capturing nurse characteristics is not surprising. However, few studies reported the influence of nurse characteristics on RN job satisfaction as a primary research aim. Within the context of this study, nurse characteristics are included as a primary research aim. Nurse characteristics are proposed to indirectly and directly influence RN job satisfaction; specifically, nurse characteristics are potentially mediated by the nurses' generation and 
psychological empowerment. Therefore, only research studies with a primary focus on examining the influence of nurse characteristics on job satisfaction are included in this review. Each of the eight articles reviewed (Adams \& Bond, 2000; Cimete, et al., 2003; Curtis, 2008; Ea, et al., 2008; Ma, et al., 2003; McNeese-Smith \& Van Servellen, 2000; Penz, et al., 2008; M.

Price, 2002) evaluated the impact of age, experience, education, gender, and geographic area on $\mathrm{RN}$ job satisfaction. The nurse participants worked primarily in acute hospital settings in the United States of America (Ea, et al., 2008; Ma, et al., 2003; McNeese-Smith \& Van Servellen, 2000), England (Adams \& Bond, 2000; M. Price, 2002), Ireland (Curtis, 2008), Istanbul (Cimete, et al., 2003) , and Canada (Penz, et al., 2008). Each of the studies had a non-experimental design. Due to these similarities, the reviewed articles are listed in chronological order by publication date.

Adams and Bond (2000) conducted a secondary analysis of data collected previously by the researchers in 1994. The original data, gathered from the descriptive correlational study, were re-examined to identify the impact of individual nurse characteristics and organizational features on nurses' job satisfaction. A total of 834 registered nurses working on adult wards in English acute hospitals completed a postal survey. The study had a $57 \%$ response rate. Job satisfaction was measured with a sub-scale of the Ward Organizational Features Scales (WOFS). The WOFS were developed in the original study to measure nurses' satisfaction with ward structure, organization, care processes, and overall job satisfaction. The results of the survey were compared to the individual nurse characteristics. The Cronbach's alpha for the job satisfaction scale was .77 in this study. Correlations, ANOVA, and multiple regression analysis procedures were conducted to evaluate the relationships between the variables. The researchers reported that age, education, and experience were not significantly related to job satisfaction. The large 
sample is a strength of this study. Limitations of the study include: the study design, a secondary analysis of data collected six years prior, was not originally designed for the purposes of this analysis and the study was conducted in England limiting the generalizability of the findings to the US nurse population.

McNeese-Smith and Servellan (2000) conducted a predictive correlational study that, in addition to age, took into consideration the developmental stage of the nurse. The purpose of the study was to evaluate the relationship between the nurse's age stage, developmental stage, and nurse outcomes: job satisfaction, productivity, and organizational commitment. A sample of 412 registered nurses, randomly selected from three US hospitals, completed a self-report survey. The study had a response rate of $65 \%$. The majority of the respondents $(66 \%)$ were staff nurses and the rest of the sample was comprised of nurse managers, charge nurses, clinical nurse specialists, educators, and case managers. Job satisfaction was measured by the Job-in-General scale, which had a Cronbach's alpha of .85 in this study. The SAS statistical package was used to conduct correlations, ANOVA, and t-test statistical procedures on the data. The researchers found that as the nurse's age increased, the nurse's job satisfaction $(\mathrm{p}=.03)$, productivity $(\mathrm{p}=.001)$, and occupational commitment $(\mathrm{p}=.001)$ also increased. The nurse's age and developmental stage predicted the nurse's job satisfaction only when added together. The large random sample and use of valid and reliable instruments are strengths of the study. The sample consisted of nurses working in Los Angeles County in California limiting the generalizability of the findings.

Price (2002) conducted a correlational study to evaluate nurses' job satisfaction and individual nurse variables. A convenient sample of 141 ward-based nurses participated from 26 adult medical/surgical wards in an English teaching hospital. The study had an $87 \%$ response rate. Nurse job satisfaction was measured by the Mueller McCloskey Nurses' Satisfaction Scale 
(MMSS) (McCloskey, 1990) which had a Cronbach's alpha of .89 in this study. The researcher also collected data regarding the nurse's age $(20-30 \mathrm{yrs}, \mathrm{n}=41 ; 31-40 \mathrm{yrs}, \mathrm{n}=68 ; 41-50 \mathrm{yrs}, \mathrm{n}=\mathrm{not}$ specified; 51-60, $\mathrm{n}=$ not specified), gender, work status, children/dependents, clinical grade, and experience. The researcher reported that job satisfaction differed based on nurses' age groups: the most satisfied nurses were in the age group 51-60 years and had worked 7-10 years part-time and the most dissatisfied nurses were in the age group 31-40 years and had worked 3-4 years full-time. No higher-level statistical procedures, beyond the descriptive statistics, were used to examine the data. The 'unspecified' number of participants in the older age groups is an additional limitation of the study. However, the systematic sampling plan, $86 \%$ response rate, and valid and reliable instruments are strengths of the study.

Cimete et al. (2003) was interested in identifying a relationship between nurses' characteristics, job satisfaction, and perceived quality of life. A total of 501 registered nurses from two university hospitals in Istanbul participated in the descriptive study. The researchers collected data on the nurse's age (19-24 yrs, 23-29 yrs, 30-34 yrs, 35-39 yrs, and $40+$ yrs), education, economic level, experience, and time of work. Nurse job satisfaction was measured with the short form Minnesota Satisfaction Questionnaire. The WHOQOL-BRIEF (the full name not provided in the article), previously tested for adequate reliability and validity, was used to measure nurses' perceived quality of the following life domains: environmental, social, psychological, and physical domains. The findings indicated a correlation between nurse job satisfaction and quality of life domains. An increased score on general perceived quality of life was related to increased age, higher level of education, higher economic level, and longer duration of work life. However, job satisfaction did not differ due to education. The nurses in the 19-24 years age group had significantly lower job satisfaction scores and nurses over 40 years 
old had the highest job satisfaction scores. Additionally, nurses with ten or more years of experience had comparatively higher job satisfaction scores than nurses with less experience. Cultural differences related to nurses who practice in Istanbul were not addressed in this study. Notable strengths of the study are the ample sample size and inclusion of quality of life which is a gap in the literature. Limitations of the study are the descriptive design, convenience sample, and findings of the study are generalizable to nurses in Istanbul.

Ma et al. (2003) conducted a secondary analysis with the purpose of examining the influence of nurses' characteristics, such as age, education, years of service, and salary, workrelated factors, and geographic-related factor on $\mathrm{RN}$ job satisfaction. The sample consisted of 3,472 RNs working in South Carolina (SC) hospitals in the year 2000. The nurses worked in intensive care units, non-intensive care units, or administrative roles. The study had a $20.2 \%$ response rate. Job satisfaction was measured with the SC Nursing Survey with a 10-item Likert scale. The Cronbach's alpha was .87 in this study. Age and years of service were gathered as continuous variables and all other variables were captured as a categorical variable. Correlation, ANOVA, and backward elimination statistical procedures were conducted to examine the impact of the independent variables on $\mathrm{RN}$ job satisfaction. The researchers found no relationship between RN job satisfaction and the nurses' age and years of experience. However, RN job satisfaction did significantly vary based on the nurses' years of service, job position, and geographic area $(\mathrm{p}<.05)$. Specifically, nurses who held positions other than staff positions, had more years of experience, and lived in small urban areas of SC had the highest levels of RN job satisfaction. A strength of the study was that a conceptual framework guided the study. Additionally, the study had a large sample size. Limitations of the study include the secondary analysis design of this study and low response rate (20\%). 
Ea et al. (2008) conducted a correlational study to examine the relationships among nurse characteristics, acculturation, and nurse job satisfaction. The convenient sample consisted of 96 Filipino registered nurses who were at the Eastern Regional Conference in Maryland in 2006. The majority $(63.5 \%)$ of the nurses currently worked in an US acute care hospital. Job satisfaction was measured using the 44-item part B of the Index of Work Satisfaction (IWS) (Stamps, 1997) which had a Cronbach's alpha of .90 in this study. Nurse demographics such as age, length of residency, and duration of practice in the US were collected using a questionnaire. Correlation and multiple regression statistical analyses were used to examine the relationship among the variables. The researchers found that acculturation, length of residency, and age predicted job satisfaction $(\mathrm{F}=6.561, \mathrm{p}<.001)$ explaining $17.9 \%$ of variance in $\mathrm{RN}$ job satisfaction. Additionally, age was found to be negatively correlated with job satisfaction $($ Standardized beta $=-570, \mathrm{p}<.05)$. Investigation of the influence of culture on $\mathrm{RN}$ job satisfaction is a strength of the design because it addressed a gap in the literature. Limitations of the study include the convenience sample, self-report design which could introduce bias, and the generalizability of the findings limited to Philippine nurses currently working in the US.

Curtis et al. (2008) conducted a non-experimental study to examine the influence of biographical variables on nurses' job satisfaction. The sample was collected using a stratified random sampling technique. A total of 610 of the selected nurses working in the Republic of Ireland participated in the study. The sample included student nurses, clinical nurses, and nurse managers. The study had a $30.5 \%$ response rate. Job satisfaction was measured using the IWS questionnaire (Stamps, 1997). The IWS subscales had Cronbach's alpha ranging from .59 (professional status) - .82 (pay). A biographical questionnaire developed for this study collected data on the nurses' characteristics such as gender, age group, education, position, and experience. 
The statistical package SPSS 11.0 was used to conduct independent-samples t-test and ANOVA procedures on the data. The researchers found that there was no difference in the nurses' job satisfaction based on gender $(t=1.135, \mathrm{p}=0.257)$. However, the nurses did significantly differ in their job satisfaction based on their age groups $(\mathrm{F}=3.5, \mathrm{p}=.008)$ with the nurses in the age 46-55 being most satisfied. Additionally, registered nurses were significantly more satisfied than degree or diploma prepared nurses $(F=4.98, p=0.007)$. There were no significant job satisfaction differences between nurses who worked less than 5 years in their current positions and those nurses who worked longer than 5 years. Strengths of the study were a valid and reliable job satisfaction instrument, mixed methods design, and a theoretical framework guided the study. A limitation of the study was the poor response rate $(30.5 \%)$, which could introduce a self-selection bias. Also, the biographical questionnaire developed for this study needs further validity and reliability testing.

Penz et al. (2010) conducted a non-experimental study to investigate individual, workplace, and community characteristics as predictors of $\mathrm{RN}$ job satisfaction. The sample was selected using a stratified random sampling procedure. The total sample included 3,933 acute care hospital nurses working in Canada. The study had a $68 \%$ response rate. For purposes of this study, only 944 nurses working in rural communities were included in the analysis. Job satisfaction was measured with a 30-item modified version of the IWS (Stamps, 1997). The Cronbach's alpha was .87 in this study. Age (birth year) and gender were also collected with a demographics questionnaire. A stepwise multiple regression analysis was conducted to examine the study variables. Of the individual nurse characteristics investigated, age was not a significant predictor of RN job satisfaction; however, gender (female) did significantly predict RN job satisfaction $(\mathrm{t}=3.47, \mathrm{p}<0.01)$. Strengths of the study include the large randomly selected sample, 
valid and reliable job satisfaction instrument, and the examination of rural areas, which addresses a gap in the literature. Limitations of the study include the secondary analysis design and generalizability of findings to rural areas in Canada.

\section{Synthesis of Nurse Characteristics Literature}

Collectively, the reviewed research studies (Adams \& Bond, 2000; Cimete, et al., 2003; Curtis, 2008; Ea, et al., 2008; Ma, et al., 2003; McNeese-Smith \& Van Servellen, 2000; Penz, et al., 2008; M. Price, 2002) evaluated the impact of age, experience, education, gender, and geographic area on RN job satisfaction. Not every study evaluated each of these factors. The findings are presented based on their pertinence to age, experience, education, gender, and geographic area and presented in order of most supported by the literature.

Age

All eight of the reviewed articles investigated the impact of nurses' age on $\mathrm{RN}$ job satisfaction (Adams \& Bond, 2000; Cimete, et al., 2003; Curtis, 2008; Ea, et al., 2008; Ma, et al., 2003; McNeese-Smith \& Van Servellen, 2000; Penz, et al., 2008; M. Price, 2002). The findings of five studies supported the proposition that nurses' age influences RN job satisfaction (Cimete, et al., 2003; Curtis, 2008; Ea, et al., 2008; McNeese-Smith \& Van Servellen, 2000; M. Price, 2002) The most prevalent finding was that $\mathrm{RN}$ job satisfaction differed based on nurses' age group (Cimete, et al., 2003; Curtis, 2008; M. Price, 2002) Age has also been identified as a predictor of RN job satisfaction in two U.S. studies (Ea, et al., 2008; McNeese-Smith \& Van Servellen, 2000); however, one study found that age was only a predictor of RN job satisfaction when statistically coupled with the nurses' developmental age (McNeese-Smith \& Van Servellen, 2000). Interestingly, one of the U.S. correlational studies found that age was 
positively correlated with RN job satisfaction (McNeese-Smith \& Van Servellen, 2000), while another study with a sample of Filipino nurses working in the U.S. reported that age was negatively correlated with RN job satisfaction (Ea, et al., 2008). Inconsistencies in findings could be related to differences in sample populations, instruments used to measure RN job satisfaction, and frameworks used to guide the studies.

Although, there were three studies that reported age did not significantly influence RN job satisfaction (Adams \& Bond, 2000; Ma, et al., 2003; Penz, et al., 2008), there is substantial evidence to support age as a factor influencing RN job satisfaction.

\section{Experience}

Five of the reviewed studies investigated the influence of experience on $\mathrm{RN}$ job satisfaction (Adams \& Bond, 2000; Cimete, et al., 2003; Curtis, 2008; Ea, et al., 2008; Ma, et al., 2003). Two studies found that experience was significantly associated with RN job satisfaction (Cimete, et al., 2003; Ea, et al., 2008). However, three studies reported that experience did not significantly impact RN job satisfaction (Adams \& Bond, 2000; Curtis, 2008; Ma, et al., 2003). Curtis et al. (2008), found there was no difference in RN job satisfaction between nurses who worked less than five years when compared to nurses who worked greater than five years. Even so, another study's findings indicted that nurses who worked greater than ten years or more were significantly more satisfied with their jobs than nurses working less years (Cimete, et al., 2003). Additionally, there is evidence to support that length of time in a nurse's current position positively impacts RN job satisfaction (Ea, et al., 2008; Ma, et al., 2003). 
Education

There were three studies that specifically examined the influence of nurses' education on RN job satisfaction (Adams \& Bond, 2000; Cimete, et al., 2003; Curtis, 2008). The majority of those researchers found that education did not significantly influence RN job satisfaction (Adams \& Bond, 2000; Cimete, et al., 2003). Nevertheless, in a sample of nurses from Ireland, registered nurses were significantly more satisfied with their jobs than diploma-prepared nurses (Curtis, 2008).

Gender

There were two studies that included an evaluation of the influence of gender on RN job satisfaction with contradictory results (Curtis, 2008; Penz, et al., 2008). A study conducted in Canada found that gender (female) predicted RN job satisfaction (Penz, et al., 2008). Still, a study conducted in Ireland found that gender did not significantly impact RN job satisfaction (Curtis, 2008). There were no studies conducted in the U.S. that examined the influence of gender on RN job satisfaction.

Geographic Region

Only one research team investigated the influence of geographic area on $\mathrm{RN}$ job satisfaction (Ma, et al., 2003). Their investigation revealed that nurses varied in RN job satisfaction based on their geographic area of residence in South Carolina (Ma, et al., 2003). Further research is necessary to determine the impact of geographic area on RN job satisfaction.

Nurse characteristics such as age, experience, education, gender, and geographic area have been found to influence RN job satisfaction (Adams \& Bond, 2000; Cimete, et al., 2003; 
Curtis, 2008; Ea, et al., 2008; Ma, et al., 2003; McNeese-Smith \& Van Servellen, 2000; Penz, et al., 2008; M. Price, 2002). The evidence to support the influence of nurse characteristics on RN job satisfaction is contradictory at best. The studies used a wide variety of instruments to measure both the nurse characteristics and $\mathrm{RN}$ job satisfaction, which could plausibly explain differing outcomes. Additionally, inconsistent results could suggest that nurse characteristics and $\mathrm{RN}$ job satisfaction are mediated by another factor(s). This study will re-examine the direct influence of nurse characteristics on RN job satisfaction, as well as investigate the possibility of a mediating influence between nurse characteristics and $\mathrm{RN}$ job satisfaction.

\section{The Relationship of Psychological Empowerment and RN Job Satisfaction}

Psychological empowerment is proposed to mediate the relationship between the concepts of nurse characteristics and $\mathrm{RN}$ job satisfaction. A literature search was conducted to retrieve primary research studies related to examining the relationship between psychological empowerment, nurses' characteristics, generation, perceived quality of life, and $\mathrm{RN}$ job satisfaction. A total of nine research studies (Casey, Saunders, \& O'Hara, 2009; Larrabee, et al., 2003; Larrabee, et al., 2010; H.K. Laschinger, Finegan, Shamian, \& Wilk, 2001; H. K. Laschinger, Finegan, Shamian, \& Wilk, 2004; H. K. Laschinger, Purdy, \& Almost, 2007; Morrison, et al., 1997) evaluated the relationship between psychological empowerment and nurse job satisfaction. There were no studies that evaluated the relationships between psychological empowerment and generation, quality of work life, and nurses' characteristics as defined in this theoretical model. All of the studies evaluating the relationship between psychological empowerment and nurse job satisfaction have been non-experimental designs. The reviewed studies were conducted in the United States (Larrabee, et al., 2003; Larrabee, et al., 2010; Morrison, et al., 1997), Canada (H. K. Laschinger, et al., 2004; H. K. Laschinger, et al., 2007), 
Ireland (Casey, et al., 2009), and Taiwan (Chang, Shih, \& Lin, 2010). The participant samples included staff nurses (Larrabee, et al., 2003; Larrabee, et al., 2010; Laschinger, et al., 2001; H. K. Laschinger, et al., 2004; Morrison, et al., 1997), nurse managers (Laschinger, et al., 2007; Morrison, et al., 1997), midwives (Casey, et al., 2009), and school nurses (Chang, et al., 2010). Due to similarities in design and research aims, the reviewed articles are presented in chronological order.

Morrison et al. (1997) conducted a non-experimental study to examine the relationship between leadership style, psychological empowerment, and job satisfaction. The convenience sample consisted of 275 nursing staff, which included executives, nurse managers, licensed practical nurses, registered nurses, nursing assistants, and administrative staff located in a regional medical center in Alabama. This study had a $64 \%$ response rate. To measure psychological empowerment, the authors report using 4 items from Sprietzer's (1995) psychological empowerment instrument. The authors do not report a rationale for including only four of the items from the psychological empowerment instrument. Nor do the authors report reliability testing of the modified use of the instrument in this study. Job satisfaction was measured by an instrument developed by Warr (1979), which had previously reported reliability coefficients of $0.78-0.90$. This job satisfaction instrument was not originally developed to measure nurse job satisfaction. Correlations, ANOVAs, and regression analysis procedures were conducted to evaluate the relationships between the variables. Psychological empowerment was found to be positively correlated to job satisfaction $(\mathrm{r}=0.41)$. Strengths of the study include a high response rate (64\%) and valid and reliable instruments. A limitation of the study could be the inclusion of nursing assistants which potentially biased the findings. Also, the study used a convenience sample. The self-report design could be another source of potential bias. 
Laschinger et al. (2001) conducted a predictive, non-experimental study to test the relationships between structural empowerment, psychological empowerment, job strain, and job satisfaction. A random sample of 404 Canadian nurses completed the survey resulting in a $72 \%$ response rate. Psychological empowerment was measured using Spreitzer's (1995) 12-item psychological empowerment scale. The alpha reliability coefficient was .89 in this study. Work satisfaction was measured with an adapted 4-item version of the Hackman and Oldham's (1975) job diagnostic survey (Laschinger, 1996). The alpha reliability coefficient was .82 in this study. Structural equation modeling techniques contained in the AMOS statistical package, within SPSS-PC, were used to test the relationships in this study. Psychological empowerment was found to have a direct and significant effect on job satisfaction $($ Beta $=.30)$. Strengths of the study include the use of theoretical framework to guide the study. Valid and reliable instruments were used which is another strength of the study. Additionally, the sample was a large randomly selected sample. Limitations of the study include a non-experimental self-report design which could introduce a self-selection bias. Also, the findings were limited to Canadian nurse population.

Larrabee et al. (2003) conducted a non-experimental, predictive study to examine the influence of nurse attitudes, including psychological empowerment, context of care, and structure of care on job satisfaction and intent to leave. The convenience sample in this study was comprised of 90 nurses that worked on medical/surgical or intensive care step-down units at a university teaching hospital in West Virginia. Psychological empowerment was measured using Spreitzer's (1995) 12-item questionnaire. The alpha coefficient in this study was .91. Job satisfaction was measured using the 38-item Work Quality Index instrument. The reported Cronbach's alpha was .95 . The SAS 8 was the statistical package used for the analysis 
completed in this study. Multivariate regression was used to determine the predictors of job satisfaction and intent to leave. Psychological empowerment was found to be a major predictor of job satisfaction explaining 54\% of the job satisfaction variance. Strengths of the study include a theoretical framework guided the study. Additionally, valid and reliable instruments were used to measure the concepts. Limitations of the study include non-experimental design and convenience sample.

Laschinger et al. (2004) conducted a longitudinal, predictive study to evaluate structural and psychological empowerment changes in a sample of Canadian nurses over time. The original sample included 600 randomly-selected nurses from the 1998 College of Nurses of Ontario registry list. The sample for this study consisted of the 185 nurses that completed the repeated questionnaire, administered three years later, resulting in a $45 \%$ return rate. The nurses in the sample worked in medical-surgical (27.3\%), critical care (37.6\%), maternal child (12.7\%), and psychiatric (22.4\%) units in the province of Ontario. Over half of the nurses were full time (64.7\%) and most (78.7\%) were diploma-prepared nurses. Psychological empowerment was measured using Spreitzer's (1995) 12-item psychological empowerment instrument. The Cronbach's alpha reliability scores were 0.87 and 0.89 for this study. Work satisfaction was measured with an adapted 4-item version of the Hackman and Oldham's (1975) job diagnostic survey (H. K. Laschinger, 1996). The Cronbach alpha reliability scores were 0.78 and 0.84 for this study. Structural equation modeling for longitudinal analysis with maximum likelihood estimation was used to analyze the proposed model. The researchers reported that changes in psychological empowerment over time did not significantly impact job satisfaction. This was a contradictory finding from the results of the original cross sectional study, which found that psychological empowerment did significantly impact job satisfaction. The researchers note that 
the first data collection point was during a time when downsizing had peaked in Ontario. The second collection point was during a period of minimal hospital restructuring. The authors suggest that psychological empowerment may have a greater mediating effect on job satisfaction during times of stress. Strengths of the study include the inclusion of generation and valid and reliable instruments. Limitations of the study include attrition, self-selection bias, and effect of history on the sample over three years.

Laschinger et al. (2007) conducted a non-experimental, predictive study to examine the relationship between 'core self-evaluation,' leader-member exchange quality (LMX), structural empowerment, psychological empowerment, and job satisfaction. The random sample included 223 acute care hospital nurse managers working in Ontario. The response rate was $63 \%$. Psychological empowerment was measured with Spreitzer's (1995) 12-item psychological empowerment instrument. The researchers reported the internal consistency for the psychological empowerment instrument as 0.72 to 0.97 . Job satisfaction was measured with the subscale of the pressure management indicator instrument. The researcher described a previously reported alpha reliability of 0.88 and the internal consistency was 0.92 for this study. Statistical analysis was completed with the SPSS 14 and AMOS 6. The researchers found that psychological empowerment had a direct positive effect on job satisfaction $($ Beta $=.35)$. A strength of the study included a large sample. The researchers used valid and reliable instruments to measure concepts. Additionally, a theoretical framework guided the study. A notable limitation of the study is the inability to generalize findings to staff nurses because the sample was comprised of managers and the instrument used to measure job satisfaction was developed specifically for managers.

Casey, et al. (2009) conducted a predictive, non-experimental study to examine the 
impact of structural, critical social, and psychological empowerment on the job satisfaction of 244 nurses and midwives in Ireland. The researchers had an 80\% response rate. The convenient sample primarily worked in the acute hospital setting (84\%). A 17-item scale (Warr, Cook, \& Wall, 1979) was used to measure job satisfaction. The Cronbach's alpha of the scale in this study was 0.88. Spreitzer's (1995) 12-item scale was used to measure psychological empowerment. The Cronbach's alpha was 0.82. Regression analysis and Spearman's rank correlation were conducted using the SPSS 15 statistical package. The researchers reported psychological empowerment as a significant predictor of job satisfaction, accounting for $7.1 \%$ of the variance in job satisfaction $(\mathrm{R} 2=.011, \mathrm{p}<.0001)$. Strengths of the study include an $80 \%$ response rate and a valid and reliable job satisfaction instrument. Limitations of the study include self-report, cross sectional design, and convenience sample.

Chang et al. (2010) conducted a study to evaluate the mediating role of psychological empowerment between school nurses' 'external factors,' such as marital status, years of nursing, and education, and their job satisfaction and organizational commitment. A total of 500 school nurses were randomly-selected from elementary schools in Taiwan. The sample consisted of 330 nurses who completed the questionnaire, resulting in a $66.7 \%$ response rate. Psychological empowerment was measured using Spreitzer's (1995) 12-item psychological empowerment instrument. In this study, the Cronbach's alpha coefficient was 0.83 . Job satisfaction was measured by a 22-item job satisfaction instrument developed by Hackman and Oldman (1975) and adapted by $\mathrm{Wu}(2000)$. The Cronbach's alpha coefficient was 0.77 in this study. The researchers did not detail how external factors were measured. The statistical packages SPSS 15 and AMOS 7 were used for statistical analysis. Simple linear regression was first used to test each of the paths in the model. Path analysis and structural equation modeling was used to test 
the relationships of the variables in the model and the mediating effect of psychological empowerment. Psychological empowerment was found to predict job satisfaction $(\mathrm{r}=0.30, \mathrm{p}<$ .001). Psychological empowerment did not fully mediate the influence of the external factors such as marital status and education. Nevertheless, psychological empowerment was found to mediate the impact of nurses' school size on job satisfaction $(\mathrm{p}<.05)$. A strength of the study included the valid and reliable instruments used to measure concepts. Another strength was the use of a theoretical framework to guide the study. Limitations of the study include a descriptive study design, convenience sample, and findings of the study are limited to school nurses in Taiwan.

Larrabee et al. (2010) conducted a non-experimental, predictive study to examine the relationship between nurse job satisfaction, psychological empowerment, intent to stay, job stress, and interpretive styles (stress resiliency). The sample included nurses from four rural and one urban acute care hospitals in West Virginia. From three rural hospitals and one urban hospital, $60 \%$ of the nurses were randomly-selected to participate. In the remaining small rural hospital, $100 \%$ of the nurses were invited to participate in the study because of the limited number of RNs employed. A sample total of 464 registered nurses completed the questionnaire, which was a 54.5\% response rate. Psychological empowerment was measured using Spreitzer's (1995) 12-item questionnaire. The Cronbach's alpha in this study was .88. Job satisfaction was measured using the 38-item WQI instrument, which had a Cronbach's alpha in this study of .95. Correlations, ANOVA, causal modeling, and path analysis were conducted to examine the relationship of the variables in this study. Psychological empowerment and job stress were found to be predictors of job satisfaction. Strengths of the study include use of a theoretical framework to guide the study, valid and reliable instruments, random selections of nurses from 
four hospitals, and ample sample size. Limitations of the study include self-report design and generalizibility of findings limited to nurses in West Virginia.

\section{Synthesis of Psychological Empowerment Literature}

There is substantial evidence to support psychological empowerment as a predictor of job satisfaction (Casey, et al., 2009; Larrabee, et al., 2003; Larrabee, et al., 2010). Evidence indicated that nurses with higher psychological empowerment scores have increased perceived job satisfaction (Laschinger, Finegan, \& Shamian, 2001; Morrison, et al., 1997). Additionally, Laschinger et al. (2001) found the relationship between structural empowerment (environmental factors in the work place) and job satisfaction was mediated by psychological empowerment. This relationship, however, was examined three years later in a longitudinal study and found no longer significant (Laschinger, et al., 2004). Chang et al. (2010) also studied the mediating effect of psychological empowerment and found such empowerment mediated the impact of the school nurses' school size on nurses' job satisfaction. Still, psychological empowerment did not fully mediate nurses' 'external factors,' such as marital status and education, on job satisfaction. In conclusion, there is substantial evidence to support the inclusion of psychological empowerment as a predictor of nurse job satisfaction. This study further investigates the proposed mediating influence of both psychological empowerment and generation between nurses' characteristics and both quality of work life and RN job satisfaction.

\section{The Relationship of Generation with RN Job Satisfaction and Quality of Work Life}

Generation is proposed to be a component of nurses' socialization. Much of the literature related to socialization is limited to exploring the concept of professional socialization (Mooney, 2007; Sochan \& Singh, 2007). New nurses described feelings of powerlessness and vulnerability 
related to poor organizational socialization (Mooney, 2007). One of the outcomes related to affirmative organizational socialization is job satisfaction (Wanberg \& Kammeyer-Mueller, 2000). However, theoretically, socialization prior to joining a workforce directly influences the ability to positively relate to one's environment, as well as one's organizational socialization. Socialization develops within the context of one's culture and generation. Thus, generational cohorts may potentially share similarities in values, which could likely influence how the cohorts perceive their work environments. Differences in perceived work environments are proposed to be manifested in RN job satisfaction and quality of work life scores.

The purpose of this literature review was to identify studies that examined the relationship between generation and $\mathrm{RN}$ job satisfaction and quality of work life. A total of five articles (Apostolidis \& Polifroni, 2006; Keepnews, Brewer, Kouner, \& Shin, 2010; Widger, et al., 2007; Wieck, Dols, \& Landrum, 2010; Wilson, et al., 2008) were found that evaluated the relationship between generation, among assorted other variables, and $\mathrm{RN}$ job satisfaction. Two articles evaluated differences in generational cohorts of nurses' perceived quality of work life (Stuenkel, Cohen, \& de la Cuesta, 2005; Wieck, et al., 2010). The nurse participants worked primarily in acute hospital settings in various nations. Each article had a non-experimental design. Due to these similarities, the reviewed articles are listed in chronological order by publication date.

Stuenkel et al. (2005) conducted a comparative study to explore generational differences related to nurses' perceptions of their work environments. A convenient sample of 272 nurses recruited from a large acute care country hospital, were categorized into the following generations: Veterans (1922-1943) $(n=10)$; Baby Boomers (1943-1960) $(n=190)$; Generation Xers (1960-1980) $(n=71)$; and Generation Nexters $(1980-2000)(n=0)$. Due to insufficient 
amount of nurses in the Veterans and Nexters generations, the researchers examined only the Baby Boomers and Generation Xers for differences. Quality of work life was measured with the Moos Work Environment Scale (WES) - Form R. No reliability or validity statistics were reported in the study. The instrument measures perception of work environment via the following variables: relationship, personal growth or goal orientation, and system/maintenance/system change; autonomy, involvement, peer cohesion, supervisor support, task orientation, innovation, work pressure, clarity, control, and physical comfort. There was no further demographic information provided regarding the type of unit the nurses worked, experience, gender, work status (full or part time) or education. T-tests were conducted to compare the results of the scales between the generations. The generations differed significantly on 5 of the 10 quality of work life scales $(\mathrm{p}<.05)$. Generation Xers perceived higher levels of involvement $(\mathrm{p}=.02)$, autonomy $(\mathrm{p}=.00)$, task orientation $(\mathrm{p}=.03)$, and greater supervisor support $(\mathrm{p}=.01)$ than Baby Boomers. Strengths of the study include the inclusion of generation and valid and reliable instruments. The poor response rate (39\%), inability to include all generations, and lack of consideration of nurse characteristics were limitations of this study.

Apostolidis \& Polifroni (2006) conducted a comparative study that evaluated the differences between nurses in the Baby Boomers and Generation Xers generations. The convenient sample included 98 medical/surgical nurses' who were selected by age and placed into either the Baby Boomer (1941-1964) or Xers (1960-1981) category. Job satisfaction was measured with the IWS Scale (Stamps \& Piedmonte, 1986). The sub-scales include pay, autonomy, professional status, interaction, task requirements, and organizational policies. The overall scale is divided into two parts that measured the perceived importance of each factor listed above (part A) and current job satisfaction (part B). The alpha coefficient of the scale in 
this study was .82 . Generation Xers were more satisfied with their professional status, interaction, autonomy, organizational policies, and task orientation. Generation Xers were less satisfied with the pay in their current position. Baby Boomers differed from Generation Xers, preferring autonomy to professional status $(\mathrm{p}<.05)$. A strength of the study is that a valid and reliable job satisfaction instrument was used. Limitations of the study were the nonexperimental self-report design and convenience sample.

Widger et al. (2007) conducted a secondary analysis on a sample of 8,207 nurses (RN and RPN) in a medical, surgical or critical care area in Ontario. The purpose of the study was to detect any generational differences in the nurses' job satisfaction, burnout, and perceived condition of their work environments. The researchers analyzed two data sets that originally evaluated nurse-related determinants of patient mortality and hospital readmissions. RN Job satisfaction was measured using the MMSS. Nurses' quality of work life was measured with the Revised Nursing Work Index (NWI-R). Psychometric properties of the instruments were deferred to previous publications. The researchers reported revising generational categories to include "cuspers" (those who may share similarities between the two generations they fall between) and increasing the nurses who would be included in Generation Y. The nurses were placed into the following generation categories: Baby Boomers $(1940-1959) \mathrm{n}=4118,50.2 \%$; Gen X (1960-1974) n=3,429, 41.8\%; Gen Y (1975 or later) $n=660,8 \%$. Significant differences among the generations were discovered. In regard to work environment, Generation Y perceived more nurse participation in hospital affairs $(\mathrm{p}=.001)$ and manager ability/support $(\mathrm{p}=.024)$ than other generations. Generation $X$ scored foundations for high-quality care $(p=.001)$ lower than other generations. In regard to job satisfaction, Baby Boomers reported higher satisfaction with extrinsic rewards $(\mathrm{p}<.001)$, scheduling $(\mathrm{p}<.001)$, balance of family and work $(\mathrm{p}<.001)$, and 
professional responsibility $(\mathrm{p}<.001)$ than nurses in Generations $\mathrm{X}$ and $\mathrm{Y}$. Furthermore, Baby Boomers reported higher overall job satisfaction $(\mathrm{p}<.001)$ than Generations $\mathrm{X}$ and $\mathrm{Y}$. In regard to burnout, Baby Boomers also reported significantly less burnout (p.001) than nurses in Generation Y. The findings are interpreted with caution as the revised generational stages resulted in a generation $\mathrm{X}$ and $\mathrm{Y}$ category that notably vary from previous nursing studies.

Wilson et al. (2008) conducted a secondary analysis study to compare RN job satisfaction among three generations of nurses. The original sample included 8456 registered nurses and registered practical nurses that worked on a medical, surgical, or critical care unit in Ontario. The study had a $65 \%$ response rate. For the purposes of this secondary analysis, 6541 RNs were categorized into the Baby Boomers (1940-1959) $(\mathrm{n}=3043)$, Generation X $(1960-1974)(\mathrm{n}=2898)$, or Generation Y (1975-onwards) ( $\mathrm{n}=600)$ cohort. Job satisfaction was measured with the 31item MMSS. The data were analyzed using the SPSS 14.0 statistical package. MANOVA procedures were conducted to examine differences in the overall job satisfaction as well as the seven components of job satisfaction among the three generations. There were significant differences in the generations' overall $\mathrm{RN}$ job satisfaction ( $\mathrm{p}<.001)$; specifically, Baby Boomer nurses were more satisfied than Generation X nurses. Baby Boomer nurses were significantly more satisfied with their pay, benefits, and scheduling than the younger generations of nurses $(p<.001)$. No differences were found between the Generation $X$ and Generation $Y$ cohorts of nurses. Strengths of the study were the large sample size, valid and reliable instruments, and inclusion of generation. A limitation of the study was the secondary analysis self-report design. Also, the inclusion of cuspers to increase the sample of Generation Y nurses could have biased the results.

Keepnews et al. (2010) conducted a secondary analysis with the purpose of investigating 
differences among generational cohorts in nurses' characteristics, job satisfaction, and other work attitudes. The sample in this study was comprised of 2,364 newly-licensed RNs from 34 states and the District of Columbia in the U.S. who were assembled in two collection points one year apart. The nurses were categorized into either the Baby Boomer $(n=251)$, Generation $X$ $(n=1643)$, or Generation $Y(n=465)$ cohort. Job satisfaction was measured using a component of the Brewer and Kovner's model (Kovner et al., 2006). The researchers report that the job satisfaction subscale had a Cronbach's alpha of .80 or greater. ANOVA, Chi square, and Bonferroni analysis procedures were used to compare the generational cohorts. The researchers found that the generations differed in their job satisfaction; Generation Y was significantly more satisfied with their jobs than Baby Boomer nurses $(p=.019)$. The large sample size was a strength of the sample. The authors did not report the birth years used to define the generational cohorts. Additionally, the job satisfaction instrument has not been frequently used in nursing research, thus restricting the comparability of these findings.

Wieck et al. (2010) conducted a comparative study to investigate generational cohorts' job satisfaction and quality of work life. The sample of 5,553 nurses was recruited via an inhospital online survey at 22 participating hospitals in the U.S. The study had a $31.9 \%$ return rate with the nurses working on a wide variety of acute care units. The nurses were placed into either the Baby Boomers ( $>40$ years old), Generation X (27-40 years old), or Millennials (18-26 years old) cohorts. Job satisfaction was measured via a survey. No reliability or validity measures were reported for the job satisfaction instrument in this study. Quality of work life was measured with the NWI-R (Aiken \& Patrician, 2000). The Cronbach's alpha was 0.97 in this study. Descriptive statistics were calculated on each of the variables. An ANOVA was conducted to compare the total quality of work life scores among the three generations. The 
researchers found that the Baby Boomer nurses were significantly more satisfied with their quality of work life than Generation X nurses ( $\mathrm{f}=6.067, \mathrm{p}=.002)$.

\section{Synthesis of Generation Literature}

\section{Job Satisfaction}

Each of the articles found significant differences in $\mathrm{RN}$ job satisfaction among the generational cohorts (Apostolidis \& Polifroni, 2006; Keepnews, et al., 2010; Widger, et al., 2007; Wieck, et al., 2010; Wilson, et al., 2008). However, there were discrepancies regarding which generation was more satisfied with their current jobs. Three of the studies reported Baby Boomer nurses were more satisfied with their jobs than Generation X nurses (Widger, et al., 2007; Wieck, et al., 2010; Wilson, et al., 2008). In a study conducted by Keepnews et al. (2010), Baby Boomer nurses were significantly less satisfied with their jobs than Generation Y nurses. Inconsistent findings could be related to variations in instruments, generational cohort categories, and sample populations.

Quality of Work Life

Two studies investigated differences in quality of work life among generations of nurses (Stuenkel, et al., 2005; Wieck, et al., 2010); both studies found that generations perceived their quality of their work life differently. More specifically, Generation X nurses perceived higher levels of autonomy than Baby Boomer nurses functioning in similar work environments (Stuenkel, et al., 2005). Interestingly, Baby Boomer nurses ranked autonomy as a higher job satisfier than Generation X nurses (Stuenkel, et al., 2005).

The findings of the reviewed articles support the proposition that generational cohorts of 
nurses differ in their perceptions of job satisfaction and quality of work life. Additionally, this evidence supports the proposition that generational cohorts share similar values and belief systems, which may mediate how nurses perceive the work environment. Thus, generational differences in work place perceptions are presumably manifested in their $\mathrm{RN}$ job satisfaction and quality of work life scores. There were no studies found that investigated the relationship(s) between nurse characteristics, psychological empowerment, generation, and RN job satisfaction.

\section{The Relationship of Quality of Work Life and RN Job Satisfaction}

Quality of work life is the value assigned to one's work context. Quality of nursing work life, in part, has been defined as an ability to satisfy personal needs through work experiences (Brooks, 2001), which indicates that quality of work life influences RN job satisfaction. Quality of work life is not clearly defined in the literature. Frequently, quality of work life is not clearly delineated from the concept of job satisfaction. Few studies have examined the impact of nurses' quality of work life on RN job satisfaction. More often, researchers have examined only one of the components of quality of work life, rather than including a comprehensive quality of work life instrument. One of the most frequently reported factors that influence nurses' perceptions of their quality of work life is autonomy (Aiken, et al., 2002; Blegan, 1993; Bratt, et al., 2000; Upenieks, 2002; Wells, et al., 2002). Autonomy, as a component of quality of work life, has been identified as an important predictor of job satisfaction (Dwyer, et al., 1992; McCloskey, 1990). Increased levels of autonomy have been associated with increased job satisfaction (Aiken, et al., 2002; Blegan, 1993; Bratt, et al., 2000; Wells, et al., 2002).

In this study, nurses' quality of work life is proposed to predict RN job satisfaction. The purpose of this literature search and review was to identify research that investigated the 
influence of quality of work life and $\mathrm{RN}$ job satisfaction. There was only one article found that included both variables (Manojlovich \& Laschinger, 2007). The article is presented and no synthesis is provided due to a lack of comparative studies. However, a brief discussion of the implications of these findings to the model developed in this study is offered in the Gaps in the Literature section.

Manojlovich \& Laschinger (2007) conducted a secondary analysis with the purpose of testing the inclusion of job satisfaction in the Nursing Work life Model. The original sample consisted of 332 acute care nurses working in Michigan. The study had a $66.4 \%$ response rate. For purpose of this analysis, 276 nurses who worked in a hospital setting were included in the study. Quality of work life was measured with the 33-item Practice Environmental Scale of the Nursing Work Index (PES-NWI). The PES-NWI had a Cronbach's alpha of 0.93 in this study. Job satisfaction was measured with the 41-item IWS, Part B instrument which demonstrated a reliability coefficient of 0.92 in this study. The statistical packages SPSS 11 and AMOS were used to conduct correlation and path analysis procedures. The researchers found that quality of work life explained $53 \%$ of the variance in job satisfaction $(\mathrm{p}<0.01)$. The quality of work life measurement, however, did not include autonomy. A strengths of the study included a theoretical framework guided the study. Also, valid and reliable instruments were used to measure the concepts. Limitations of the study include non-experimental secondary analysis design and convenience sample.

\section{Summary of the Literature Gaps \\ Overview}

This study was designed to address the gaps in the literature regarding $\mathrm{RN}$ job 
satisfaction. Currently, all of the nursing research found that examines the relationship between RN job satisfaction and nurse characteristics, generation, psychological empowerment, and quality of work life concepts are descriptive level studies. There has been no study found that incorporates all of these concepts within one theoretical model. In addition, inconsistent findings regarding predictors of job satisfaction further supports the need for a theoretical model that would allow researchers the opportunity to explore the relationships between nurses' personal characteristics, psychological empowerment, generation, quality of work life, and RN job satisfaction in one study. The Theoretical Model of Nurse Outcomes provides both theoretical (described in chapter 1) and empirical support for the inclusion for each of the proposed RN Job Satisfaction predictors. The next section offers a discussion of the literature gaps related to each of the concepts included in the model used in this study.

\section{Nurse Characteristics}

How nurses' characteristics impact RN job satisfaction has yet to be understood by researchers. There is evidence that supports a positive correlation with age and job satisfaction. However, the conceptual links of the relationship are not evident. Inconsistent findings in the literature may suggest that researchers are not accurately measuring age by disregarding developmental and social influences that attach meaning to a particular age. For example, although previous work has highlighted generational differences when perceiving the work environment (Stuenkel, et al., 2005), this has not been considered by researchers when examining RN job satisfaction. By understanding the social process of aging, researchers may then better design studies that capture the predictors of $\mathrm{RN}$ job satisfaction.

In addition to age, nurse characteristics such as education and experience were also found 
to have an inconsistently significant relationship with RN job satisfaction. Although the studies were similar in design, there were differences in the studies' research settings, measurement of nurse characteristics, and lack of consistently reliable and valid instruments, leading to an incongruent body of knowledge. Nurse characteristics have not been conceptually defined in the literature. In addition, nurse characteristics have yet to be investigated as a mediated influence on $\mathrm{RN}$ job satisfaction. If the influences of nurse characteristics are mediated by psychological empowerment and generation, as proposed in this study, the inconsistent findings in the literature may be more clearly understood.

\section{Generation}

All of the studies that evaluated generational differences in nurses have been conducted since 2000. There was slight disagreement amongst the researchers as to how to define generational categories, which lends to cautious synthesis of the results. Additionally, the variables and the instruments used to measure predictors of job satisfaction were widely varied. In consideration of these factors, the findings suggest that generations of nurses differ in their job satisfaction. No studies were found that examined the influence of generation on RN job satisfaction within the context of a guiding theoretical framework. Additionally, no studies found examined the relationship between nurses' generation and psychological empowerment. This study was developed to investigate the potential mediating effect of generation on nurses' quality of work life and RN job satisfaction. Additionally, this study will explore potential

generational differences in psychological empowerment. Although two studies have evaluated the relationship of generation on quality of work life, this study will further investigate that relationship with a quality of work life instrument that includes autonomy. 


\section{Psychological Empowerment}

Psychological empowerment has been identified as a primary predictor of job satisfaction and intent to leave a job (Larrabee, et al., 2003). However, there has been minimal investigation of psychological empowerment in RN job satisfaction literature. There were no studies found that investigated the relationship between psychological empowerment and quality of work life. Although one study investigated the mediating effect of psychological empowerment between nurses' marital status and education on job satisfaction, the study was conducted in Taiwan with

a group of school nurses. Consequently, this merits further investigation in the United States with a staff nurse population. Further research is needed to investigate the potential mediating effect of psychological empowerment on $\mathrm{RN}$ job satisfaction. This study will examine the mediating effect of psychological empowerment on nurse characteristics and RN job satisfaction. In addition, the study will be the first study to evaluate nurses' psychological empowerment with regard to their generation. This study will also be the first study to examine the relationship between psychological empowerment and nurses' quality of work life.

\section{Quality of Work Life}

Both generation and psychological empowerment have been independently related to job satisfaction; however, little is known about the relationships among generation, psychological empowerment, and nurse-perceived quality of work life. Quality of work life is not well delineated from RN job satisfaction in the nursing literature. Quality of nursing work life, in part, has been defined as an ability to satisfy personal needs through work experiences (Brooks, 2001), which indicates quality of work life could influence one's job satisfaction. Further research is needed to explore quality of work life as a predictor of RN job satisfaction. This 
study will further investigate relationships between quality of work life and RN job satisfaction. Furthermore, this study will explore predictors of nurses' quality of work life and how those predictors may directly and indirectly influence $\mathrm{RN}$ job satisfaction.

\section{Review of Instruments}

A review of literature related to each of the instruments used in this study is provided in the following section. A brief description of each concept is discussed. Next, the instrument used to measure the concept in this study is described. Then, a literature review of previous studies that have used the instrument is provided. Finally, the rationale for using each instrument in this study is presented.

\section{Nurse Characteristics}

Nurse characteristics are defined as the nurse's physical and demographic attributes. Within the context of the Theoretical Model of Nurse Outcomes, personality traits are purposefully not included in this conceptual definition. There were no identified instruments developed to specifically measure nurse characteristics; rather, nurse characteristics were gathered in studies with various demographic data collection questions. Additionally, there lacks consistency in which nurse characteristics are gathered in nurse job satisfaction studies. Therefore, the nurse job satisfaction literature was reviewed with the purpose of identifying the most commonly collected nurse characteristics.

Over 134 articles were reviewed for nurse characteristics that have been found to significantly influence nurses' perceptions of their work place. The list of evidence-based work place variables measured in this study is presented in Table 1. 


\section{Psychological Empowerment}

The 12-item psychological empowerment instrument (Spreitzer, 1995) is the major instrument for measuring psychological empowerment in employees. The validity of the instrument was examined through face content and expert evaluation. The convergent and discriminate validity of the instrument were assessed using second-order confirmatory factor analysis. The reliability of the instrument's empowerment measures was assessed by evaluating the Cronbach's alphas and test-retest coefficients (Spreitzer, 1995). The Cronbach's alpha reliability coefficient for the overall scale was .72 in the sample of mid-level managers and .62 for the lower level employees. The convergent and divergent validity and reliability levels were acceptable with a reported range of $.62-.72$. The Cronbach's alpha ranges for each dimension were: 'Meaning' (.85-.87), 'Competence’ (.81 - .84), 'Self-determination’ (.79 - .81) and 'Impact' (.75 - .88). An excellent model fit was obtained in the mid-level manager sample (AGFI $=.93, \mathrm{RMSR}=.04, \mathrm{NCNFI}=.97)$. The fit was modest, though also acceptable, for the lowerlevel employee sample $(\mathrm{AGFI}=.87, \mathrm{RMSR}=.07, \mathrm{NCNFI}=.98)$. Test-retest reliability was assessed by collecting data responses from the two differing samples at two time points of five months apart. Adequate internal consistency and test-retest reliability were demonstrated with alpha coefficients ranging from .79-.85.

Although originally developed and tested in business management, the instrument has since been determined a valid and reliable instrument in 50 different work populations including nursing. The instrument has been established as a reliable and valid (Aryee \& Chen, 2006) measurement in, among others, customer service employees (Cronbach's alphas $=.81-.92$; (Carless, 2004); elementary teachers (Cronbach’s alphas = .885 - .976; (Dee, Henkin, \& Duemer, 2003); Philippine hotel, food, bank, call center, and airline employees (Cronbach's alphas $=.77$ - 
.87; (Hechanova, Alampay, \& RFranco, 2006); private club employees (Cronbach's alphas = .68-.79; (Corsun \& Enz, 1999); female internet users in Hong-Kong (Cronbach's alphas = .76.92; (S. L. Y. Hu \& Leung, 2003); and Pharmacists (Cronbach's alphas = .88-.92; (Kahaleh \& Gaither, 2003). The instrument has also been translated and validated in Chinese (Aryee \& Chen, 2006), Flemish, and Finnish populations (Kirkman \& Shapiro, 2001). The reliability of the instrument in nurses has been well established and consistent with other studies (DeCicco, et al., 2006; Larrabee, et al., 2003; H.K. Laschinger, et al., 2001; H. K. Laschinger, et al., 2004; Morrison, et al., 1997) with Cronbach's alphas ranging from .74-.94 amongst the four subscales.

Rationale for Psychological Empowerment Instrument

Overall, the psychological empowerment instrument is valid and reliable and the predominate instrument used to measure psychological empowerment. Kraimer et al. (1999) published an analysis report of the instrument, in which the construct was deemed a valid measurement instrument in a population of nurses. The instrument is a self-report questionnaire; therefore, objectivity should remain high amongst differing administrators. Each dimension was measured separately with 3 -items, lending to a well-balanced instrument that limits participant burden. The simplistic instrument measures each item equally with a 7-point Likert scale; however, little is known about participant reactivity when measuring psychological empowerment.

\section{Generation}

Nurses participating in the study will be categorized into one of the following generational cohorts based on their provided birth year: Veterans (1922-1943), Baby Boomers 
(born between 1943-1960), Generation X (born between 1960-1980), and Millennials (born between 1980-2000; (Sherman, 2006). Each of the nursing research studies varied slightly on the years used to categorize the generational cohorts. These categories were used in this study because the rationale for the years was based on socialization patterns and, therefore appropriate for the purpose of this study (Sherman, 2006).

\section{Quality of Work Life}

Quality of work life is the value assigned to one's work context. Quality of work life reflects nurses' perceptions of their work environments. There have been many instruments and combination of instruments used to capture nurses' perceptions of their work environments. A critical appraisal of the Revised Nursing Work Index (Aiken \& Patrician, 2000), used to measure nurses' quality of work life is presented in the following section.

The Revised Nursing Working Index (NWI-R)

The most frequently used instrument to measure quality of work life in nursing literature is the Nursing Work Index (NWI). The NWI was developed based on findings from early research on Magnet hospitals (Kramer \& Hafner, 1989) resulting in 65 items derived from organizational traits reported by nurses in Magnet hospitals. Kramer \& Hafner (1989) report content validity of the instrument was established based on the Magnet hospital characteristics, an extensive review of literature on job satisfaction and quality of work life, and critique of instrument by three of the four Magnet hospital researchers. The mean NWI scores for hospitals were highly correlated with turnover rates $(r=.95)$; job satisfaction and quality of care was highly correlated $(r=.89$ to $.95, \mathrm{p}<.001)$. The instrument was not intended for interest of the nurses' responses at the individual level, but at an organizational level or group of nurses in a unit. The NWI was 
modified to enhance researchers' ability to capture individual nurses' traits.

The Revised Nursing Work Index (NWI-R; Aiken, Havens, \& Sloane, 2000) consists of 51 items rated with a 4-point Likert-type scale measuring nurses' perceptions of selected organizational traits in their work place. For theoretical purposes, items were clustered into the subscales: autonomy, control over practice setting, and nurse-physician relationship (Aiken, et al., 2000). The Cronbach's alphas for 3 of the subscales measuring autonomy (.78), control over the practice setting (.79), and nurse-physician relations (.73) were acceptable (Aiken, et al., 2000).

Validity of the original instrument based on findings from Magnet hospital research. Scores are correlated with organizations associated with better outcomes, such as patient satisfaction (Aiken, Sochalski, \& Lake, 1997), decreased mortality (Aiken, Smith, \& Lake, 1994), lower emotional exhaustion and burnout, and lower incidence of needle stick injuries (Aiken, et al., 1997). Validity also assessed by comparing results of NWI-R scores of a known group, Magnet hospitals, to non-Magnet hospitals (Aiken \& Patrician, 2000). Reliability was assessed by examination of the heterogeneity of respondents, value-laden responses, hours the nurses worked per week, and treatment effects at the hospital level. Stability of the instrument was tested by test-retest methods and comparing the results of findings when the instrument was administered by different investigators. The Cronbach's alpha for the overall scale was 0.96 . The Cronbach's alphas for each subscale were as follows: autonomy was 0.75 , control was 0.79 , and relationships with physicians was 0.76 (Aiken \& Patrician, 2000).

The NWI-R has been used internationally to measure nurses' perceptions of their work environment and other variables, such as structural empowerment, burnout, patient care, job 
satisfaction, Magnet hospital characteristics, and needle stick injury in Canada (Estabrooks, et al., 2002; H. K. Laschinger, Almost, \& Tuer-Hodes, 2003; Tigert \& Laschinger, 2004), United States (Choi, Bakken, Larson, Du, \& Stone, 2004; Foley, Kee, Minick, Harvey, \& Jennings, 2002; Upenieks, 2002), New Zealand (Budge, Carryer, \& Wood, 2003), Finland (TervoHeikkinen, Partanen, Aalto, \& Vehvilainen-Julkunen, 2008) and Macao (A. O. Chan \& Huak, 2004; M. F. Chan, et al., 2009).

Rationale for Instrument Selection: Quality of Work Life

Although no instrument measures all concepts associated with a nurse's quality of work life, the NWI-R measures autonomy, control over practice, and nurse-physician collaboration, which are among the components most associated with nurses' quality of work life. The purpose of the dissertation study is to examine the predictors of job satisfaction. The NWI-R was chosen to measure quality of life for this study because this instrument includes an autonomy scale, is affordable, and is the most widely cited instrument in nursing research that measures quality of work life.

\section{Job Satisfaction}

Within the context of the theoretical model, job satisfaction is "the extent to which employees like their jobs" (Stamps, 1997). Nurses' feelings about their jobs are associated with their perceptions of the work environments. Satisfaction is influenced by the value assigned to one's work context; therefore, job satisfaction is a manifestation of the nurses' perceptions of their quality of work life. For example, the nurse's quality of work life reflects the extent to which the nurse is autonomous, while job satisfaction reflects the nurse's contentment with their level of expressed autonomy. A critical appraisal of the Global Job Satisfaction Questionnaire 
instrument used to measure nurses' job satisfaction is presented in the following section.

The Global Job Satisfaction Questionnaire

The Global Job Satisfaction questionnaire is a 4-item global measure adapted from Hackman and Oldman's (1975) Job Diagnostic Survey (H. K. Laschinger \& Havens, 1996). The Job Diagnostic Survey consists of items rated on a 5-point Likert scale that have a reported Cronbach's alpha of 0.83 (H. K. Laschinger, et al., 2001; H. K. Laschinger \& Havens, 1996). Sarmiento et al. (2004) used this instrument in a descriptive correlation study of 89 Canadian full-time college nurse educators testing a theoretical model specifying the relationships among structural empowerment, burnout, and work satisfaction. Structural empowerment and emotional exhaustion were predicators of perceived job satisfaction. The internal consistency has ranged from 0.78 to 0.84 (H. K. Laschinger, et al., 2004). The instrument was used in a model testing study, which found structural empowerment directly influenced psychological empowerment and nurse job satisfaction (H. K. Laschinger, et al., 2004).

Rationale for Job Satisfaction Instrument

The purpose of the dissertation study is to examine the influence of nurse characteristics, psychological empowerment, generation, quality of work life on RN job satisfaction. Within the context of the theoretical model used in this study, job satisfaction is viewed as a dependent outcome of nurses' perceived quality of work life. Therefore, the most effective instrument would focus on nurses' global job satisfaction rather than include questions about nurses' satisfaction with their quality of work life. Based on the items included in the survey, reliability and validity, wide use in nursing literature, and best theoretical fit for measuring nurses' job satisfaction, the Global Job Satisfaction Questionnaire was used to measure RN job satisfaction 
in this study.

Figure 1: RN characteristic variables associated with $\mathrm{RN}$ job satisfaction

\begin{tabular}{|l|l|}
\hline RN Characteristics Variables & Support for Inclusion \\
\hline Age & $\begin{array}{l}\text { (Beecroft, Dorey, \& Wenten, 2008; Blegan, 2006; M. F. Chan, et al., 2009; Cimete, et } \\
\text { al., 2003; Curtis, 2008; Flanagan \& Flanagan, 2002; Kuokkanen, et al., 2003; Lu, } \\
\text { While, \& Barriball, 2007; McGillis Hall, et al., 2008; Norman, et al., 2005; M. Price, } \\
\text { 2002; Rambur, et al., 2003; Zurmehly, 2008) }\end{array}$ \\
\hline Education & $\begin{array}{l}\text { (Beecroft, et al., 2008; Blegan, 2006; Cimete, et al., 2003; Coomber \& Barriball, 2007; } \\
\text { Curtis, 2008; Lu, et al., 2007; McGillis Hall, et al., 2008; Rambur, et al., 2003; Sourdif, } \\
\text { 2004; Yin \& Yang, 2002; Zurmehly, 2008) }\end{array}$ \\
\hline Experience & $\begin{array}{l}\text { (Blegan, 2006; Cameron, Horsburgh, \& Armstrong Stassen, 1994; M. F. Chan, et al., } \\
\text { 2009; Chen-Chung, et al., 2003; Cimete, et al., 2003; Cowin, 2002; Flanagan \& } \\
\text { Flanagan, 2002; Gardulf, et al., 2005; Larrabee, et al., 2003) }\end{array}$ \\
\hline Gender & $\begin{array}{l}\text { Avallone \& Gibbon, 1998; Flanagan \& Flanagan, 2002; Krausz, Kedem, Tal, \& Amir, } \\
\text { 1992; Zahra, 1985) }\end{array}$ \\
\hline Geographic Region & (Ma, et al., 2003) \\
\hline
\end{tabular}




\section{CHAPTER 3: METHODOLOGY \\ Overview of the Chapter}

The purpose of this chapter is to present the methodology for the study. First, the purpose and design of the study are discussed. Second, the sample, instruments, and procedures used are provided. Third, the data collection and data management is described. Finally, the statistical analysis procedure is provided.

\section{Purpose and Design}

The Theoretical Model of Nurse Outcomes provides a conceptual framework from which to explore the influence of nurse characteristics, generation, psychological empowerment, and quality of work life on Registered Nurse (RN) job satisfaction. This predictive, nonexperimental study was designed with the primary purpose of identifying predictors of $\mathrm{RN}$ job satisfaction. Another objective of the study was to examine the relationships among the concepts described in the Theoretical Model of Nurse Outcomes. The research questions for this study were:

1. What relationships exist between the concepts of nurse characteristics, psychological empowerment, generation, quality of work life, and $\mathrm{RN}$ job satisfaction?

2. Are the concepts of nurse characteristics, psychological empowerment, generation, and quality of work life predictors of RN job satisfaction? 
Sample

Context

The study was conducted via a web-based survey. Web-based survey techniques have been found as effective a data collection method as paper-and-pencil questionnaires (Pettit, 2002). A web-based survey method has both advantages and disadvantages. Some of the most notable benefits of web-based data collection include lower research costs (Duffy, 2002; Lakeman, 1997), less time to obtain data (Duffy, 2002; Lakeman, 1997; Schmidt, 1997), participant convenience (Ahern, 2005; Lakeman, 1997), ability to reach a larger population (Ahern, 2005; Betz \& Farr, 2005; Wright, 2005), and improved accuracy of data entry (Ahern, 2005). Most of the disadvantages are related to concerns of data integrity (Sax, Gilmartin, \& Bryant, 2003; Wright, 2005), being limited to populations with internet access (Granello \& Wheaton, 2004; Sax, et al., 2003), and security issues (Sax, et al., 2003). For the purpose and nature of this study, the benefits of a web-based methodology outweighed the disadvantages.

Data were collected for this study using Survey Monkey, a Web research management company. The Unlimited data collection plan (purchased for $\$ 16.67$ per month), offered the following key features: (1) unlimited questions; (2) custom redirect - upon completion of the survey, participants with any questions or concerns were directed to the researcher's e-mail address; (3) responses collected via Web links; (4) fully accessible data anytime and (5) downloading of data into an Excel file, reducing costs associated with data entry and eliminating data entry errors. 


\section{Participants}

The sample for this study encompassed RNs in the United States. The inclusion criteria required that each participant hold a current RN license in the U.S., be employed as a direct patient care provider, have the ability to read English, and have access to the Internet. Any data inadvertently collected from nurses outside the United States were not included in this study. A power analysis, based on recommendations for multiple regression with interactions for testing models with 21 items, was conducted using the following equation: $50+8(21)=218$ (Tabachnick \& Fidell, 2007). The sample demonstrated sufficient power with a total of 223 nurses.

\section{Measurements of Concepts}

\section{Generation}

Nurses participating in the study were placed into one of the following generational cohorts based on the birth year they provide: Veterans (1922-1943), Baby Boomers (born between 1943-1960), Generation X (born between 1960-1980), and Millennials (born between 1980-2000) (Sherman, 2006).

\section{Psychological Empowerment}

The Psychological Empowerment Instrument is a 12-item self-report scale with four subscales: meaning, self-determination, competence, and impact. Each sub-scale has three items measuring the dimension of psychological empowerment using a 7-point Likert response scale ranging from 1 (very strongly disagree) to 7 (very strongly agree) resulting in a total possible score range of 12-84. High scores indicate high levels of empowerment, which is considered a positive characteristic. The instrument was developed specifically to measure psychological 
empowerment in the work place. It generally takes respondents five minutes to complete the questionnaire. The study was found to be a valid instrument for the nurse population (Kraimer, Seibert, \& Liden, 1999). The Cronbach's alphas have ranged from .74-.94 amongst the four subscales in the nursing literature (DeCicco, et al., 2006; Larrabee, et al., 2003; Laschinger, et al., 2001; Laschinger, et al., 2004; Morrison, et al., 1997). In this study, the Cronbach alpha for the total psychological empowerment scale was 0.897 (meaning $=0.943$, competence $=0.939$, self-determination $=0.931$, and impact $=0.948)$.

\section{Quality of Work Life}

The Revised Nursing Working Index (NWI-R). The NWI-R (Sochalski, Estabrooks, \& Humphrey, 1999) consists of 49 items rated with a 4-point Likert-type scale measuring nurses' perceptions of selected organizational traits in their work place. For theoretical purposes, items were clustered into the subscales: autonomy, control over practice setting, and nurse-physician relationship (Aiken \& Patrician, 2000). The Cronbach alphas for three of the subscales, autonomy (.78), control over the practice setting (.79), and nurse-physician relations (.73), were acceptable (Aiken \& Patrician, 2000). In this study, NWI-R demonstrated a Cronbach alpha of 0.95 (leadership $=0.929$, resources $=0.872$, collaboration $=0.833)$. It generally takes respondents' 10 minutes to complete the survey. The validity and reliability of the instrument has been previously demonstrated in nursing literature (Aiken \& Patrician, 2000; Aiken, et al., 1994; Aiken, et al., 1997).

\section{RN Job Satisfaction}

The Global Job Satisfaction Questionnaire. The Global Job Satisfaction questionnaire is a 4item global measure adapted from Hackman and Oldman's (1975) Job Diagnostic Survey 
(Laschinger \& Havens, 1996). The items are measured on a 5-point Likert scale. The instrument has been established as a valid and reliable tool with Cronbach's alphas ranging from 0.78-0.84 (Laschinger, et al., 2004). In this study, the global job satisfaction scale had a Cronbach alpha of 0.883. It generally takes respondents less than five minutes to take the survey.

\section{Nurse Characteristics}

A demographics survey included the collection of data on the nurses' age, gender, education, experience, and geographic area. Age and experience were collected as continuous variables. Gender (male/female), education (Diploma, ADN, BSN, MSN, and Doctorate), and geographic area (state) were collected at the categorical level of measurement. The ten items should take participants less than five minutes to respond.

\section{Procedures Used}

\section{Ethical Considerations}

The study was approved by the West Virginia University Institutional Review Board. Participants' consent was implied by virtue of completing the on-line survey. Participants' anonymity was protected using the 'Web Link Collector' option offered by Survey Monkey. The Web Link Collector method does not track the participants' names oremails.. The SSL encryption package was purchased which protects the survey link and survey page during data transmission. Additionally, Survey Monkey implements the following data protection measures: (1) servers are maintained in a locked cage, (2) password and biometric recognition is a requirement for entry into the infrastructure, (3) digital surveillance, (4) firewalls restricting access to surveys, (5) QualysGuard network security audits performed weekly, and (6) Hackersafe scans performed daily. Once the data were transmitted to the researcher, the data 
were maintained within a password-protected computer within the researcher's locked office.

\section{Data Collection}

The target population for this study was currently practicing RNs providing direct patient care. Links to nursing-focused websites have been found to be an effective recruitment strategy for Web-based nursing research (Nogueras, 2006). Additionally, the use of Facebook as a means of interacting professionally has dramatically increased over the last year. Although using Facebook has not been cited in the literature as an effective recruitment strategy, the potential is promising. Postings on a Facebook wall, such as an invitation to participate in a study, are immediately distributed to each of the members. There are hundreds of professional nursing Facebook pages with thousands of nurse members. Due to its lack of cost and ease of implementation, Facebook was included as a recruitment strategy in this study. The distribution of invitations to participate was implemented by the following:

1. An invitation to participate in the study and a link to the survey was provided to the following nursing Facebook walls:

a. American Nurses Association

b. Advance for Nurses

c. Nursing

d. American Academy of Nursing

e. American Academy of Nurse Practitioners

f. Academy of Medical-Surgical Nurses

g. American Academy for Men in Nursing 


\section{h. American Academy for Critical Care Nurses}

i. Emergency Nurses Association

j. Emergency Nurses Association

k. National Association of Hispanic Nurses

1. National League for Nursing

m. West Virginia University School of Nursing

2. An invitation to participate in the study and a link to the survey was

provided to the following nursing discussion boards/blogs/forums:

a. allnurses.com/nursing-blogs

3. In addition to web-based recruitment strategies, nurses were invited to participate in the following manner: A listing of national teaching hospitals was identified at www.theagapecenter.com/Hospitals/index.htm. A query letter was e-mailed to the Chief Executive Officer of the nursing department. The letter described the purpose of the study, as well as an invitation for staff nurses at the institution to participate.

Nurse participants were given the opportunity to submit their names in a gift certificate raffle. The raffle consisted of twenty $\$ 50$ Mastercard gift certificates.

\section{Data Management}

The results from the on-line survey were transferred into an Excel file by the Survey Monkey research program using standard procedures. The data were then transferred into the 
SPSS program. Categorical variables were coded, as necessary, for inclusion in multiple regression and structural equation modeling statistical procedures. For statistical purposes, geographic area was condensed into standard U.S. regions (northeast, west, south, and mid-west) (http://www.census.gov/geo/www/us_regdiv.pdf).

\section{Analysis}

The statistical package for Social Sciences (SPSS)/Predictive Analytics Software (PASW) Package 18 was used for the analysis in this study. Descriptive statistical procedures were conducted on both the categorical and continuous variables. Continuous nurse characteristics and psychological empowerment, quality of work life, and RN job satisfaction scores were assessed for measures of central tendency, variability, and normality. Cases in which violations of the assumptions underlying various parametric statistical procedures occurred, the non-parametric equivalent procedure was used. Inspection for missing data was completed using Case pairwise exclusion procedures available in SPSS, in which only cases that were missing pertinent data were excluded from the statistical procedures.

Scatterplots were used to explore the relationship between variables prior to performing correlational procedures. Additionally, a smooth regression line was used to assess curvilinearity. Reliability coefficients (Cronbach's alpha) were performed on the psychological empowerment (Spreitzer, 1995), NWI-R, and Global job satisfaction (H. K. Laschinger \& Havens, 1996) instruments. Correlations, t-test, ANOVA, and General linear modeling (GLM) procedures were used in this study. Level of significance was set at .05. The following section specifically details the statistical procedures used to examine the research questions. 


\section{Statistical Analysis Procedures}

Research question 1: What relationships exist between the concepts of nurse characteristics, psychological empowerment, generation, quality of work life, and RN job satisfaction?

Prior toperforming the regression procedures, relationships among nurse characteristics (age, education, experience, gender, and geographical region), psychological empowerment, generation, quality of work life, and $\mathrm{RN}$ job satisfaction were investigated. The relationships between pairs of categorical variables (gender, education, geographic region, and generation) were evaluated with the chi-square for independence tests. Associations between categorical variables (education, geographic region, and generation) and continuous variables (age, experience, psychological empowerment, quality of work life, and RN job satisfaction) were identified with analysis of variances (ANOVAs). Bartlett's test of Sphericity and Kaiser-MeyerOlkin were run to assess the factorability of the correlation matrix. A post-hoc Tukey analysis procedure was conducted to identify which groups had significant differences. Pearson's correlation coefficients were used to examine relationships between continuous variables (age, experience, psychological empowerment, quality of work life, and $\mathrm{RN}$ job satisfaction). Correlation effect size was established using Cohen's (1988) parameters of $r=.10$ is a small effect size, $r=.30$ is a moderate effect size, $r=.50$ is a large effect size. T-tests were used to evaluate associations between the dichotomous variable (gender) and the continuous variables (age, experience, psychological empowerment, quality of work life, and $\mathrm{RN}$ job satisfaction).

Research question 2: Are the concepts of nurse characteristics, psychological empowerment, generation, and quality of work life predictors of $\mathrm{RN}$ job satisfaction?

Candidate predictors of RN job satisfaction were further analyzed using GLM regression 
procedures. GLM allows the simultaneous evaluation of the relative influence of multiple independent variables on a dependent variable. Additionally, in contrast to path analysis, GLM has more sophisticated coding procedures that can better tolerate the inclusion of nominal level variables. 


\title{
CHAPTER 4: RESULTS
}

\author{
Introduction
}

The results of this predictive, non-experimental study are presented in this chapter. First, the process used for data verification is presented. Next, the descriptive results of the sample are discussed. Finally, the findings of the study based on the research questions are provided.

\section{Data Analysis}

The statistical Package for Social Sciences (SPSS)/Predictive Analytics Software (PASW) Package 18 for windows was used for the data analysis. Reliability coefficients (Cronbach's alpha) were performed on the psychological empowerment (Spreitzer, 1995), NWIR, and Global job satisfaction (H. K. Laschinger \& Havens, 1996) instruments. Correlations, Chi-square test for independence, t-test, ANOVA, and General linear modeling (GLM) procedures were used in this study. Level of significance was set at .05 .

\section{Data Verification}

The following steps were taken in response to a report that West Virginia University (WVU) undergraduate nursing students may have inappropriately taken the study questionnaire intended for registered nurses (RNs). The deviation to the original protocol (presented below) was submitted and approved by the WVU Institutional Review Board for the Protection of Human Subjects.

1. Download data with the respondents' internet protocol (IP) address

2. Use the IP2 Locator software to identify the city and state of each respondent 
3. Verify the accuracy of each respondents' self-selected state using the IP address. There were no discrepentancies between the respondents' self-selected state and respondents' computer IP addresses.

4. Omit respondents from Morgantown, Fairmont, Clarksburg, Bruceton Mills, and Kingwood cities located in West Virginia. Morgantown and surrounding cities are residencies of commuting WVU nursing students. A total of 41 respondents were omitted based on the location of their IP addresses.

5. Verify that all persons who provided their identifying information to participate in the raffle are RNs, by searching state board of nursing websites. There were a total of 35 respondents who provided their name and address in order to participate in the raffle. Of the 35 respondents, two respondents' $\mathrm{RN}$ license could not be verified. Those two respondents were omitted from the study based on IP address.

6. Verify that each respondent's age and reported years of experience are compatible responses. There were no discrepancies noted.

7. Verify that each respondent's age and reported generation are compatible responses. There were no discrepancies noted.

8. Verify that each respondent's reported years since earning basic RN degree and years in current position are compatible responses. There were no discrepancies noted.

9. Responses to each variable were evaluated for extreme outliers using the SPSS/PAWS program. No extreme outliers were noted.

\section{Description of Demographic Characteristics}

A total of 345 nurses responded to the on-line survey. Of those respondents, 122 were omitted due to incomplete responses to major study variables or location in North Central West 
Virginia. Thus, the study sample was comprised of 223 nurses. The demographics of the sample are presented in Table 1. The average age of the nurses in this sample was 37 years and the average total years of experience as a $\mathrm{RN}$ was 9 years (Table 2). The majority of the nurses in the sample were married (56\%), lived in the south (58\%), and worked full time $(56 \%)$.

The sample was comprised of a slightly lower proportion of female nurses (91\%) as compared to the nurses who reported currently working (92.6\%) in the 2008 National Sample Survey of Registered Nurses (NSSRN). There was a slightly higher proportion of Caucasians (89.2\%) compared to the NSSRN sample (84.9\%). The educational background of this sample in comparison to the NSSRN sample, respectively is as follows: Diploma 3.6\% versus 14\%, Associate Degree of Nursing (ADN) 31.8\% versus 35.1\%, Bachelor of Science in Nursing (BSN) $51.1 \%$ versus $34.6 \%$, Master of Science in Nursing (MSN) 13\% versus $10.9 \%$, and Doctor of Philosophy $(\mathrm{PhD})$ in nursing .4\% versus .46\%. Additionally, the proportion of nurses in each of the generations in this sample and the NSSRN sample were respectively as follows: Baby Boomers 26.9\% versus 56.6\%, Generation X 38.6\% versus 30\%, and Millennial nurses $34.5 \%$ versus $9 \%$. The difference could reflect generational response bias due to the differing data collection methods of this study (web-based survey) and the NSSRN (paper survey). 
Table 1. Descriptive Data for Categorical Level Demographic Characteristics $(\mathrm{N}=22)$

\begin{tabular}{|c|c|c|}
\hline Characteristic & Frequency & Percent \\
\hline *Gender & 223 & 100 \\
\hline Female & 203 & 91 \\
\hline Male & 20 & 9 \\
\hline Race & 223 & 100 \\
\hline Caucasian & 199 & 89.2 \\
\hline African American & 8 & 3.6 \\
\hline Hispanic & 4 & 1.8 \\
\hline Native American & 2 & 0.9 \\
\hline Asian & 4 & 1.8 \\
\hline Other & 6 & 2.7 \\
\hline Marital status & 222 & 100 \\
\hline Single & 74 & 33.3 \\
\hline Married & 124 & 55.9 \\
\hline Divorced & 19 & 8.6 \\
\hline Widowed & 2 & 0.9 \\
\hline Separated & 3 & 1.4 \\
\hline *Education & 223 & 100 \\
\hline Diploma & 8 & 3.6 \\
\hline ADN & 71 & 31.8 \\
\hline BSN & 114 & 51.1 \\
\hline MSN & 29 & 13.0 \\
\hline $\mathrm{PhD}$ & 1 & 0.4 \\
\hline *Generation & 223 & 100 \\
\hline Baby Boomers & 60 & 26.9 \\
\hline Generation X & 86 & 38.6 \\
\hline Millennials & 77 & 34.5 \\
\hline
\end{tabular}




\begin{tabular}{|c|c|c|}
\hline Characteristic & Frequency & Percent \\
\hline Years since RN degree & 222 & 100 \\
\hline$<1 \mathrm{yr}$ & 23 & 10.4 \\
\hline $1-5 \mathrm{yrs}$ & 98 & 44.3 \\
\hline $6-10 \mathrm{yrs}$ & 28 & 12.7 \\
\hline$>10 \mathrm{yrs}$ & 72 & 32.6 \\
\hline Primary work status & 222 & 100 \\
\hline Emergency & 14 & 6.3 \\
\hline Maternity & 11 & 5.0 \\
\hline ICU & 50 & 22.5 \\
\hline Step down & 27 & 12.2 \\
\hline Medical/Surgical & 48 & 21.7 \\
\hline Skilled nursing & 6 & 2.7 \\
\hline Pediatric & 1 & 0.5 \\
\hline Other & 65 & 29.3 \\
\hline Work status & 213 & 100 \\
\hline Full (36 hrs or more) & 172 & 80.8 \\
\hline Part (20-35 hrs) & 31 & 14.6 \\
\hline Casual (<20 hrs) & 10 & 4.7 \\
\hline Years in current position & 222 & 100 \\
\hline$<1 \mathrm{yr}$ & 53 & 23.9 \\
\hline $1-2 \mathrm{yrs}$ & 78 & 35.1 \\
\hline $3-5$ yrs & 34 & 15.3 \\
\hline $6-10 \mathrm{yrs}$ & 32 & 14.4 \\
\hline $10 \mathrm{yrs}$ & 25 & 11.3 \\
\hline Geographic region & 222 & 100 \\
\hline Northeast & 42 & 18.9 \\
\hline Midwest & 31 & 14 \\
\hline
\end{tabular}




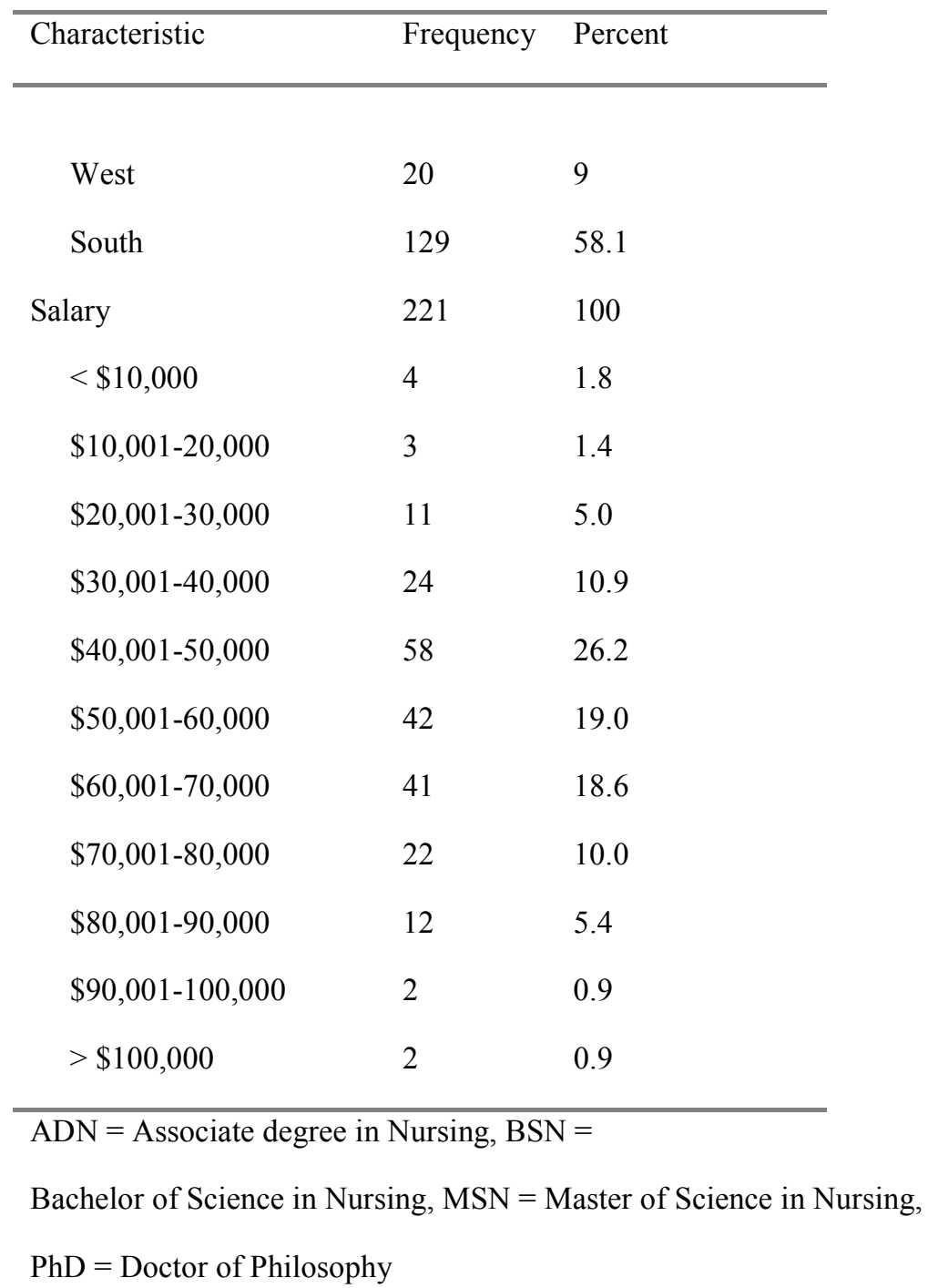

Table 2. Descriptive Data for Continuous Level Demographic Characteristics

\begin{tabular}{llllll}
\hline Characteristic & $\mathrm{n}$ & Mean & SD & Range & Median \\
\hline *Age & 218 & 37.32 & 11.4 & $22-65$ & 36 \\
*Yrs as RN & 219 & 9.01 & 10.05 & $0-42$ & 4 \\
\hline
\end{tabular}

* Study variable, $\mathrm{RN}=$ registered nurse 


\section{Description of Theoretical Variables}

Distribution statistical analysis found that age $($ mean $=37.32, \mathrm{SD}=11.4)$ and total years as a $\mathrm{RN}($ mean $=9.01, \mathrm{SD}=10.05)$ were extremely positively skewed, indicating a young sample of nurses. Psychological empowerment (mean $=59.82, \mathrm{SD}=12.09)$ scores were slightly negatively skewed indicating that this sample consisted of slightly more nurses with higher than average psychological empowerment scores. $\mathrm{RN}$ job satisfaction $($ mean $=11.1, \mathrm{SD}=4.19)$ and quality of work life $($ mean $=81.30, \mathrm{SD}=18.50)$ scores were normally distributed. Because of the deviations in normality in age, experience, and psychological empowerment variables, all parametrically derived significant results were verified with the non-parametric equivalent. For comparison with prior studies, mean scores for each of the instruments were used in the statistical procedures (Table 3).

Table 3. Psychological Empowerment, Quality of Work Life, and Job Satisfaction Scales $(\mathbf{N}=223)$

\begin{tabular}{lllllc}
\hline Instrument & $\mathrm{N}$ & $\begin{array}{l}\text { Mean Score } \\
\text { Range }\end{array}$ & $\mathrm{M}$ & $\mathrm{SD}$ & $\begin{array}{c}\text { Cronbach's } \\
\text { Alpha }\end{array}$ \\
\hline $\begin{array}{l}\text { Psychological } \\
\text { empowerment }\end{array}$ & 222 & $1.75-7.00$ & 4.97 & 1.00 & 0.897 \\
\hline Meaning & 223 & $1.00-7.00$ & 5.70 & 1.27 & 0.943 \\
\hline Competence & 222 & $1.67-7.00$ & 5.84 & 1.13 & 0.939 \\
\hline Self-determination & 223 & $1.00-7.00$ & 4.89 & 1.44 & 0.931 \\
\hline Impact & 223 & $1.00-7.00$ & 3.51 & 1.66 & 0.948 \\
\hline Quality of work life & 223 & $1.03-3.62$ & 2.39 & 0.54 & 0.950 \\
\hline Leadership & 223 & $1.00-4.00$ & 2.42 & 0.65 & 0.929 \\
\hline Resources & 223 & $1.10-4.00$ & 2.68 & 0.62 & 0.872 \\
\hline Collaboration & 223 & $1.00-3.50$ & 2.05 & 0.52 & 0.833 \\
\hline Job satisfaction & & & & & \\
\hline
\end{tabular}


Research Question 1: What relationships exist between the concepts of nurse characteristics, psychological empowerment, generation, quality of work life, and $R N$ job satisfaction?

\section{Relationship Between Pairs of Categorical Variables}

The relationships between pairs of categorical variables (gender, education, geographic region, and generation) were evaluated with the chi-square for independence tests. Based on geographic region, nurses' significantly differed in their education levels, Pearson Chisquare $(\mathrm{n}=222)=24.808, \mathrm{p}=0.003$, Cramer's $\mathrm{V}=0.193$. The majority $(51.6 \%)$ of ADN prepared nurses were located in the Midwest region, whereas the majority (54.3\%) of BSN prepared nurses were located in the South. Additionally, there were significant differences in nurses' educational levels and generation, Pearson Chi-square $(\mathrm{n}=223)=28.211, \mathrm{p}=0.000$, Cramer's V $=0.252$. The majority (68.8\%) of Millennial nurses were BSN prepared, as compared to $35 \%$ of the Baby Boomer nurses who were BSN prepared. Of the total number of Diploma prepared nurses, $75 \%$ of them were in the Baby Boomer generation. However, Baby boomers also had the highest percentage (46.7\%) of MSN prepared nurses.

\section{Associations between Categorical and Continuous Variables}

Associations between categorical variables (education, geographic region, and generation) and continuous variables (age, experience, psychological empowerment, quality of work life, and RN job satisfaction) were identified with one-way analysis of variances (ANOVAs). A post-hoc Tukey analysis procedure was conducted to identify which groups had significant differences.

The results of the one-way ANOVAs are presented in Table 4. There were 
significant differences in age based on education $(\mathrm{F}=8.051, \mathrm{p}<0.001)$. Nurses with a BSN were significantly younger than nurses with Diploma, ADN, or MSN degrees $(p<0.05)$. In addition, nurses' experience (years in current position) $(\mathrm{F}=4.653, \mathrm{p}<0.001)$, psychological empowerment $(\mathrm{F}=4.653, \mathrm{p}=0.004)$, and $\mathrm{RN}$ job satisfaction $(\mathrm{F}=2.675, \mathrm{p}=0.048)$ significantly differed based on their educational level. Nurses with a MSN had significantly more years of experience and higher levels of both psychological empowerment and job satisfaction than nurses with a BSN $(\mathrm{p}<0.05)$.

Nurses located in the Midwest geographic region had significantly lower psychological empowerment scores than nurses in the Northeast and South $(\mathrm{F}=4.168, \mathrm{p}<0.05)$. Similarly, nurses' in the Midwest reported poorer perceptions of their quality of work place than the nurses' in the Northeast and South regions $(\mathrm{F}=3.111, \mathrm{p}=0.027)$.

Generations differed in their experience $(\mathrm{F}=117.589, \mathrm{p}<0.001)$, psychological empowerment $(F=6.177, p=0.002)$, and $R N$ job satisfaction $(F=5.407, p=0.005)$. Baby Boomers were significantly older, had more years of experience, and higher levels of both psychological empowerment and job satisfaction than Generation $\mathrm{X}$ and Millennial nurses $(\mathrm{p}<$ $0.05)$.

Not surprisingly, there were significant differences between nurses' age and experience $(\mathrm{F}=21.033, \mathrm{p}<0.001)$. There were also differences in nurses' psychological empowerment based on experience $(\mathrm{F}=6.878, \mathrm{p}<0.001)$. More specifically, nurses with increased experience (years in current position) reported higher levels of psychological empowerment. 
Table 4. Results of ANOVA and Post hoc Comparisons Between Study Variables

\begin{tabular}{|c|c|c|c|c|}
\hline Variable 1 & Variable 2 (n) & Means (SD) & ANOVA & Tukey HSD \\
\hline \multirow[t]{5}{*}{ Age } & Education (218) & $37.32(11.40)$ & $\mathrm{F}=8.051$ & \\
\hline & Diploma (8) & $46.63(9.02)$ & $\mathrm{p}<0.001$ & Diploma \& BSN p $=0.012$ \\
\hline & $\operatorname{ADN}(70)$ & $38.57(11.20)$ & & $\mathrm{ADN} \& \mathrm{BSN} \mathrm{p}=0.049$ \\
\hline & BSN (110) & $34.25(10.30)$ & & $\mathrm{BSN} \& \mathrm{MSN} \mathrm{p}=0.001$ \\
\hline & MSN (30) & $43.17(12.56)$ & & \\
\hline \multirow[t]{5}{*}{ Experience } & Education (219) & $9.01(10.05)$ & $\mathrm{F}=11.517$ & \\
\hline & Diploma (8) & $17.25(14.70)$ & $\mathrm{p}<0.001$ & Diploma \& BSN p $=0.011$ \\
\hline & $\operatorname{ADN}(71)$ & $8.58(10.01)$ & & ADN \& MSN p $<0.001$ \\
\hline & BSN (110) & $6.56(7.87)$ & & BSN \& MSN p $<0.001$ \\
\hline & MSN (30) & $16.83(11.30)$ & & \\
\hline \multirow[t]{5}{*}{ PE } & Education (222) & $4.99(1.01)$ & $F=4.653$ & \\
\hline & Diploma (8) & $4.54(1.11)$ & $\mathrm{p}=0.004$ & \\
\hline & $\operatorname{ADN}(70)$ & $5.02(0.93)$ & & \\
\hline & BSN (113) & $4.84(0.99)$ & & $\mathrm{BSN} \& \mathrm{MSN} \mathrm{p}=0.003$ \\
\hline & MSN (30) & $5.55(1.05)$ & & \\
\hline \multirow[t]{5}{*}{ JS } & Education (223) & $2.78(1.05)$ & $F=2.675$ & \\
\hline & Diploma (8) & $2.88(1.16)$ & $\mathrm{p}=0.048$ & \\
\hline & $\operatorname{ADN}(71)$ & $2.71(1.03)$ & & $\mathrm{BSN} \& \mathrm{MSN} \mathrm{p}=0.035$ \\
\hline & BSN (113) & $2.70(1.00)$ & & \\
\hline & MSN (30) & $3.28(1.16)$ & & \\
\hline
\end{tabular}




\begin{tabular}{|c|c|c|c|c|}
\hline Variable 1 & Variable 2 (n) & Means (SD) & ANOVA & Tukey HSD \\
\hline \multirow[t]{5}{*}{$\mathrm{PE}$} & Geographic Region (221) & $4.98(1.00)$ & $\mathrm{F}=4.168$ & \\
\hline & Northeast (42) & $5.27(1.04)$ & $\mathrm{p}=0.007$ & $\mathrm{NE} \& \mathrm{MW} p=0.007$ \\
\hline & Midwest (31) & $4.51(0.93)$ & & $\mathrm{MW} \& \mathrm{~S} p=0.040$ \\
\hline & West (20) & $4.72(1.19)$ & & \\
\hline & South (128) & $5.04(0.94)$ & & \\
\hline \multirow[t]{5}{*}{ QWL } & Geographic Region (222) & $2.40(0.50)$ & $\mathrm{F}=3.111$ & \\
\hline & Northeast (42) & $2.31(0.49)$ & $\mathrm{p}=0.027$ & $\mathrm{NE} \& \mathrm{MW} p=0.049$ \\
\hline & Midwest (31) & $2.61(0.43)$ & & $\mathrm{MW} \& \mathrm{~S} \mathrm{p}=0.046$ \\
\hline & West (20) & $2.51(0.54)$ & & \\
\hline & South (129) & $2.35(0.50)$ & & \\
\hline \multirow[t]{4}{*}{ Experience } & Generation (219) & $9.01(10.05)$ & $\mathrm{F}=117.589$ & \\
\hline & Baby Boomers (60) & $20.51(11.49)$ & $\mathrm{p}<0.001$ & BB \& GenX p $<0.001$ \\
\hline & Generation X (84) & $6.46(5.47)$ & & GenX \& Mill $p=0.002$ \\
\hline & Millennials (75) & $2.68(1.92)$ & & Mill \& BB p $<0.001$ \\
\hline \multirow[t]{4}{*}{$\mathrm{PE}$} & Generation (222) & $4.99(1.01)$ & $F=6.177$ & \\
\hline & Baby Boomers (60) & $5.36(1.10)$ & $\mathrm{p}=0.002$ & BB \& Mill $p=0.023$ \\
\hline & Generation X (86) & $4.80(1.02)$ & & GenX \& BB p $=0.002$ \\
\hline & Millennials (76) & $4.91(0.84)$ & & \\
\hline
\end{tabular}




\begin{tabular}{|c|c|c|c|c|}
\hline Variable 1 & Variable 2 (n) & Means (SD) & ANOVA & Tukey HSD \\
\hline \multirow[t]{4}{*}{ JS } & Generation (223) & $2.78(1.05)$ & $\mathrm{F}=5.407$ & \\
\hline & Baby Boomers (60) & $3.15(1.12)$ & $\mathrm{p}=0.005$ & BB \& GenX $p=0.006$ \\
\hline & Generation X (86) & $2.62(1.05)$ & & \\
\hline & Millennials (77) & $2.68(0.92)$ & & Mill \& BB p $=0.021$ \\
\hline \multirow[t]{7}{*}{ Age } & Experience (218) & $37.32(11.40)$ & $\mathrm{F}=21.033$ & $<1 \& 6-10 p<0.001$ \\
\hline & $<1 \mathrm{yr}(53)$ & $34.17(9.75)$ & $\mathrm{p}<0.001$ & $1-2 \& 6-10 p<0.001$ \\
\hline & $1-2$ yrs (77) & $33.66(9.63)$ & & $3-5 \& 6-10 p=0.002$ \\
\hline & $3-5$ yrs (32) & $34.31(9.25)$ & & $6-10 \&>10 p=0.027$ \\
\hline & $6-10$ yrs (31) & $43.58(10.83)$ & & $>10 \& 1-2 p<0.001$ \\
\hline & $>10$ yrs $(25)$ & $51.36(9.27)$ & & $>10 \&<1 \mathrm{p}<0.001$ \\
\hline & & & & $>10 \& 3-5 p<0.001$ \\
\hline \multirow[t]{6}{*}{ PE } & Experience (221) & $4.99(1.01)$ & $\mathrm{F}=6.878$ & \\
\hline & $<1$ yr (53) & $4.58(1.13)$ & $\mathrm{p}<0.001$ & $<1 \& 6-10 p<0.001$ \\
\hline & $1-2$ yrs (77) & $4.85(0.86)$ & & $1-2 \& 6-10 p=0.005$ \\
\hline & $3-5$ yrs (34) & $5.07(0.95)$ & & \\
\hline & $6-10$ yrs (32) & $5.55(0.84)$ & & \\
\hline & $>10$ yrs $(25)$ & $5.42(1.01)$ & & $>10 \&<1 \mathrm{p}=0.003$ \\
\hline
\end{tabular}

$\mathrm{ADN}=$ Associate degree in Nursing, $\mathrm{BSN}=$ Bachelor of Science in Nursing, MSN = Master of Science in Nursing, $\mathrm{PhD}=$ Doctor of Philosophy, $\mathrm{NE}=$ Northeast, $\mathrm{MW}=$ Midwest, $\mathrm{S}=$ South, $\mathrm{BB}=$ Baby Boomers, GenX = Generation X, Mill $=$ Millennials, $\operatorname{yr}(\mathrm{s})=$ year $(\mathrm{s})$ 
Correlations between Continuous Variables

Spearman's Rho correlation coefficients were used to examine relationships between continuous variables (age, experience, psychological empowerment, quality of work life, and RN job satisfaction) because of the deviations in normality in age, experience, and psychological empowerment variables.

The results of the correlations are presented in Table 5. Age and total years as a RN were strongly positively correlated $(\mathrm{r}=0.649, \mathrm{p}<0.05)$. There was a strong relationship between psychological empowerment and $\mathrm{RN}$ job satisfaction $(\mathrm{r}=0.641, \mathrm{p}<0.01)$. $\mathrm{RN}$ job satisfaction is also strongly related to nurses' perceptions of their quality of work life $(r=-0.642, p<0.01)$. High scores on the NWI-R used to measure quality of work life indicate poor perceptions of their work environments; thus, the higher the NWI-R score, the worse the nurse perceived their quality of work life.

A moderate positive relationship between nurses' total years as a $\mathrm{RN}$ and psychological empowerment was demonstrated $(\mathrm{r}=0.345, \mathrm{p}<0.01)$. There was also a moderate relationship between psychological empowerment and quality of work life $(r=-0.369, p<0.01)$

There was a weak relationship between age and psychological empowerment $(\mathrm{r}=$ $0.166, \mathrm{p}<0.05)$. Additionally, age and $\mathrm{RN}$ job satisfaction had a weak positive relationship $(\mathrm{r}=$ $0.135, \mathrm{p}<0.05)$. RN job satisfaction was also weakly positively related to the total number of years as a $\mathrm{RN}(\mathrm{r}=0.178)$. 
Table 5. Correlations of Age, Experience (Years as RN), Quality of Work Life (QWL), Psychological Empowerment (PE), and Job Satisfaction (JS)

\begin{tabular}{|c|c|c|c|c|c|}
\hline & Age & Yrs as RN & QWL & $\mathrm{PE}$ & JS \\
\hline Age & --- & & & & \\
\hline Years as RN & $0.649^{*}$ & --- & & & \\
\hline QWL & 0.101 & 0.001 & --- & & \\
\hline PE & $0.166^{*}$ & $0.345 * *$ & $-0.369 * *$ & --- & \\
\hline JS & $0.135^{*}$ & $0.178 * *$ & $-0.642 * *$ & $0.641 * *$ & --- \\
\hline
\end{tabular}

T-tests between Dichotomous and Continuous Variables

T-tests were used to evaluate associations between the dichotomous variable (gender) and the continuous variables (age, experience, psychological empowerment, quality of work life, and RN job satisfaction). Female nurses had significantly more years of experience (mean $=9.39$, SD $=10.238)$ as a $\mathrm{RN}$ as compared to male nurses $($ mean $=5.42, \mathrm{SD}=7.097 ; \mathrm{t}=2.208, \mathrm{p}=0.036)$. There were no other significant gender differences.

Research Question 2: Are the concepts of nurse characteristics, psychological empowerment, generation, and quality of work life predictors of $R N$ job satisfaction?

The results of the GLM procedure are presented in Table 6. Education, years in current $\mathrm{RN}$ position, total years as a $\mathrm{RN}$, quality of work life, and psychological empowerment were identified as candidate predictors of RN job satisfaction. Four variables (generation, years in 
current position, quality of work life, and psychological empowerment) predicted RN job satisfaction, explaining $63.7 \%$ of the variance of $\mathrm{RN}$ job satisfaction.

Table 6. Results of the General Linear Modeling Procedure for Candidate Predictors of RN Job Satisfaction

\begin{tabular}{lllllllll}
\hline $\begin{array}{l}\text { Candidate } \\
\text { Predictor }\end{array}$ & $\begin{array}{l}\text { Type III } \\
\text { Sum of } \\
\text { Square }\end{array}$ & df & $\begin{array}{l}\text { Mean } \\
\text { square }\end{array}$ & F & $\begin{array}{l}\text { p- } \\
\text { value }\end{array}$ & $\begin{array}{l}\text { Partial Eta } \\
\text { squared }\end{array}$ & $\begin{array}{l}\text { Noncent. } \\
\text { Parameter }\end{array}$ & $\begin{array}{l}\text { Observed } \\
\text { Power }\end{array}$ \\
\hline $\begin{array}{l}\text { Corrected } \\
\text { Model }\end{array}$ & 154.350 & 12 & 12.862 & 30.054 & 0.000 & 0.638 & 360.645 & 1.000 \\
Intercept & 15.333 & 1 & 15.333 & 35.826 & 0.000 & 0.149 & 35.826 & 1.000 \\
QWL* & 39.377 & 1 & 39.377 & 92.007 & 0.000 & 0.310 & 92.007 & 1.000 \\
PE* & 38.531 & 1 & 38.531 & 90.029 & 0.000 & 0.305 & 90.029 & 1.000 \\
Yrs in current & 6.279 & 4 & 1.570 & 3.668 & 0.007 & 0.067 & 14.672 & 0.875 \\
position* & & & & & & & & 0.232 \\
Generation* & 2.667 & 2 & 1.334 & 3.116 & 0.046 & 0.030 & 6.595 \\
Education & 1.100 & 3 & 0.367 & 0.857 & 0.464 & 0.012 & 2.570 & 0.235 \\
Yrs as RN & 0.032 & 1 & 0.032 & 0.074 & 0.786 & 0.000 & 0.074 & 0.058
\end{tabular}

R Squared $=0.638$ (Adjusted R Squared $=0.616$ )

* Significant predictor of RN job satisfaction with significance at the 0.05 level

$\mathrm{QWL}=$ quality of work life, $\mathrm{PE}=$ psychological empowerment, Yrs $=$ years, $\mathrm{df}=$ degree of freedom, noncent $=$ noncentrality 


\section{Summary}

A purpose of this study was to examine the relationships among the concepts in the Theoretical Model of Nurse Outcomes. There were significant relationships among the concepts in the model. Generations of nurses' differed in their education, experience, psychological empowerment, and RN job satisfaction. There were significant differences in nurses' education, psychological empowerment, and quality of work life based on geographic region. Quality of work life and age were related to RN job satisfaction. Additionally, years in the current position and education impacted nurses' psychological empowerment and RN job satisfaction. Psychological empowerment, a predictor of RN job satisfaction, was related to nurses' age, experience, quality of work life, and $\mathrm{RN}$ job satisfaction. The primary purpose of this study was to identify predictors of RN job satisfaction. Quality of work life, psychological empowerment, years in current position, and generation were significant predictors of RN job satisfaction explaining $63.7 \%$ of the variance in $\mathrm{RN}$ job satisfaction. 


\title{
CHAPTER 5: DISCUSSION AND IMPLICATIONS
}

\author{
Introduction
}

A discussion of the findings based on the research questions is presented in this chapter. First, the results of the findings, in light of the Theoretical Model of Nurse Outcomes (TMNO) and previous research, are presented. Next, the strengths and limitations of the study are discussed. Finally, potential implications for future research and nursing management are offered.

Discussion of Findings

Research Question 1: What relationships exist between the concepts of nurse characteristics, psychological empowerment, generation, quality of work life, and RN job satisfaction?

This discussion related to question one is organized by the concepts of psychological empowerment, generation, and quality of work life. Discussion of the concepts of nurse characteristics and registered nurse $(\mathrm{RN})$ job satisfaction are threaded throughout each of those categories.

\section{Psychological empowerment}

The finding that nurses' psychological empowerment significantly differed based on their education, experience, geographic region was an anticipated finding. Nurses with a BSN had significantly lower psychological empowerment scores than nurses' with a MSN degree. Additionally, psychological empowerment was significantly positively correlated with nurses' experience. There have been no studies identified in nursing literature that have specifically investigated the link between education, experience, and psychological empowerment. However, 
these findings suggest the theoretical premise that psychological empowerment is an intrinsic characteristic amenable to change and is potentially enhanced by education and experience. The finding that the nurses' psychological empowerment significantly differed based on geographic region could also be attributed to education. Implications regarding the geographic findings are tentative due to insufficient power, however the findings propose directions for future research. Nurses in the Mid-West had significantly lower psychological empowerment scores than nurses in the Northeast and South. It is notable that the majority of nurses in the Mid-West had an ADN degree, where as the majority of nurses in the South had BSN degrees. Within the context of this study, it is difficult to ascertain if learned behaviors within an educational program, acquired skills on the job, or simply life experience contributed to the enhanced psychological empowerment, as age was also found to be positively correlated with psychological empowerment. This finding is consistent with a previous study that found a significant difference between nurses' age and total psychological empowerment scores (Knol \& vol Linge, 2009). Psychological empowerment was positively correlated with perceived quality of work life and $\mathrm{RN}$ job satisfaction. Job satisfaction has been found to be a predictor of intent to leave the job (Larrabee, 2003). Therefore, if nurses' with lower levels of psychological empowerment leave their jobs, it is reasonable to assume that nurses with higher empowerment are the nurses most likely to remain in their jobs and have a higher likelihood of responding to an online survey. Further, this finding could suggest that younger nurses with low psychological empowerment scores may eventually leave their nursing jobs.

Considering the correlation between psychological empowerment and age, it is not surprising that generations of nurses' differed in their psychological empowerment. More specifically, Baby Boomer nurses had significantly higher levels of psychological empowerment 
than both the Millennial and Generation X nurses. This is the first study to evaluate generations for differences in psychological empowerment. However, previous literature found that generations differed in what they valued in their jobs (Apostolidis \& Polifroni, 2006; Cox, 2000; Stuenkel et al., 2005; Thomas \& Velthouse, 1990), but evidence is lacking to indicate the impact of value differences. Within the context of the TMNO, the ability to be empowered is intrinsically motivated, and with optimal psychological empowerment, persons could find meaning and satisfaction despite difficult environments. Nurses' psychological empowerment is theorized to attenuate the resonation of nurses' actual work environments with relation to the nurses' value systems. Therefore, nurses' perceptions of their quality of work life and RN job satisfaction are outcomes related to the nurses' psychological empowerment. Nurses' perceptions of their work environments, influenced by psychological empowerment, reflect nurses' work values and motivation. Values inherently different within generational cohorts would, thus, be a contributing factor to the differences in psychological empowerment. The finding that nurses with higher psychological empowerment have increased levels of RN job satisfaction is an anticipated finding based on the theoretical model tested in this study. Psychological empowerment is a concept pertaining to persons' intrinsic processes of perceiving and assigning meaning to their environments. Therefore, one would expect that persons with higher levels of empowerment, or rather, enhanced abilities to discover the meaning of their work, would manifest higher levels of perceived job satisfaction. This finding is consistent with previous studies that also found a positive correlation between psychological empowerment and RN job satisfaction (Laschinger, et al., 2001; Morrison, et al., 1997). Longitudinal studies that measure nurses' psychological empowerment over time, as well as evaluating the psychological 
empowerment of nurses' upon their job exit interviews may provide greater insight into this dynamic relationship.

\section{Generation}

The finding that older generations had greater years of experience, but less educational preparation than younger generations is consistent with previously published studies (Wilson et al., 2008; McNeese-Smith \& Crook, 2003). In this sample, the percentage of BSN-prepared nurses increased with each preceding generation reflecting current national educational trends among nurses. According to the American Association of Colleges of Nursing (AACN; 2010a), enrollment in entry-level BSN programs in $2009-2010$, increased $6.1 \%$ for the $10^{\text {th }}$ consecutive year. Part of this rise could be attributed to employers placing greater emphasis on highly trained nurses. In addition, younger generations of nurses have greater access to educational programs than older generations had available even a decade ago. Currently, there are approximately 200 more accelerated BSN programs in the nation as compared to the 31 accelerated BSN programs available to nurses in 1990 (AACN, 2010b). One would also anticipate that older generations of nurses would have increased years of experience based simply on increased age and, thus have had a longer time period to work than younger generations.

This was the first study to investigate the relationship between generations and psychological empowerment. However, the finding that Baby Boomers had significantly higher levels of psychological empowerment than the younger generations is a theoretically expected finding since Baby Boomers also had higher levels of job satisfaction. Psychological empowerment has been identified as a predictor of $\mathrm{RN}$ job satisfaction; thus, one would 
anticipate the finding that generations with significantly higher levels of psychological empowerment would demonstrate higher levels of $\mathrm{RN}$ job satisfaction. Despite various work environments, previous research has consistently reported Baby Boomers as significantly more satisfied with their jobs than younger generations (Apostolidis \& Polofroni, 2006; Widger et al., 2007; Wilson et al., 2008). This suggests that each generation's values and the perceived presence of those values in the work environment could be a contributing factor to their job satisfaction. Thus, perhaps consideration to what is most valued by each generation would be an effective strategy to retaining younger generations.

\section{Quality of Work Life}

This was the first study to investigate the relationship between quality of work life and geographic region. Within the context of the TMNO, quality of work life is the value assigned to one's work and individual contexts and is mediated by nurses' psychological empowerment and generational socialization. Therefore, whether factors associated with nurse characteristics impacted nurses' perceptions of their quality of work life is dependent upon the influence of the mediating factors. This study found that nurses in the Northeast and South had more positive perceptions of their quality of work life than the nurses located in the Mid-West region. In this study, quality of work life was strongly correlated with psychological empowerment The finding supports that enhanced psychological empowerment could be the more influential determinant of nurses' perceptions of quality of work life rather than the differences related to their geographic region alone.

This was the first study to explore the relationship between generations of nurses and their perceived quality of work life. The finding that the generational cohorts did not differ in 
their quality of work life is an anticipated finding within the context of the TMNO used in this study. Baby Boomers did not differ in their quality of work life as compared to the Millennial and Generation X nurses; however, Baby Boomers exhibited higher levels of RN job satisfaction than the Millennial and Generation X nurses. Although quality of work life and RN job satisfaction were found to be highly correlated, this finding supports the theorized proposition that generations differ in their job values and those value differences could manifest into job satisfaction differences regardless of the work environment. In other words, despite the same perceptions of their quality of work life, the younger generations of nurses demonstrated significantly less satisfaction with their jobs. This is consistent with a previously published study that identified RN job satisfaction as an outcome of nurses' perceived quality work life (Gifford, 2002).

Research Question 2: Are the concepts of nurse characteristics, psychological empowerment, generation, and quality of work life predictors of $R N$ job satisfaction?

This was the first study in the Unites States to investigate gender as a predictor of $\mathrm{RN}$ job satisfaction. Because there were no significant differences in nurses' job satisfaction based on gender, gender was not included in the prediction model. This finding is consistent with a study conducted in Ireland (Curtis, 2008), though inconsistent with a study conducted in Canada, which found that gender predicted RN job satisfaction (Penz et al., 2008). Further investigation of the relationship between gender and $\mathrm{RN}$ job satisfaction is necessary before inferring implications. Inconsistent findings could be attributed to male nurse recruitment challenges. Although the American Assembly of Men in Nursing internet site advertised this study and the sample size reflected the current population percentage of male nurses, the sample of nurses remains low for statistical purposes. 
Education, years in current RN position, total years as a RN, quality of work life, and psychological empowerment were identified as candidate predictors of RN job satisfaction. Of those variables, quality of work life, psychological empowerment, years in current position, and generation, predicted RN job satisfaction, explaining $63.7 \%$ of the variance of RN job satisfaction. Quality of work life and psychological empowerment were the most powerful predictors of RN job satisfaction. This is the first study to identify quality of work life as a predictor of RN job satisfaction. Quality of work life was theoretically anticipated to predict RN job satisfaction. An important finding of this study is the delineation between the concepts of quality of work life and RN job satisfaction. Though strongly correlated concepts, nurses' perceptions of their quality of work life would precede their perceived satisfaction with the job.

Psychological empowerment, as a predictor of $\mathrm{RN}$ job satisfaction, is a finding consistent with previously published studies (Larrabee, 2003; Casey, 2009; Larrabee, 2010). The strong predictive association of both quality of work life and psychological empowerment suggests that the nurses' intrinsic processes of developing perceptions and meanings within their work environments are crucial antecedents of RN job satisfaction. Although differences in RN job satisfaction among generational cohorts' have been identified in previous research (Apostolidis, 2006; Widger, 2007;Wilson, 2008; Keepnews, 2010;Wieck, 2010), this is the first study to identify generation as a predictor of RN job satisfaction within a theoretical model. Theoretically, generation was a proposed mediating factor between nurses' characteristics and perceived quality of work life; therefore, the finding that generation predicted $\mathrm{RN}$ job satisfaction would not be unanticipated. Further research is necessary to investigate the mediating influence of generation within the context of the theoretical model of nurse outcomes. 
Interestingly, although nurses' time in current position was found to be predictive of RN job satisfaction, nurses' total years as a $\mathrm{RN}$ was not a predictor of $\mathrm{RN}$ job satisfaction in this study. This finding is consistent with previous research studies that found nurses' time in a current position positively impacts RN job satisfaction (Ea et al., 2008; Ma et al., 2003). However, three previously conducted studies reported that experience did not significantly impact RN job satisfaction (Adams, 2000; Ma, 2003; Curtis, 2008). Inconsistent findings related to the relationship between total years of RN experience and job satisfaction could be contributed to mediating factors impacting the influence of RN experience such as psychological empowerment or generation.

Strengths and Limitations

Although a limitation of this study is the cross-sectional design, the use of a theoretical framework provides a guide from which speculations regarding conceptual relationships can more confidently be made by the researcher. Another strength of this study is that the instruments used in this study have been demonstrated to be valid and reliable for nurse populations.

A cross sectional survey design lends to a participant self-selection bias potentially limiting the generalizability of the findings. This study captured nurses' responses at a single point in time. Perceptions of $\mathrm{RN}$ job satisfaction and contributing variables may change over time. Additionally, nurses who chose to participate in this online survey could differ from the target population on attributes influential to the dependent variable, RN job satisfaction. For example, particularly dissatisfied nurses who feel they lack a voice within their organization may feel compelled to respond to an anonymous online survey. Likewise, the survey was advertised 
on professional nursing internet sites and theoretically, nurses who are particularly passionate about nursing are frequenters of such sites. Further research is necessary to investigate potential attribute differences among nurses engaged with professional nursing websites and those who are not. Additionally, although the overall power was sufficient for the General Linear Modeling analysis, there were several categorical variables, such as geographic region, which lacked sufficient power. Future researchers testing this theoretical model should consider a larger sample size within each of the categorical variables such as geographic region and gender.

With survey designs, there is also a threat of falsification of response or identity. Because of the increased anonymity related to internet surveys, data validation procedures are particularly important. When conducting internet surveys, researchers should consider the purposeful inclusion of questions that allow for data verification. A strength of this study was that the questionnaire items allowed for extensive data verification: the IP address of each respondent was cross-referenced with the respondent's self-selected state; the accuracy of the respondent's self-selected generation was verified with the reported age; each of the respondent responses to years of experience, time in current position, years since degree completion, current position, highest degree earned, salary, and age were collectively compared for feasibility and discrepancies. As was done in this study, researchers interested in internet survey design should consider locking the survey to allow for only one response per computer, thus inhibiting the ability of so inclined respondents to repeatedly respond.

Although internet surveys pose some threats to external validity, this design does potentially reduce the risk of participant reactivity or the Hawthorne effect. Nurses' values, perceptions, and satisfaction with their jobs are guarded information for some nurses. Although distribution of RN job satisfaction surveys via nurses' places of employment may increase 
confidence in capturing the target population, this sampling technique could also raise nurses' suspicions that their responses will be accessible to their employers, thereby hindering their willingness to participate or provide honest responses.

\section{Implications for Nursing Management}

Nurse administrators may consider this evidence when working on strategic plans to attract and retain nurses. Although implications based on this study are tentative, the results indicate the need for administrators to consider the differences between generations of nurses. Administrators should consider what different generations of nurses value in their job and maintain flexibility in their efforts to meet those needs. Generations are socialized within a similar time frame, which often leads to similarities in what a generation of people find meaningful or important. Managing a multi-generational workforce can be a challenge. Challenges arise because generations of nurses often have difficulty relating to one another. For example, one generation values a strong work ethic in which "a real nurse" works five days a week and more during times of high census, while another generation may value self-scheduling and living a balanced lifestyle. The generation valuing a strong work ethic may misinterpret only working two 12 hour shifts as less dedicated, potentially leading to conflicts. As the nurse manager better understands how each of the generations of nurses perceive their work environments, the manager can not only enhance $\mathrm{RN}$ job satisfaction, but also assist the generations of nurses to better understand and appreciate each other.

Psychological empowerment was found to be positively correlated with age, education, experience, and perceived quality of work life. These findings have important implications for nurse managers, as psychological empowerment was found to be a predictor of RN job 
satisfaction. Because psychological empowerment improved with increased age, education, and experience, it is presumable that psychological empowerment is amenable to interventions. However, it remains unclear the impact of aging and maturity on the development of one's psychological empowerment. Psychological empowerment is a motivational process in which inherent characteristics, as well as environmental factors influence persons' abilities to discover the meaning, enhanced competence, and self-determination necessary to impact their environments. Therefore, nurse managers should consider leadership strategies that aim to improve nurses' feelings of competency and self-determination. Such strategies should first include assessing nurses' feelings of confidence, self-assurance, mastery of skills, and autonomy. Assessment of nurses' psychological empowerment could be incorporated the individual level during annual reviews. The findings of this study suggest that younger nurses, in particular, may benefit from workshops directed at increasing these concepts related to psychological empowerment. Additionally, older nurses with greater years of experience could be partnered with younger nurses with purposes of not only orienting the new nurse to the job, but also incorporating confidence boosting activities.

Nurse managers could also assess the psychological empowerment of the nurses on the unit collectively. Assessing nurses' perceived feelings of control over what happens in the department, influence, and ability to impact the unit, would be beneficial in developing strategies to enhance the overall level of psychological empowerment of the nursing unit. Department meetings and task forces in which nurses participate in mission and goal development, policy changes, evidence-based practice changes, and quality improvement initiatives could enhance nurses' psychological empowerment and, thus positively influence their perceived quality of 
work life and job satisfaction. Although such strategies need further evaluation for effectiveness, they could be implemented with minimal additional costs to the organization.

\section{Implications for Research}

This is the first study to theoretically link the concepts of nurse characteristics, psychological empowerment, generation, quality of work life, and RN job satisfaction. The results of this study offer initial support for the model. Future research is needed to further investigate the model, the links between the concepts, and outcomes related to RN job satisfaction. Replication studies should strive to obtain a representative RN sample that would increase the generalizability of these findings and strengthen the implications for nurse administrators.

Further model development includes incorporating the concept of nurses' work environment factors in future research. Within the context of the TMNO, work environment includes factors such as RN-patient ratios, salary, leadership style, and physician collaboration. Ideally, data collection should measure nurses' actual work environment factors, not just nurses' perceptions. It is proposed that the actual work environment and the nurses' perceptions of those work environment factors are mediated by the nurses' psychological empowerment and generation.

Future model development could include further development of the higher order concepts of internalization and socialization. The internal process of assigning meaning to one's environment is likely more complex than what is captured by measuring only a nurse's psychological empowerment. The intrinsic concepts of hardiness (Larrabee, 2003) and stress resiliency (Larrabee et al., 2010) have been demonstrated to predict psychological 
empowerment, thus potentially influencing nurse perceptions of $\mathrm{RN}$ job satisfaction. As psychological empowerment captures only a portion of one's internalization process, so too generation is only one small reflective piece of one's socialization. Cultural influences, as a significant aspect of one's socialization, could be included in future studies.

Further development is necessary pertaining to nurse outcomes associated with this model. This study included RN job satisfaction; however, researchers have indicated that concepts such as nurse fatigue, nurse perceived quality of care, nurse surveillance, and research utilization have important implications for patient outcomes. The provision of consistently excellent nursing care is influenced by the nurse's motivation. Each of these concepts, in addition to $\mathrm{RN}$ job satisfaction, could potentially influence nurses' motivation and, thus impact care provision.

An important consideration for future research should include the link between nurse outcomes and patient outcomes. Investigating the link between nurse outcomes and acute care quality indicators such as nosocomial infection rates, falls, patient satisfaction, pain management, patient education, and maintenance of skin integrity provides further practice and educational implications for this model (ANA, 1996). Additionally, further investigation of the impact nurses' values on patient outcomes is needed.

\section{Conclusion}

A multitude of nurse satisfaction studies have been conducted in an effort to identify contributing factors to RN job satisfaction. The TMNO was developed in an effort to theoretically link major concepts found to be associated with $\mathrm{RN}$ job satisfaction. There were significant relationships among the concepts in the model. Generations of nurses' differed in 
their education, experience, psychological empowerment, and RN job satisfaction. There were significant differences in nurses' education, psychological empowerment, and quality of work life based on geographic region. Psychological empowerment was related to nurses' age, education, experience, quality of work life, and $\mathrm{RN}$ job satisfaction. The primary purpose of this study was to identify predictors of RN job satisfaction. Quality of work life, psychological empowerment, years in current position, and generation were significant predictors of RN job satisfaction explaining $63.7 \%$ of the variance in $\mathrm{RN}$ job satisfaction. The findings of this study support the TMNO, offering a framework for future research and potential for interventional studies related to enhancing $\mathrm{RN}$ job satisfaction. In a profession in which nurses' job performance is directly influenced by their perceptions, understanding the factors that predict perceived job satisfaction is necessary to create environments that support nurses. 


\section{APPENDIX 1: INSTRUMENTS FOR STUDY}

1. Have you taken this survey before?

Yes (1) $\quad \square \quad$ No (2)

\section{Empowerment}

These questions inquire about your level of satisfaction with your work activities. Please indicate how satisfied you are in your present job with each of these items by circling the appropriate number.

\section{Satisfied}

2. The work I do is very important to me. $\quad \begin{array}{llllllllll} & 1 & 2 & 3 & 4 & 5 & 6 & 7\end{array}$

3. My job activities are personally

$\begin{array}{lllllll}1 & 2 & 3 & 4 & 5 & 6 & 7\end{array}$
meaningful to me.

4. The work I do is meaningful to me.

1

23

3

4

5

5. I am confident about my ability to do my job.

$\begin{array}{lllllll}1 & 2 & 3 & 4 & 5 & 6 & 7\end{array}$

6. I am self-assured about my capabilities to $\quad \begin{array}{lllllllll}1 & 2 & 3 & 4 & 5 & 6 & 7\end{array}$ perform my work activities. 
7. I have mastered the skills necessary for

1

$$
2
$$

3

4

5

6

7 my job

8. I have significant autonomy in

$\begin{array}{lllllll}1 & 2 & 3 & 4 & 5 & 6 & 7\end{array}$ determining how I do my job.

9. I can decide on my own how to go about doing my work.

10. I have considerable opportunity for independence and freedom in how I do my job.

11. My impact on what happens in my department is large.

12. I have a great deal of control over what happens in my department

1

123

4

$5 \quad 6$

7

(20)

$\begin{array}{lllllll}2 & 3 & 4 & 5 & 6 & 7\end{array}$

$\begin{array}{lllllll}1 & 2 & 3 & 4 & 5 & 6 & 7\end{array}$

13. I have significant influence over what happens in my department.

$\begin{array}{llllllll}1 & 2 & 3 & 4 & 5 & 6 & 7\end{array}$




\section{Global Job Satisfaction}

PLEASE INDICATE THE EXTENT TO WHICH YOU AGREE OR DISAGREE WITH EACH STATEMENT:

14. I feel very satisfied with my job.

\section{Strongly \\ disagree}

12

12 jobs.

16. I feel I would be happy to work here until I retire.

17. I feel that the health care facility provides a supportive work environment in which to work.

1

2

1

\section{Strongly \\ agree}

$\begin{array}{lll}3 & 4 & 5\end{array}$

$\begin{array}{lll}3 & 4 & 5\end{array}$

3

45

2

3

45

\section{Revised Nursing Work Index}

For each item in this section, please indicate the extent to which you agree that the following items are present in your current job.

\begin{tabular}{|c|c|c|c|c|c|}
\hline & & Strongly & Somewhat & Somewhat & Strongly \\
\hline & & Agree & Agree & Disagree & Disagree \\
\hline 18 & $\begin{array}{l}\text { Adequate support services allow me to } \\
\text { spend time with my patients }\end{array}$ & 1 & 2 & 3 & 4 \\
\hline 19. & $\begin{array}{l}\text { Physicians and nurses have good working } \\
\text { relationships }\end{array}$ & g & 2 & 3 & 4 \\
\hline 20. & $\begin{array}{l}\text { A good orientation program for newly } \\
\text { employed nurses }\end{array}$ & 1 & 2 & 3 & 4 \\
\hline 21 . & $\begin{array}{l}\text { Supervisory staff that is supportive of } \\
\text { nurses }\end{array}$ & 1 & 2 & 3 & 4 \\
\hline
\end{tabular}


22. Active staff development of continuing education programs for nurses

23. Career development/clinical ladder opportunity

24. Opportunity for nurses to participate in policy decisions

25. Support for new and innovative ideas about patient care

26. Enough time and opportunity to discuss patient care problems with other nurses

27. Enough registered nurses on staff to provide quality patient care

28. A nurse manager who is a good manager and leader

29. A chief nursing officer who is highly visible and accessible to staff

30. Enough staff to get work done

31. Freedom to make important patient care and work decisions

32. Praise and recognition for a job well done

33. The opportunity for staff nurses to consult 1 with clinical nurse specialties or expert nurse clinicians

34. A lot of teamwork between nurses and physicians 
37. Nursing staff are supported in pursuing degrees in nursing

38. A clear philosophy of nursing that pervades the patient care environment

39. Working with nurses who are clinically competent

40. A nurse manager who backs up the nursing staff in decision-making, even if the conflict is with a physician

41. Administration that listens and responds to employee concerns

42. An active quality assurance program

43. Staff nurses are involved in the internal governance of the hospital

44. Collaboration (joint practice) between nurses and physicians

45. A preceptor program for newly hired RNs

46. Staff nurses have the opportunity to serve 1 on hospital and nursing committees

47. The contributions that nurses make to patient care are publicly acknowledged

48. Nurse managers consult with staff on daily problems and procedures

49. Working with experienced nurses who 'know' the hospital system 
50. RNs and assistive personnel have goo working relationships

51. RNs and nursing students have good working relationships

Please complete the following information. Kindly circle or write in your answer:

52. Gender (check one): $\quad$ Female(1) $\quad \square \quad$ Male (2)

53. Age:

54. Generation (check one):

Veterans (1922-1943)

Baby Boomers (born between

1943-1964)

Generation X (born between

1965-1980)

Millennials (born between

1980-2000)

55. Marital Status:

$\begin{array}{llllll}\text { Single } & \square & (1) & \text { Widowed } & \square & \text { (4) } \\ \text { Married } & \square & (2) & \text { Separated } & \square & \text { (5) } \\ \text { Divorced } & \square & \text { (3) } & & & \end{array}$


56. Which one of the following would you use to describe your race?
African American
Native American Indian
Asian or Alaska Native
Caucasian (white)
Middle Eastern
Hispanic
Native Hawaiian or
Other Pacific Islander

57. Your highest nursing education level (check one):

$\begin{array}{lll}\text { Diploma } & \square & (1) \\ \text { ADN } & \square & (2) \\ \text { BSN } & \square & (3) \\ \text { MSN } & \square & (4) \\ \text { DNP } & \square & (5) \\ \text { PhD } & \square & (6)\end{array}$

58. You completed your basic R.N. education (check one):
less than 1 year ago
6- 10 years ago
(3)
$1-5$ years ago
(2)
$>10$ years ago
(4)

59. You have been in your current position for
Less than 1 year
$\square \quad(1)$
$6-10$ years
$1-2$ years
$\square \quad(2)$
$>10$ years
$3-5$ years
$\square \quad(3)$

(5) 
60. How many total years have you practiced as a registered nurse?

61. Your primarily work setting is (check one):
$\square$ Medical unit
(1)
$\square$ ICU Step Down unit
(4) $\quad \square$ Other (write in)
$\square$ Surgical unit
(2) $\square$ Peds Med Surg
Medical/Surgical unit
(3) $\square \quad \mathrm{ICU} / \mathrm{CCU}$

62. Your current work status:

Part-time (20 hours or less a week)

Full-time ( $>20$ hours a week)

63. In which state do you currently work: (drop down menu with each state listed)

64. Which is your current salary range from your primary nursing position:

$$
\begin{aligned}
& <10,000 \square \\
& 10,0001-20,000 \\
& 20,001-30,000 \square \\
& 30,001-40,000 \square \\
& 40,001-50,000 \square \\
& 50,001-60,000 \square \\
& 60,001-70,000 \square \\
& 70,001-80,000 \square \\
& 80,001-90,000 \square \\
& 90,001-100,000 \\
& >100,000 \square
\end{aligned}
$$


65. Are you actively licensed to practice as a registered nurse $(\mathrm{RN})$ in any U.S. State or the District of Columbia?

$\begin{array}{lll}\text { Yes(1) } \quad \square & \text { No (2) }\end{array}$

66. Did you receive your initial nurse education in the United States?

Yes(1) $\quad \square \quad$ No (2) 


\section{References}

Adams, A., \& Bond, S. (2000). Hospital nurses' job satisfaction, individual and organizational characteristics. Journal of Advanced Nursing, 32(3), 536-543.

Ahern, N. R. (2005). Using the internet to conduct research. Nurse Researcher, 13(2), 55-70.

Aiken, L. H. (2001). More nurses, better patient outcomes: why isn't it obvious? Effective clinical practice 4(5), 223-225.

Aiken, L. H., Clarke, S. P., \& Sloane, D. M. (2002). Hospital staffing, organization, and quality of care: Cross-national findings. Nursing Outlook, 50(5), 187-194.

Aiken, L. H., Havens, D. S., \& Sloane, D. M. (2000). Magnet nursing services recognition programme. Nurs Stand, 14(25), 41-47.

Aiken, L. H., \& Patrician, P. A. (2000). Measuring organizational traits of hospitals: the Revised Nursing Work Index. Nursing Research, 49(3), 146-153.

Aiken, L. H., Smith, H. L., \& Lake, E. T. (1994). Lower Medicare mortality among a set of hospitals known for good nursing care. Medical Care, 32(8), 771-787.

Aiken, L. H., Sochalski, J., \& Lake, E. T. (1997). Studying outcomes of organizational change in health services. Medical Care, 35(11 Suppl), NS6-18.

Apostolidis, B. M., \& Polifroni, E. C. (2006). Nurse work satisfaction and generational differences. Journal of Nursing Administration, 36(11), 506-509.

Aryee, S., \& Chen, Z. X. (2006). Leader-member exchange in a Chinese context: Antecedents, the mediating role of psychological empowerment and outcomes Journal of business research, 59(7), 793-801.

Avallone, I., \& Gibbon, B. (1998). Nurses' perceptions of their work environment in a Nursing Development Unit. Journal of Advanced Nursing, 27(6), 1193-1201. 
Beecroft, P. C., Dorey, F., \& Wenten, M. (2008). Turnover intention in new graduate nurses: a multivariate analysis. Journal of Advanced Nursing, 62(1), 41-52.

Best, M. F., \& Thurston, N. E. (2004). Measuring nurse job satisfaction. Journal of Nursing Administration, 34(6), 283-290.

Best, M. F., \& Thurston, N. E. (2006). Canadian public health nurses' job satisfaction. Public Health Nursing, 23(3), 250-255.

Betz, H. B., \& Farr, L. A. (2005). Accessing internet survey data collection methods with ethnic nurse shift workers. Chronobiology International, 21(6), 1003-1013.

Blegan, M. A. (1993). Nurses' job satisfaction: a meta-analysis of related variables. Nursing Research, 42(1), 36-41.

Blegan, M. A. (2006). Stress and Coping in Nurse Managers: Stress in the Health Care Work Environment. Nursing Economics, 24(4), 193-203,211.

Boyle, D. K., Bott, M. J., Hansen, H. E., Woods, C. Q., \& Taunton, R. L. (1999). Managers' leadership and critical care nurses' intent to stay. American Journal of Critical Care, 8(6), $361-371$.

Bratt, M. M., Broome, M., Kelber, S., \& Lostocco, L. (2000). Influence of stress and nursing leadership on job satisfaction of pediatric intensive care unit nurses. American Journal of Critical Care, 9(5), 307-317.

Brooks, B. A. (2001). Quality of nursing work life in acute care. Journal of Nursing Care Quality, 19, 269-275.

Budge, C., Carryer, J., \& Wood, S. (2003). Health correlates of autonomy, control and professional relationships in the nursing work environment. Journal of Advanced Nursing, 42(3), 260-268. 
Cameron, S. J., Horsburgh, M. E., \& Armstrong Stassen, M. (1994). Job satisfaction, propensity to leave and burnout in RNs and RNAs: a multivariate perspective. Canadian Journal of Nursing Administration, 7(3), 43-64.

Carless, S. A. (2004). Does pyschological empowerment mediate the relationship between psychological climete and job satisfaction? Journal of Business and Psychology, 18(4), 405-425.

Casey, M., Saunders, J., \& O'Hara, J. (2009). Impact of critical social empowerment on psychological empowerment and job satisfaction in nursing and midwifery settings. Journal of Nursing Management, 18, 24-34.

Cavanagh, S. J., \& Coffin, D. A. (1992). Staff turnover among hospital nurses. Journal of Advanced Nursing, 17(11), 1369-1376.

Chan, A. O., \& Huak, C. Y. (2004). Influence of work environment on emotional health in a health care setting. Occupational Medicine (Oxford, England), 54(3), 207-212.

Chan, E. Y., \& Morrison, P. (2000). Factors influencing the retention and turnover intentions of registered nurses in a singapore hospital. Nursing and Health Sciences, 2(2), 113-121.

Chan, M. F., Luk, A. L., Leong, S. M., Yeung, S. M., \& Van, I. K. (2009). Factors influencing Macao nurses' intention to leave current employment. Journal of Clinical Nursing, 18(6), 893-901.

Chang, L. C., Shih, C. H., \& Lin, S. M. (2010). The mediating role of psychological empowerment on job satisfaction and organizational commitment for school health nurses: A cross-sectional questionnaire survey. International Journal of Nursing Studies, 47, 427-433. 
Chen-Chung, M., Samuels, M. E., \& Alexander, J. W. (2003). Factors that influence nurses' job satisfaction. Journal of Nursing Administration, 33(5), 293-299.

Choi, J., Bakken, S., Larson, E., Du, Y., \& Stone, P. W. (2004). Perceived nursing work environment of critical care nurses. Nursing Research, 53(6), 370-378.

Cimete, G., Gencalp, N. S., \& Keskin, G. (2003). Quality of life and job satisfaction of nurses. Journal of Nursing Care Quality, 18(2), 151-158.

Conger, J. A., \& Kanungo, R. N. (1988). The empowerment process: integrating theory and practice. Academy of Management Review, 13(3), 471-482.

Coomber, B., \& Barriball, K. L. (2007). Impact of job satisfaction components on intent to leave and turnover for hospital-based nurses: a review of the research literature. International Journal of Nursing Studies, 44(2), 297-314.

Corsun, D. L., \& Enz, C. A. (1999). Predicting psychological empowerment among service workers: the effect of support-based relationships. Human Relations, 52(2), 205-224.

Cowin, L. (2002). The effects of nurses' job satisfaction on retention: an Australian perspective. Journal of Nursing Administration, 32(5), 283-291.

Curtis, E. A. (2008). The effects of biographical variables on job satisfaction among nurses. The British Journal of Nursing, 17(3), 174-180.

Daiski, I. (2004). Changing nurses' dis-empowering relationship patterns. Journal of Advanced Nursing, 48(1), 43-50.

DeCicco, J., Laschinger, H., \& Kerr, M. (2006). Perceptions of empowerment and respect: effect on nurses' organizational commitment in nursing homes. Journal of Gerontological Nursing, 32(5), 49-56. 
Dee, J. R., Henkin, A. B., \& Duemer, L. (2003). Structural antecedents and psychological and psychological correlates of teacher empowerment. Journal of Educational Administration, 41(3), 0957-8234.

Duffy, M. E. (2002). Methodological issues in web-based research. Journal of Nursing Scholarship, 34(1), 83-88.

Dwyer, D. J., Schwartz, R. H., \& Fox, M. L. (1992). Decision-making autonomy in nursing. Journal of Nursing Administration, 22(2), 17-23.

Ea, E. E., Griffin, M. Q., L'Eplattenier, N., \& Fitzpatrick, J. J. (2008). Job satisfaction and acculturation among Filipino registered nurses. Journal of Nursing Scholarship, 40(1), $46-51$.

Estabrooks, C. A., Tourangeau, A. E., Humphrey, C. K., Hesketh, K. L., Giovannetti, P., Thomson, D., et al. (2002). Measuring the hospital practice environment: a Canadian context. Research in Nursing \& Health, 25(4), 256-268.

Flanagan, N. A., \& Flanagan, T. J. (2002). An analysis of the relationship between job satisfaction and job stress in correctional nurses. Research in Nursing \& Health, 25(4), 282-294.

Foley, B. J., Kee, C. C., Minick, P., Harvey, S. S., \& Jennings, B. M. (2002). Characteristics of nurses and hospital work environments that foster satisfaction and clinical expertise. Journal of Nursing Administration, 32(5), 273-282.

Fulton, Y. (1997). Nurses' views on empowerment: a critical social theory perspective. Journal of Advanced Nursing, 26(3), 529-536. 
Gardulf, A., Soderstrom, I. L., Orton, M. L., Eriksson, L. E., Arnetz, B., \& Nordstrom, G. (2005). Why do nurses at a university hospital want to quit their jobs? Journal of Nursing Management, 13(4), 329-337.

Gifford, B. D. (2002). The relationship between hospital unit culture and nurses' quality of work life. Journal of Healthcare Management, 47(1), 13-25.

Granello, D. H., \& Wheaton, J. E. (2004). Using web-based surveys to conduct counseling research. In J. W. B. a. G. R. Walz (Ed.), Cybercounseling and Cyberlearning: An Encore (pp. 287-306). Greensboro, NC: CAPS Press.

Harris, R. P., Helfand, M., Woolf, S. H., Lohr, K. N., Mulrow, C. D., Teutsch, S. M., et al. (2001). Current methods of the US Preventive Services Task Force: a review of the process. American Journal of Preventive Medicine, 20 (3 Suppl), 21-35.

Hayhurst, A., Saylor, C., \& Stuenkel, D. (2005). Work environmental factors and retention of nurses. Journal of Nursing Care Quality, 20(3), 283-288.

Health Resources and Services Administration (2008). The Registered Nurse Population:

Findings from the 2008 National Sample Survey of Registered Nurses Retrieved 2010: http://bhpr.hrsa.gov/healthworkforce/rnsurvey04/

Hechanova, R. M., Alampay, B. A., \& RFranco, E. P. (2006). Psychological empowerment, job satisfaction and performance among Filipino service workers. Asian Journal of Social Psychology, 9(1), 72-78.

Hu, J., Herrick, C., \& Hodgin, K. (2004). Managing the multigenerational nursing team. Health Care Manager, 23(4), 334-340. 
Hu, S. L. Y., \& Leung, L. (2003). Effects of expectancy-value, attitudes, and use of the internet on psychological empowerment experienced by chinese women at the workplace. Telematics and Informatics, 20(4), 365-382.

Hung, R. (2002). A note on nurse self-scheduling. Nursing Economic\$, 20(1), 37-39.

Inglehart, M., \& Brown, D. R. (1990). Professional identity and academic achievement-considerations for the admission process. Academic Medicine, 65(9), S3-4.

Irvine, D. M., \& Evans, M. G. (1995). Job satisfaction and turnover among nurses: integrating research findings across studies. Nursing Research, 44(4), 246-253.

Jones, C. B., Stasiowski, S., Simons, B. J., Boyd, N. J., \& Lucas, M. D. (1993). Shared governance and the nursing practice environment. Nurs Econ, 11(4), 208-214.

Kahaleh, A. A., \& Gaither, C. A. (2003). Effects of empowerment on pharmacists' organizational behaviors. Journal of the American Pharmaceutical Association 45(7), 700-708.

Katz, R. (1984). Empowerment and synergy expanding the community's healing resources. Prevention in Human Services (3), 201-226.

Keepnews, D. M., Brewer, C. S., Kouner, C. T., \& Shin, J. H. (2010). Generational differences among newly liscensed registered nurses. Nursing Outlook, 58, 155-163.

Kirkman, B. L., \& Shapiro, D. L. (2001). The Impact of Team Members' Cultural Values on Productivity, Cooperation, and Empowerment in Self-Managing Work Teams. Journal of Cross-Cultural Psychology, 32(5), 597-617.

Kraimer, M. L., Seibert, S. E., \& Liden, R. C. (1999). Psychological empowerment as a multidimensional construct: A construct validity test. Educational and Psychological Measurement, 59, 127-142. 
Kramer, M., \& Hafner, L. P. (1989). Shared values: impact on staff nurse job satisfaction and perceived productivity. Nursing Research, 38(3), 172-177.

Krausz, M., Kedem, P., Tal, Z., \& Amir, Y. (1992). Sex-role orientation and work adaptation of male nurses. Research in Nursing \& Health, 15(5), 391-398.

Kuokkanen, L., \& Leino-Kilpi, H. (2000). Power and empowerment in nursing: three theoretical approaches. Journal of Advanced Nursing, 31(1), 235-241.

Kuokkanen, L., Leino-Kilpi, H., \& Katajisto, J. (2003). Nurse empowerment, job-related satisfaction, and organizational commitment. Journal of Nursing Care Quality, 18(3), 184-192.

Kupperschmidt, B. R. (2000). Multigeneration employees: strategies for effective management. The Health Care Manager, 19(1), 65-76.

Lakeman, R. (1997). Using the internet for data collection in nursing research. Computers in Nursing, 15(5), 269-275.

Larrabee, J. H., Janney, M. A., Ostrow, C. L., Withrow, M. L., Hobbs, G. R., \& Burant, C. (2003). Predicting registered nurse job satisfaction and intent to leave. Journal of Nursing Administration, 33(5), 271-283.

Larrabee, J. H., Persily, C. A., Simoni, P., Johnston, P., Marcischak, T. L., Mott, C. L., et al. (2010). Influence of stress resiliency on $\mathrm{RN}$ job satisfaction and intent to stay. Western Journal of Nursing Research, 32(1), 81-102.

Laschinger, H. K. (1996). A theoretical approach to studying work empowerment in nursing: a review of studies testing Kanter's theory of structural power in organizations. Nursing Administration Quarterly, 20(2), 25-41. 
Laschinger, H. K., Almost, J., \& Tuer-Hodes, D. (2003). Workplace empowerment and magnet hospital characteristics: making the link. Journal of Nursing Administration, 33(7-8), 410-422.

Laschinger, H. K., Finegan, J., \& Shamian, J. (2001). The impact of workplace empowerment, organizational trust on staff nurses' work satisfaction and organizational commitment. Health Care Management Review, 26(3), 7-23.

Laschinger, H. K., Finegan, J., Shamian, J., \& Wilk, P. (2001). Impact of structural and psychological empowerment on job strain in nursing work settings: expanding Kanter's model. Journal of Nursing Administration, 31(5), 260-272.

Laschinger, H. K., Finegan, J., Shamian, J., \& Wilk, P. (2004). A longitudinal analysis of the impact of workplace empowerment on work satisfaction. Journal of Organizational Behavior, 25, 527-545.

Laschinger, H. K., \& Havens, D. S. (1996). Staff nurse work empowerment and perceived control over nursing practice: Conditions for work effectiveness. Journal of Nursing Administration, 26(9), 27-35.

Laschinger, H. K., Purdy, N., \& Almost, J. (2007). The impact of leader-member exchange quality, empowerment, and core self-evaluation on nurse manager's job satisfaction. Journal of Nursing Administration, 37(5), 221-229.

Leiter, M. P., Jackson, N. J., \& Shaughnessy, K. (2009). Contrasting burnout, turnover intention, control, value congruence and knowledge sharing between Baby Boomers and Generation X. Journal of Nursing Management, 17(1), 100-109. 
Lu, H., While, A. E., \& Barriball, K. L. (2007). Job satisfaction and its related factors: a questionnaire survey of hospital nurses in Mainland China. International Journal of Nursing Studies, 44(4), 574-588.

Lucas, M. D., Atwood, J. R., \& Hagaman, R. (1993). Replication and validation of anticipated turnover model for urban registered nurses. Nursing Research, 42(1), 29-35.

Lyons, S. (2005). Are gender differences in basic human values a generational phenomenon? Retrieved 10/9/2008: http://findarticles.com/p/articles/mi_m2294/is_910_53/ai_n16084047

Ma, C. C., Samuels, M. E., \& Alexander, J. W. (2003). Factors that influence nurses' job satisfaction. Journal of Nursing Administration, 33(5), 293-299.

Mannheim, B. (1993). Gender and the effects of demographics, status and work values on work centrality. Work and Occupations, 20(1), 3-22.

Manojlovich, M. (2005). Linking the practice environment to nurses' job satisfaction through nurse-physician communication. Journal of Nursing Scholarship, 37(4), 367-373.

Manojlovich, M., \& Laschinger, H. (2007). The Nursing Worklife Model: extending and refining a new theory. Journal of Nursing Management, 15(3), 256-263.

McCloskey, J. C. (1990). Two requirements for job contentment: autonomy and social integration. Image Journal of Nursing Scholarship, 22(3), 140-143.

McGillis Hall, L., Doran, D., \& Pink, L. (2008). Outcomes of interventions to improve hospital nursing work environments Journal of Nursing Administration, 38(1), 40-46.

McNeese-Smith, D. K., \& Crook, M. (2003). Nursing values and a changing nurse workforce. Journal of Nursing Administration, 33(5), 260-270. 
McNeese-Smith, D. K., \& Van Servellen, G. (2000). Age, developmental, and job stage influences on nurse outcomes. Outcomes Management for Nursing Practice, 4(2), 97104.

Minnesota Hospital Association $(2005,2008)$. Best practices in nursing retention: leading a dynamic workforce, from http://web.mhanet.com/userdocs/articles/best_practice_nursing_dec05.pdf

Mooney, M. (2007). Newly qualified Irish nurses' interpretation of their preparation and experiences of registration. Journal of Clinical Nursing, 16(9), 1610-1617.

Moore, K. A. (2001). Hospital restructuring: impact on nurses mediated by social support and a perception of challenge. Journal of Health and Human Services Administration, 23(4), 490-517.

Morrison, R. S., Jones, L., \& Fuller, B. (1997). The relation between leadership style and empowerment on job satisfaction of nurses. Journal of Nursing Administration, 27(5), 27-34.

Moss, R., \& Rowles, C. J. (1997). Staff nurse job satisfaction and management style. Nursing Management, 28(1), 32-34.

Newman, M., Sime, A. M., \& Corcoran-Perry, S. A. (1991). The focus of the discipline of nursing. Advances in Nursing Science, 14(1), 1-6.

Nogueras, D. J. (2006). Occupational commitment, education, and experience as a predictor of intent to leave the nursing profession. Nursing Economics, 24(2), 86-93, 55.

Norman, L. D., Donelan, K., Buerhaus, P. I., Willis, G., Williams, M., Ulrich, B., et al. (2005). The older nurse in the workplace: does age matter? Nursing Economics, 23(6), 282-289, 279. 
Penz, K., Stewart, N. J., D'Arcy, C., \& Morgan, D. (2008). Predictors of job satisfaction for rural care registered nurses in Canada. Western Journal of Nursing Research, 30(7), 785-800.

Pettit, F. A. (2002). A camparison of world-wide web and paper-and-pencil personality questionnaires. Behavior Research Methods, Instruments, and Computers, 34(1), 50-54.

Price, J. L., \& Mueller, C. W. (1981). A causal model for turnover for nurses. Academy of Management, 24(3), 543-565.

Price, M. (2002). Job satisfaction of registered nurses working in an acute hospital. British Journal of Nursing, 11(4), 275-280.

Rambur, B., Palumbo, M. V., McIntosh, B., \& Mongeon, J. (2003). A statewide analysis of RNs' intention to leave their position. Nursing Outlook, 51(4), 182-188.

Reed, P. J. (2003). The Theory of Self-Transcendence. In M. J. S. P. R. Liehr (Ed.), Middle range theory for nursing (pp. 145-165). New York: Springer.

Rodwell, C. M. (1996). An analysis of the concept of empowerment. Journal of Advanced Nursing, 23(2), 305-313.

Rokeach, M. (1973). The nature of human values. New York: The Free Press.

Rokeach, M. (1979). Understanding human values. New York: The Free Press.

Sarmiento, T. P., Laschinger, H. K., \& Iwasiw, C. (2004). Nurse educators' workplace empowerment, burnout, and job satisfaction: testing Kanter's theory. Journal of Advanced Nursing, 46(2), 134-143.

Sax, L. J., Gilmartin, S. K., \& Bryant, A. N. (2003). Assessing response rates and non responsive bias in web and paper surveys. Research on Higher Education, 44(4), 409-432.

Schmidt, W. C. (1997). World-wide web survey research: Benefits, potential problems, and solutions. Behavior Research Methods, Instruments, and Computers, 29, 274-279. 
Schonpflug, U. (2001). Intergenerational transmission of values. Journal of Cross-Cultural Psychology, 32, 174-185.

Shader, K., Broome, M. E., Broome, C. D., West, M. E., \& Nash, M. (2001). Factors influencing satisfaction and anticipated turnover for nurses in an academic medical center. Journal of Nursing Administration, 31(4), 210-216.

Sherman, R. O. (2006). Leading a Multigenerational Nursing Workforce: Issues, Challenges and Strategies. Online Journal of Issues in Nursing, 11(2), Manuscript 2.

Siu, H. M., Laschinger, H. K., \& Vingilis, H. (2005). The effect of problem-based learning on nursing students' perceptions of empowerment. The Journal of Nursing Education, 44(10), 459-469.

Sochalski, J., Estabrooks, C. A., \& Humphrey, C. K. (1999). Nurse staffing and patient outcomes: evolution of an international study. Canadian-Journal-of-Nursing-Research, 31(3), 69-88.

Sochan, A., \& Singh, M. D. (2007). Acculturation and socialization: voices of internationally educated nurses in Onterio. International Nursing Review, 54, 130-136.

Sourdif, J. (2004). Predictors of nurses' intent to stay at work in a university health center. Nursing Health Science, 6(1), 59-68.

Spreitzer, G. M. (1995). Psychological empowerment in the workplace: Dimensions, measurement, and validation. Academy of Management Journal, 38(5), 1442-1465.

Stamps, P. L. (1997). Nurses and work satisfaction : an index for measurement (2nd ed.). Chicago, Ill.: Health Administration Press.

Stamps, P. L., \& Piedmonte, E. (1986). Nurses and work satisfaction. Ann Arbor, MI: Health Administration Press Perspectives. 
Strachota, E., Normandin, P., O'Brien, N., Clary, M., \& Krukow, B. (2003). Reasons registered nurses leave or change employment status. Journal of Nursing Administration, 33(2), 111-117.

Stuenkel, D. L., Cohen, J., \& de la Cuesta, K. (2005). The multigenerational nursing work force: essential differences in perception of work environment. Journal of Nursing Administration, 35(6), 283-285.

Suzuki, E., Itomine, I., Kanoya, Y., Katsuki, T., Horii, S., \& Sato, C. (2006). Factors affecting rapid turnover of novice nurses in university hospitals. Journal of Occupational Health, 48(1), 49-61.

Tabachnick, B. G., \& Fidell, L. S. (2007). Using Multivariate Statistics (5th edition ed.). Boston: Allyn \& Bacon

Tervo-Heikkinen, T., Partanen, P., Aalto, P., \& Vehvilainen-Julkunen, K. (2008). Nurses' work environment and nursing outcomes: a survey study among Finnish university hospital registered nurses. International Journal of Nursing Practice, 14(5), 357-365.

Thomas, K. W., \& Velthouse, B. A. (1990). Cognitive elements of empowerment: an "interpretive" model of intrinsic task motivation. Academy of Management Review, 15(4), 666-681.

Tigert, J. A., \& Laschinger, H. K. (2004). Critical care nurses' perceptions of workplace empowerment, magnet hospital traits and mental health. Dynamics, 15(4), 19-23.

Tzeng, H. M. (2002). The influence of nurses' working motivation and job satisfaction on intention to quit: an empirical investigation in Taiwan. International Journal of Nursing Studies, 39(8), 867-878. 
Ulrich, B. T., Buerhaus, P. I., Donelan, K., Norman, L., \& Dittus, R. (2005). How RNs view the work environment: results of a national survey of registered nurses. Journal of Nursing Administration, 35(9), 389-396.

Upenieks, V. V. (2002). Assessing differences in job satisfaction of nurses in magnet and nonmagnet hospitals. Journal of Nursing Administration, 32(11), 564-576.

Waldman, J. D., Kelly, F., Arora, S., \& Smith, H. L. (2004). The shocking cost of turnover in health care. Health Care Management Review, 29(1), 2-7.

Walker, L., \& Avant, K. (2005). Strategies for Theory Construction in Nursing (4th ed.). Upper Saddle River, NJ: Pearson Prentice Hall.

Wanberg, C. R., \& Kammeyer-Mueller, J. D. (2000). Predictors and outcomes of proactivity in the socialization process. Journal of Applied Psychology, 85(3), 373-385.

Warr, P., Cook, J., \& Wall, T. (1979). Scales for the measurement of som work attitudes and aspects of psychological well-being. Journal of Occupational Psychology, 52, 129-148.

Wells, N., Roberts, L., \& Medlin, L. C. (2002). Issues related to staff retention and turnover. Seminars for Nurse Managers, 10(3), 171-179.

Whitbeck, L. B., \& Gecas, V. (1988). Value attributions and value transmission between parent and child. Journal of Marriage and Family, 50, 829-840.

Widger, K., Pye, C., Cranley, L., Wilson-Keates, B., Squires, M., \& Tourangeau, A. (2007). Generational differences in acute care nurses. Nursing Leadership, 20(1), 49-61.

Wieck, K. L., Dols, J., \& Landrum, P. (2010). Retention priorities for the intergenerational nurse workforce. Nursing Forum, 45(1), 7-17. 
Wilson, B., Squires, M., Widger, K., Cranley, L., \& Tourangeau, A. (2008). Job satisfaction among a multigenerational nursing workforce. Journal of Nursing Management, 16(6), 716-723.

Wright, K. B. (2005). Researching internet-based populations: Advantages and disadvantages of online survey research, online questionnaire authoring packages, and websurvey services. Journal of Computer-Mediated Communication, 10(3), article 11.

Yeatts, D. E., \& Seward, R. R. (2000). Reducing turnover and improving health care in nursing homes: the potential effects of self-managed work teams. Gerontologist, 40(3), 358-363.

Yin, J. C., \& Yang, K. P. (2002). Nursing turnover in Taiwan: a meta-analysis of related factors. International Journal of Nursing Studies, 39(6), 573-581.

Zahra, S. A. (1985). Determinants of organizational commitment in a health care setting. Journal of Health and Human Resources Administration, 8(2), 188-208.

Zurmehly, J. (2008). The relationship of educational preparation, autonomy, and critical thinking to nursing job satisfaction. Journal of Continuing Education in Nursing, 39(10), 453-460.

\footnotetext{
John H. $\mathrm{DN}$ : $\mathrm{Cn}=J$ John H. Hagen, $\mathrm{o}=$ West
Virginia University Libraries,

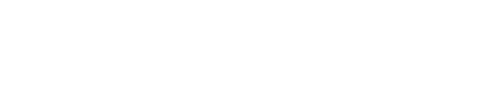

